Prepared for the U.S. Department of Energy

under Contract DE-AC05-76RL01830

\title{
Analysis of Flood Hazards for the Materials and Fuels Complex at the Idaho National Laboratory Site
}

Final Report
RL Skaggs
T Kim
SA Breithaupt
DL Ward
SR Waichler

November 2010

\section{Pacific Northwest}

NATIONAL LABORATORY

Proudly Operated by Battelle Since 1965 


\title{
DISCLAIMER
}

This report was prepared as an account of work sponsored by an agency of the United States Government. Neither the United States Government nor any agency thereof, nor Battelle Memorial Institute, nor any of their employees, makes any warranty, express or implied, or assumes any legal liability or responsibility for the accuracy, completeness, or usefulness of any information, apparatus, product, or process disclosed, or represents that its use would not infringe privately owned rights. Reference herein to any specific commercial product, process, or service by trade name, trademark, manufacturer, or otherwise does not necessarily constitute or imply its endorsement, recommendation, or favoring by the United States Government or any agency thereof, or Battelle Memorial Institute. The views and opinions of authors expressed herein do not necessarily state or reflect those of the United States Government or any agency thereof.

\author{
PACIFIC NORTHWEST NATIONAL LABORATORY \\ operated by \\ BATTELLE \\ for the \\ UNITED STATES DEPARTMENT OF ENERGY \\ under Contract DE-AC05-76RL01830
}

Printed in the United States of America
Available to DOE and DOE contractors from the Office of Scientific and Technical Information,
P.O. Box 62, Oak Ridge, TN 37831-0062;
ph: (865) 576-8401
fax: $(865) 576-5728$
email: reports@adonis.osti.gov

\begin{abstract}
Available to the public from the National Technical Information Service, U.S. Department of Commerce, 5285 Port Royal Rd., Springfield, VA 22161 ph: (800) 553-6847 fax: $(703) 605-6900$ email: orders@ntis.fedworld.gov online ordering: http://www.ntis.gov/ordering.htm
\end{abstract}

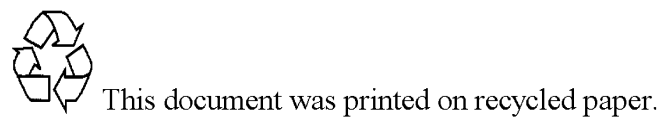

(9/2003) 


\section{Analysis of Flood Hazards for the Materials and Fuels Complex at the Idaho National Laboratory Site}

\section{Final Report}

$\begin{array}{ll}\text { RL Skaggs } & \text { T Kim } \\ \text { SA Breithaupt } & \text { DL Ward } \\ \text { SR Waichler } & \end{array}$

November 2010

Prepared for

the U.S. Department of Energy

under Contract DE-AC05-76RL01830

Pacific Northwest National Laboratory

Richland, Washington 99352 



\section{Summary}

Researchers at Pacific Northwest National Laboratory conducted a flood hazard analysis for the Materials and Fuels Complex (MFC) site located at the Idaho National Laboratory (INL) site in southeastern Idaho. The general approach for the analysis was to determine the maximum water elevation levels associated with the design-basis flood (DBFL) and compare them to the floor elevations at critical building locations. Two DBFLs for the MFC site were developed using different precipitation inputs: probable maximum precipitation (PMP) and 10,000-year recurrence interval precipitation. Both precipitation inputs were used to drive a watershed runoff model for the surrounding upland basins and the MFC site. Outflows modeled with the Hydrologic Engineering Centers Hydrologic Modeling System were input to the Hydrologic Engineering Centers River Analysis System hydrodynamic flood routing model.

Using the most conservative assumptions for the PMF (i.e., all culverts at the MFC and the diversion ditch located upstream of the MFC are blocked) produced flood levels exceeding floor elevations at eight locations ranging from $3.20 \mathrm{ft}$ at MFC Building 774 (ZPPR Support Wing) to $0.1 \mathrm{ft}$ at MFC Building 767 (EBR-II Reactor Plant Building). The flood resulting from the 10,000-year precipitation event, assuming the culverts and the diversion ditch were open (i.e., unblocked), exceeded floor elevations at two locations-the MFC Building 785 (Hot Fuel Examination Facility) by $0.1 \mathrm{ft}$. and MFC Building 786 (Hot Fuel Examination Facility substation) by $0.03 \mathrm{ft}$.

To provide additional perspective on the relative significance of the results obtained, a limited sensitivity analysis was conducted on the hydraulic analysis evaluating the change in maximum water surface as a function of the assumed roughness coefficients used in the hydraulic analysis. These results showed that reducing the Manning's roughness coefficient from 0.035 (representative of lightly vegetated sagebrush) to 0.013 (representative of asphalt) at the MFC cross sections for the 10,000-year precipitation event decreased the maximum water-surface elevations to levels below all floor elevations.

An analysis was also conducted for the Transient Reactor Experiment and Test (TREAT) Facility site, located in a separate drainage approximately $4700 \mathrm{ft}$ northwest of the MFC. Results indicate that flows generated by the PMP will produce a maximum water-surface elevation at the TREAT site of only $5114.82 \mathrm{ft}$, approximately $7 \mathrm{ft}$ below the floor elevation of the TREAT Warehouse (MFC Building 723) and over $9 \mathrm{ft}$ below the floor elevation of the TREAT reactor building (MFC Building 720). 



\section{Acronyms and Abbreviations}

\begin{tabular}{|c|c|}
\hline ANL-W & Argonne National Laboratory - West (previous designation of the MFC site) \\
\hline $\mathrm{B}$ & basin \\
\hline CFA & Central Facilities Area \\
\hline CFE & critical flood elevation \\
\hline cfs & cubic feet per second \\
\hline DBFL & design-basis flood \\
\hline DEM & Digital Elevation Model \\
\hline DOE & Department of Energy \\
\hline EPA & Environmental Protection Agency \\
\hline ESRP & Eastern Snake River Plain \\
\hline $\mathrm{ft}$ & foot(feet) \\
\hline GIS & geographic information system \\
\hline HEC-HMS & Hydrologic Engineering Centers Hydrologic Modeling System \\
\hline HEC-RAS & Hydrologic Engineering Centers River Analysis System \\
\hline HMR & Hydrometeorological Report \\
\hline $\mathrm{hr}$ & hour(s) \\
\hline in. & inch(es) \\
\hline INL & Idaho National Laboratory \\
\hline LiDAR & Light Detection and Ranging \\
\hline MFC & Materials and Fuels Complex \\
\hline $\mathrm{mi}$ & mile(s) \\
\hline $\mathrm{mi}^{2}$ & square mile(s) \\
\hline $\min$ & minute(s) \\
\hline NAVD & North American Vertical Datum \\
\hline NGVD & National Geodetic Vertical Datum \\
\hline NOAA & National Ocean Atmospheric Administration \\
\hline PC & Performance Category \\
\hline PMF & probable maximum flood \\
\hline PMP & probable maximum precipitation \\
\hline PNNL & Pacific Northwest National Laboratory \\
\hline SCS & Soil Conservation Service \\
\hline SSCs & structures, systems, and components \\
\hline STP & Sewage Treatment Plant \\
\hline TREAT & Transient Reactor Experiment and Test Facility \\
\hline $\mathrm{UH}$ & unit hydrograph \\
\hline USACE & U.S. Army Corps of Engineers \\
\hline
\end{tabular}


USGS

W

yr
U.S. Geological Survey

watershed

year(s) 


\section{Contents}

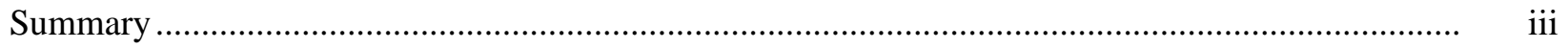

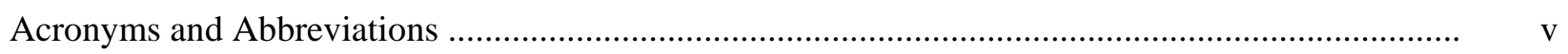

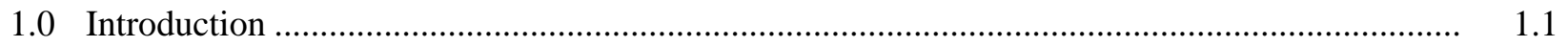

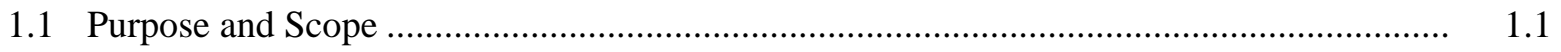

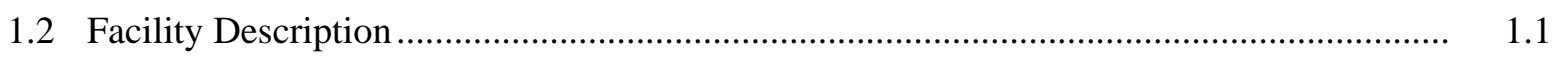

1.3 Report Contents and Organization ........................................................................... 1.3

2.0 Analysis and Results....................................................................................... 2.1

2.1 Determination of the Probable Maximum Precipitation and 10,000-Year Storm ............... 2.1

2.2 Determination of the Probable Maximum Flood and 10,000-Year Flood ......................... 2.10

2.2.1 Unit Hydrographs.............................................................................................. 2.10

2.2.2 HEC-HMS Model Results......................................................................... 2.12

2.3 Hydraulic Analysis and Determination of Peak Elevation............................................. 2.17

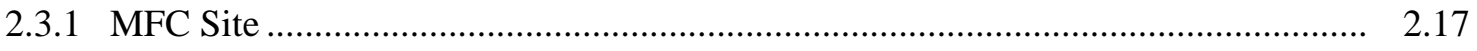

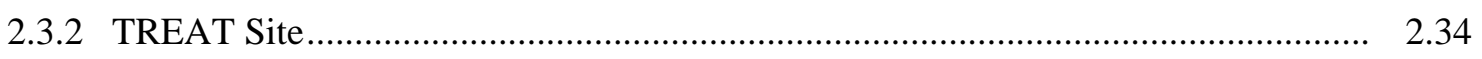

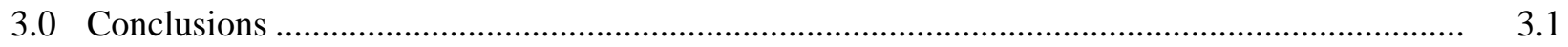

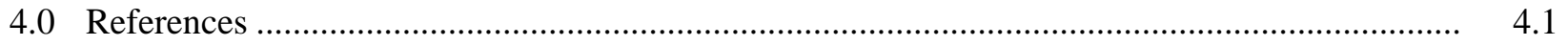

Appendix A - Additional Climate Data Plots..................................................................... A.1

Appendix B - Terrain Data Processing................................................................................... B.1 


\section{Figures}

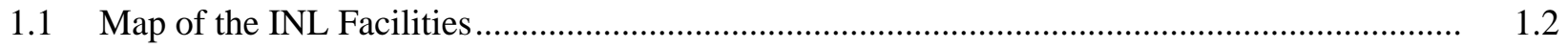

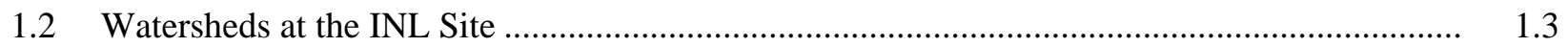

2.1 Watersheds Simulated with HEC-HMS and Subbasins Simulated with HEC-RAS................... 2.2

2.2 General Storm PMP by Season ......................................................................................... 2.4

2.3 Design Storm Hyetographs Based on the General Storm PMP ................................................. 2.5

2.4 Local Storm PMP and Hyetograph with 15-Minute Intervals for the Design Storm................. 2.6

2.5 Snow Depth at the CFA Meteorological Station During Water Year 1993 ............................... 2.7

2.6 10,000-Year Precipitation Event Depth vs. Duration and 5-Minute Interval Storm

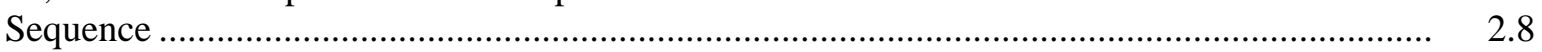

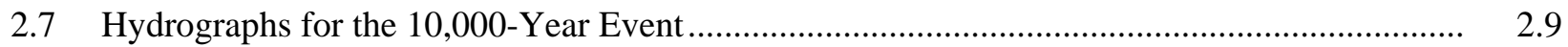

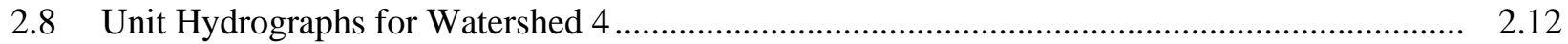

2.9 SCS Triangular and HMS Curvilinear Unit Hydrographs for All Watersheds .......................... 2.13

2.10 PMF Hydrographs for the Local Storm ............................................................................ 2.14

2.11 PMF Hydrographs for the General Storm ............................................................................ 2.15

2.12 PMF Hydrographs for the General Storm with Hypothetical Snowmelt Added ...................... 2. 2.16

2.13 Four Subbasins Used for the HEC-RAS Model Analysis and HEC-RAS CrossSection Layout for the MFC Site and Surrounding Areas ..................................................... 2.18

2.14 Detail of HEC-RAS Cross Sections Overlaid onto the Buildings of the MFC Site................... 2.19

2.15 Plan View of HEC-RAS Model Setup for the MFC Site and Surrounding Areas.................... 2.20

2.16 Flows Input to the HEC-RAS Hydraulic Model for the PMF Event ........................................ 2.21

2.17 Combined Profiles of the Maximum Water Level for all Subbasins from the PMP

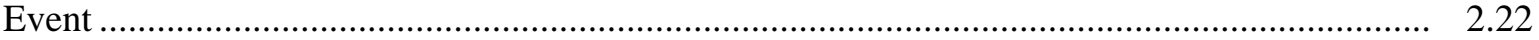

2.18 Individual Profiles of the Maximum Water Level for Each Subbasin from the PMP

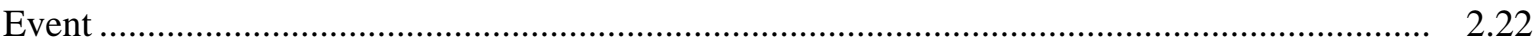

2.19 Maximum Water Level at Cross-Section 286 from the PMP Event ...................................... 2.23

2.20 Combined Profiles of the Maximum Water Level for all Subbasins from the PMP Event

2.21 Individual Profiles of the Maximum Water Level for Each Subbasin from the PMP

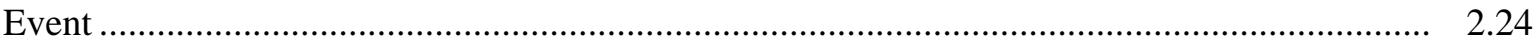

2.22 Maximum Water Level at Cross-Section 286 from the PMP Event .......................................... 2.25

2.23 Flows Paths and Maximum Flows for the PMF for Blocked and Open Cases ......................... 2.25

2.24 Flows Input to the HEC-RAS Model for the 10,000-Year Return Period Event ....................... 2.28

2.25 Combined Profiles of the Maximum Water Level for all Subbasins from the 10,000-Year Return Period Event

2.26 Individual Profiles of the Maximum Water Level for Each Subbasin from the 10,000-Year Return Period Event for the Blocked Case

2.27 Maximum Water Level at Cross-Section 286 from the 10,000-Year Return Period Event 
2.28 Combined Profiles of the Maximum Water Level for all Subbasins from the 10,000-Year Return Period Event ........................................................................................... 2.30

2.29 Individual Profiles of the Maximum Water Level for Each Subbasin from the 10,000-Year Return Period Event.

2.30 Maximum Water Level at Cross-Section 286 from the 10,000-Year Return Period Event

2.31 Flows Paths and Maximum Flows for the 10,000-Year Return Period Event for Blocked and Open Cases.

2.32 Cross Sections Used for the TREAT Site 2.34

2.33 Profile and Location Where the Maximum Water Level Was Extracted for TREAT 2.35

2.34 Inundation Areas and Maximum Water Level at the Middle Cross Section for TREAT Site

2.35 Comparison of Maximum Water-Surface Elevations for a Range of Flows and with a Flow Estimated from the Rational Method of the Peak PMP Intensity

\section{Tables}

1.1 Structures, Systems, and Components Critical to MFC Operations

2.1 Watershed and Unit Hydrograph Parameters

2.2 Comparison of the Floor Elevations of Buildings at the MFC Site and the Maximum Water-Surface Elevations Obtained from the HEC-RAS Model.

2.3 Results from Sensitivity Analyses Comparing the Maximum Water-Surface Elevations at Cross-Section Station 286 at the MFC Site 



\subsection{Introduction}

U.S. Department of Energy (DOE) Order 420.1B (DOE 2005) establishes facility and programmatic safety requirements for nuclear and explosives safety design criteria, fire protection, criticality safety, the mitigation of natural phenomena hazards at nuclear facilities, including the Idaho National Laboratory (INL). DOE's INL, in southeastern Idaho, encompasses nine major operational areas, including the Materials and Fuels Complex (MFC). Located on 60 acres in the southeastern corner of the INL site, the MFC is largely devoted to research and development of nuclear technologies and nuclear environmental management. In partial fulfillment of the requirements of DOE Order 420.1 B, INL directed Pacific Northwest National Laboratory (PNNL) to conduct an assessment of the potential for flooding at the MFC.

\subsection{Purpose and Scope}

An INL review of the MFC operations and facilities in accordance with DOE Order 420.1B determined the highest Performance Category (PC) for existing facilities at MFC is PC-3. Further, MFC contains several facilities that could be affected by natural phenomena hazards, including flooding. Consequently, in accordance with DOE-STD-1020-2002, Natural Phenomena Hazards Design and Evaluation Criteria for Department of Energy Facilities (DOE 2002), an evaluation of the flood design basis for the structures, systems, and components (SSCs) at the MFC is required. This consists of the following:

- determining the design-basis flood (DBFL) for each flood hazard as defined by the hazard annual probability of exceedance and applicable combinations of flood hazards

- evaluating the site stormwater management system (e.g., site runoff and drainage, roof drainage)

- developing a flood design strategy for the DBFL that satisfies the criteria performance goals (e.g., build above the DBFL, harden the facility)

- designing civil engineering systems (e.g., buildings, buried structures, site drainage, retaining walls, dike slopes, etc.) to the applicable DBFL and design requirements.

In partial fulfillment of these requirements, the study presented here is limited to providing the hydrologic inputs necessary for estimating the probability of flood water inundating structures, systems, and components (SSCs) at MFC (i.e., peak flood elevations exceeding critical flood elevations (CFEs).

\subsection{Facility Description}

Most of the INL site is located in Pioneer Basin-a closed topographic depression. Portions of six watersheds either drain surface water to or from the site (Figures 1.1 and 1.2). The MFC (or, as it was once known, ANL-W) is in a closed basin, located in the American Falls watershed, which generally drains from the INL site to the Snake River. The MFC includes the Transient Reactor Experimental and Test (TREAT) Facility located approximately $4700 \mathrm{ft}$ from the primary MFC site, but within a separate subwatershed. In 1963, the ANL-W reached an unanticipated flood level, which may have prompted the 
construction of a diversion dam that still functions at the MFC today. A second flood event in January 1969 involved rain and snow melt runoff over frozen ground; water levels reached and overtopped US Highway 20, south of the MFC.

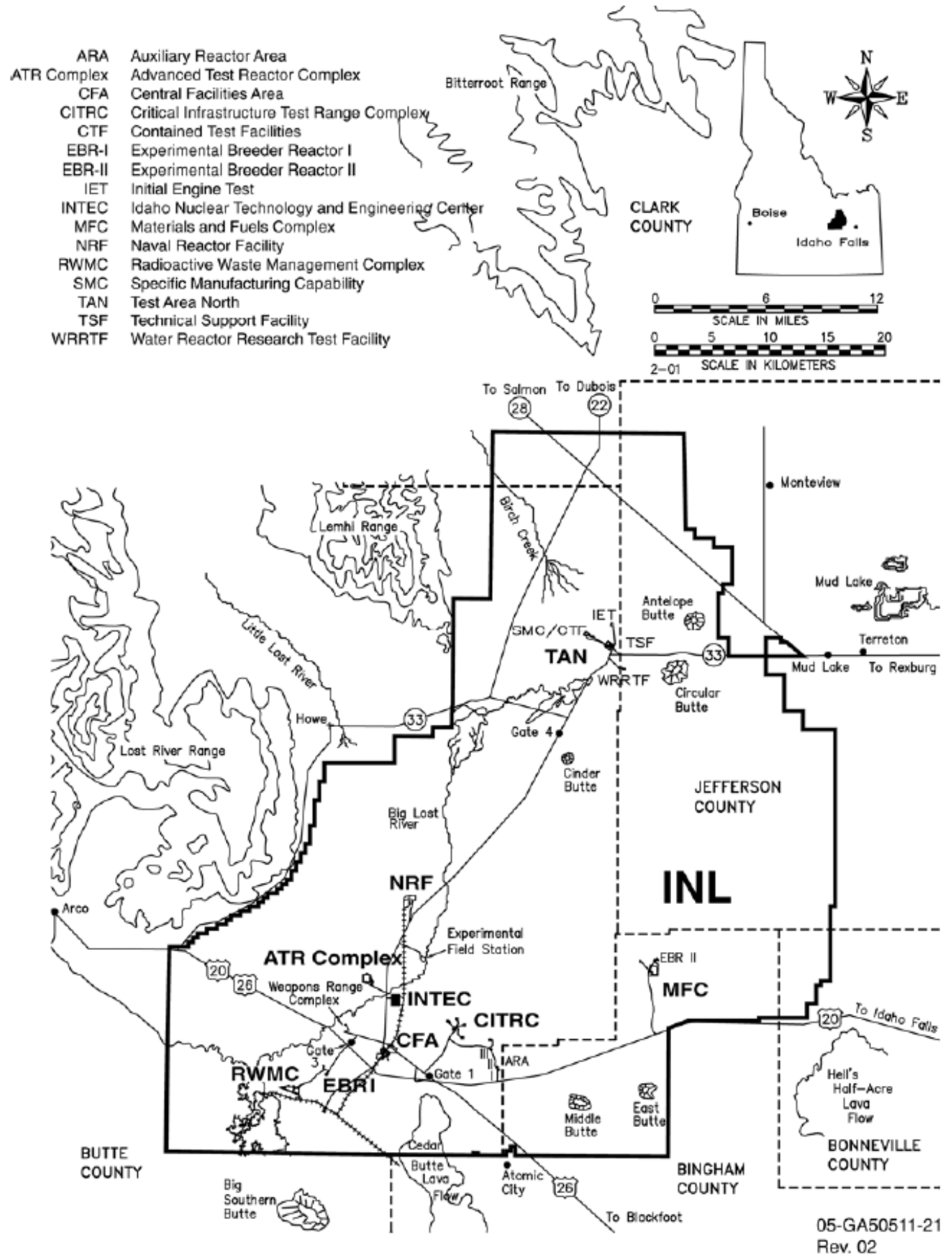

Figure 1.1. Map of the INL Facilities 


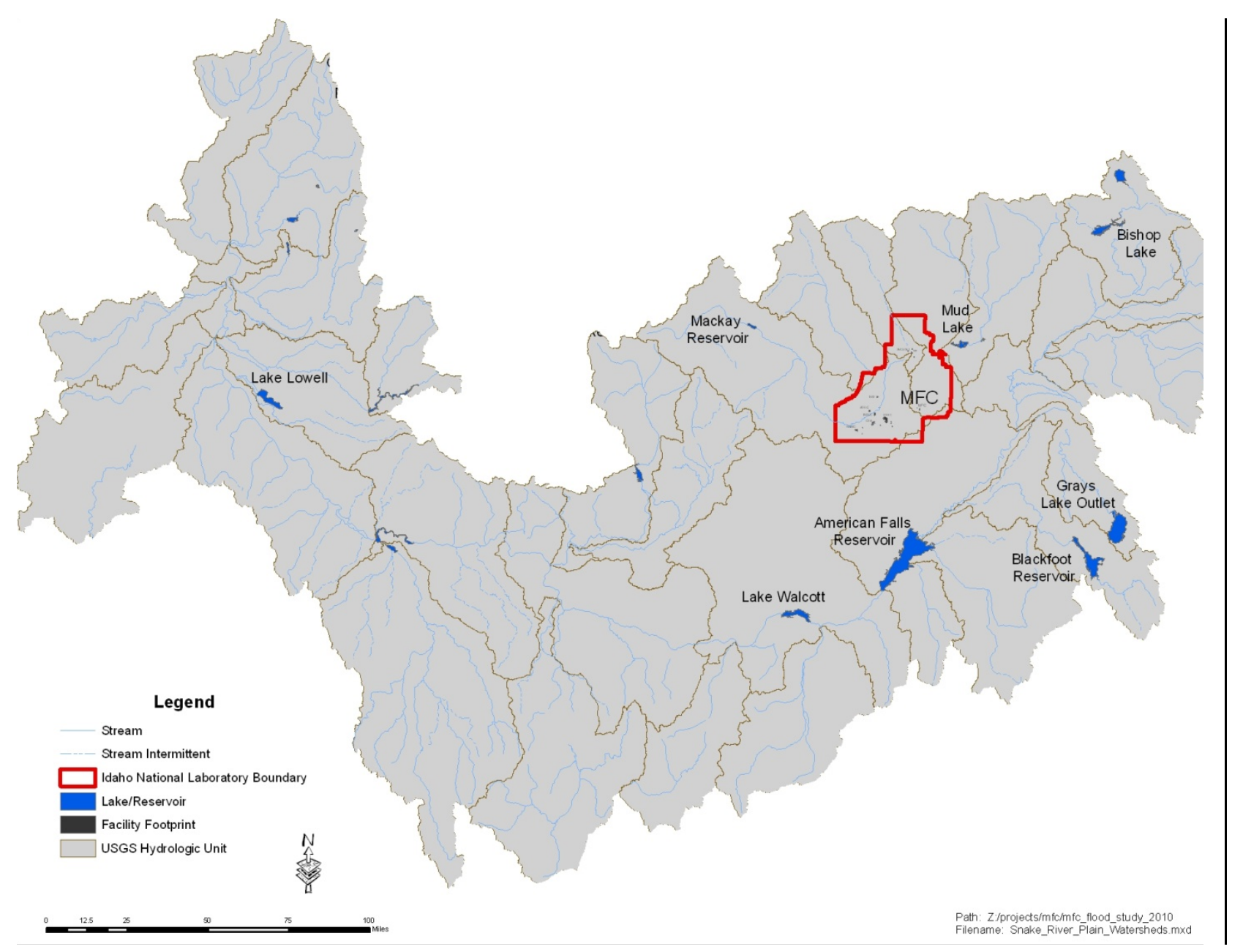

Figure 1.2. Watersheds at the INL Site

Although the MFC site is not affected by flows from other major watersheds in the region, it can be subject to runoff from six upgradient subbasins and from overland flow, ponding, and localized runoff from roofs and other impermeable surfaces located at the facility. The total upgradient contributing watershed area is $7.8 \mathrm{mi}^{2}$. During times of high precipitation, runoff can occur as sheet flow or channelized flow flowing downgradient toward the lowest point in the basin. Based on the DOE 420.1B requirements, runoff/drainage (overland flow) is the only potential type of flooding event that needs to be considered at MFC. So, each of the subbasins that can contribute potential flood flows to MFC must be assessed to determine the potential for overland flow flooding to affect SSCs and human health and safety at MFC. In response to INL's request, PNNL researchers conducted a comprehensive flood hazard assessment to evaluate the potential flood risks to MFC SSCs and site personnel. The SSCs are listed in Table 1.1.

\subsection{Report Contents and Organization}

The ensuing sections of this report describe the flood hazards analysis performed to evaluate the flood design basis for SSCs at the MFC as specified in DOE Order and Standards. Section 2.0 describes the 
methodology and results of the flood hazard and sensitivity analyses for the MFC and the flood hazard analysis for the nearby TREAT Facility. Section 3.0 presents conclusions. Appendixes A and B contain supplemental climate data plots and terrain data processing information, respectively.

Table 1.1. Example Structures, Systems, and Components at MFC

\begin{tabular}{|c|c|}
\hline MFC-704 & Fuel Manufacture Facility (FMF) \\
\hline MFC-719 & Vehicle Entry Post \\
\hline MFC-720 & TREAT Reactor Building \\
\hline MFC-723 & TREAT Warehouse \\
\hline MFC-752 & Laboratory and Office Building \\
\hline MFC-752 & Laboratory and Office Building \\
\hline MFC-752 & Laboratory and Office Building \\
\hline MFC-752 & Laboratory and Office Building \\
\hline MFC-765 & Fuel Conditioning Facility (FCF) \\
\hline MFC-765 & Fuel Conditioning Facility (FCF) \\
\hline MFC-767 & EBR-II Reactor Plant Building \\
\hline MFC-767 & EBR-II Reactor Plant Building \\
\hline MFC-767 & EBR-II Reactor Plant Building \\
\hline MFC-774 & ZPPR Support Wing \\
\hline MFC-775 & ZPPR Vault-Workroom Equipment Room \\
\hline MFC-776 & ZPPR Reactor Cell \\
\hline MFC-785 & Hot Fuel Examination Facility (HFEF) \\
\hline MFC-786 & HFEF Substation \\
\hline MFC-787 & Fuels and Applied Science Building (FASB) \\
\hline MFC-792 & SSPSF Control Room \\
\hline MFC-792A & Space and Security Power System Facility Annex \\
\hline MFC-794 & Contaminated Equipment Storage Building \\
\hline MFC-794 & Contaminated Equipment Storage Building \\
\hline MFC-798 & Radioactive Liquid Waste Treatment Facility \\
\hline MFC-1702 & Radiochemistry Laboratory (RCL) \\
\hline
\end{tabular}




\subsection{Analysis and Results}

The MFC contains PC-0, 1, 2 and 3 facilities. Therefore, according to DOE-STD-1020-2002, the site stormwater and flood management system must ensure protection against a mean flood hazard probability equal to or less than $1 \times 10^{-4}$. The DBFLs for the MFC were based on estimating the probable maximum precipitation (PMP) and 10,000-year precipitation events and then using them as input to a watershed runoff model for the surrounding upland basins as well as the MFC site itself. Runoff, or outflows, were modeled using the U.S. Army Corps of Engineers (USACE) Hydrologic Engineering Centers Hydrologic Modeling System (HEC-HMS) and Hydrologic Engineering Centers River Analysis System (HEC-RAS) software. Simulated hydrographs for the two events from HEC-HMS were input to the HEC-RAS hydraulic flood routing model to determine peak water-surface elevations at the MFC SSCs.

The details of the flood hazard analysis for the MFC using the described approach is presented in the following sections in three parts:

- determination of the PMP and 10-000-year storm

- determination of the probable maximum flood (PMF) and 10,000-year flood

- hydraulic analysis and determination of the maximum water-surface elevation.

\subsection{Determination of the Probable Maximum Precipitation and 10,000-Year Storm}

Two DBFLs for the MFC site were developed using different precipitation inputs: PMP and 10,000-year precipitation. Both precipitation events were used as input to a watershed runoff model for the surrounding upland basins and the MFC site itself. Runoff, or outflows, from watersheds W1-W6 (Figure 2.1 and Table 2.1) were modeled using the USACE's HEC-HMS software. Runoff from subbasins designated as B1 through B4 (as shown in Figure 2.1) was estimated using the Rational Method within HEC-RAS. Outflows modeled with HEC-HMS were input to the HEC-RAS hydrodynamic flood routing model. Each of the major elements of the analyses and associated results were reviewed by the project team and technical reviewers for reasonableness and accuracy.

The PMP was estimated using the guidance provided in Hydrometeorological Report (HMR) No. 57 Probable Maximum Precipitation - Pacific Northwest States (NWS 1994). PMP is defined as "theoretically, the greatest depth of precipitation for a given duration that is physically possible over a given size storm area at a particular geographical location at a certain time of the year.” The PMP is the potential rainfall that could result from optimal atmospheric conditions and circumstances; it represents an upper limit for a particular duration and area, and is "not a quantity that is expected to be observed."

HMR 57 provides background and methods for both general and local storms. General storms are defined as major synoptic events that produce precipitation over areas of at least $500 \mathrm{mi}^{2}$ and for durations that often exceed 6 hours. Local storms are defined as having areas of up to $500 \mathrm{mi}^{2}$ and durations up to 6 hours. Climate data indicate that both types of storms can occur during any season in the Pacific Northwest, but general storms are less common during the summer months, and local storms primarily 
occur from April through October. For watersheds less than $10 \mathrm{mi}^{2}$ in area, HMR 57 recommends that both general and local PMPs be considered for use. The watershed containing the MFC site is $7.8 \mathrm{mi}^{2}$ in area.

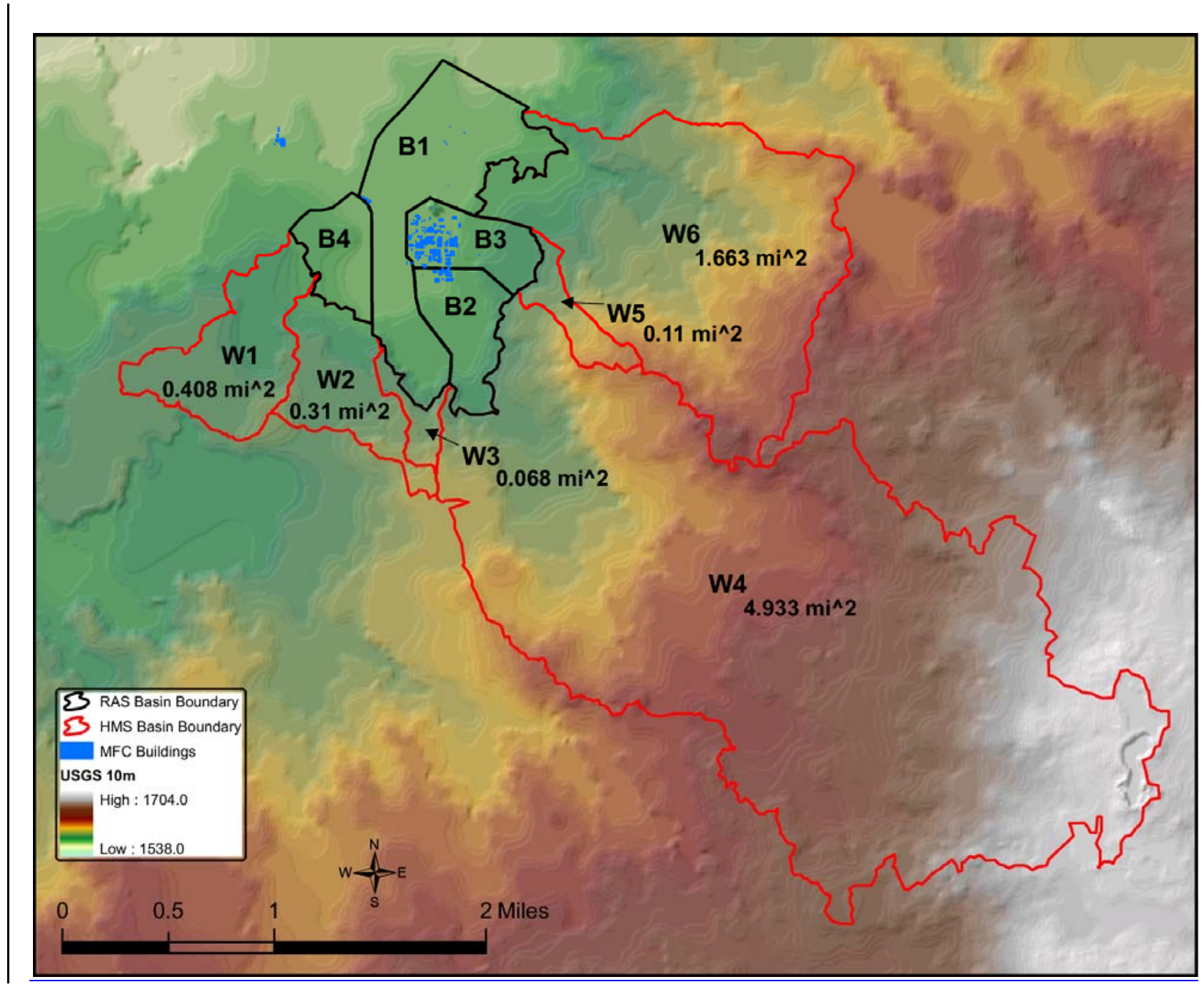

Figure 2.1. Watersheds (W) Simulated with HEC-HMS and Subbasins (B) Simulated with HEC-RAS

The starting point for the general storm PMP is the all-season 10- $\mathrm{mi}^{2}$, 24-hour PMP index value. The index value is multiplied by factors that account for season, storm duration, and basin size. The index value was $8.5 \mathrm{in}$. for the INL location. Scripts written in the R language were used to implement the HMR 57 PMP computations. The general storm PMP values for the unique seasons and for durations of 1, 6, 24, 48, and 72 hours are plotted as points in Figure 2.2. The all-season PMP is by definition the maximum of all the seasons, which for much of the Pacific Northwest east of the Cascades occurs in June. For convenience in deriving incremental precipitation for the design storm, a semi-log model was fit to the points using simple linear regression: $\mathrm{PMP}=\mathrm{a} * \log ($ duration $)+\mathrm{b}$, where $\mathrm{a}$ and $\mathrm{b}$ are the slope and intercept, respectively. The differences between successive hourly cumulative precipitation values from the curve were calculated and arranged in a pattern like that of Figure 2.3 for the design storm. The total 
72-hour, all-season precipitation was 10.97 in., and the maximum hourly increment was 1.54 in. The winter months, November to March, have a somewhat lower general storm PMP, 8.78 in. over 72 hours, and a maximum hourly increment of 1.23 in.

Table 2.1. Watershed and Unit Hydrograph Parameters

\begin{tabular}{lrrrrrr}
\hline & W1 & W2 & W3 & W4 & W5 & W6 \\
\cline { 2 - 7 } Area (mi ${ }^{2}$ ) & 0.408 & 0.310 & 0.068 & 4.933 & 0.110 & 1.663 \\
Volume in acre-feet of 1 in. rainfall over basin & 21.760 & 16.533 & 3.627 & 263.093 & 5.867 & 88.693 \\
Mean basin slope (\%) & 1.664 & 2.016 & 2.867 & 2.762 & 2.868 & 2.911 \\
Main channel length (mi) & 1.580 & 0.978 & 0.363 & 7.702 & 0.762 & 2.199 \\
Mean main channel slope (\%) & 0.498 & 1.104 & 2.067 & 1.337 & 2.171 & 1.283 \\
Weighted main channel slope (\%) & 0.415 & 0.845 & 1.918 & 0.716 & 2.029 & 1.127 \\
Main channel length to centroid (mi) & 0.801 & 0.376 & 0.054 & 2.589 & 0.313 & 1.008 \\
SCS lag (hr) & 0.982 & 0.608 & 0.231 & 2.708 & 0.418 & 0.968 \\
SCS time base (hr), 1 hr rain, triangular & 3.958 & 2.959 & 1.951 & 8.565 & 2.450 & 3.919 \\
SCS time base (hr), 15 min rain, triangular & 2.957 & 1.958 & 0.950 & 7.563 & 1.449 & 2.918 \\
SCS time of rise (hr), 1 hr rain & 1.482 & 1.108 & 0.731 & 3.208 & 0.918 & 1.468 \\
SCS peak flow (cfs), 1 hr rain, triangular & 133.0 & 135.2 & 45.0 & 743.4 & 57.9 & 547.7 \\
SCS peak flow (cfs), 1 hr rain, curved & 170.8 & 167.9 & 43.8 & 860.7 & 66.8 & 702.8 \\
SCS time of rise (hr), 15 min rain & 1.107 & 0.733 & 0.356 & 2.833 & 0.543 & 1.093 \\
SCS peak flow (cfs), 15 min rain, triangular & 178.1 & 204.4 & 92.4 & 841.8 & 98.0 & 735.7 \\
SCS peak flow (cfs), 15 min rain, curved & 197.5 & 237.4 & 116.4 & 875.2 & 118.4 & 816.2 \\
\hline
\end{tabular}

The local storm PMP process was similar, with a starting index value of $8.7 \mathrm{in}$. for a $1-\mathrm{mi}^{2}$ area below 6000 -ft elevation over 1 hour. The PMP values 0.25 , 0.5, 0.75, 1, 2, 3, 4, 5, and 6 hours are shown in Figure 2.4. An exponential model of the form PMP $=\mathrm{a}$ * duration $\mathrm{b}+\mathrm{c}$, where $\mathrm{a}, \mathrm{b}, \mathrm{c}$ are coefficients, fit using nonlinear least-squares regression, was used to derive the 15-minute incremental precipitation over 6 hours. The lower part of Figure 2.4 shows the 15-minute intervals in the design storm sequence from high to low, as recommended by HMR 57. The total 6-hour precipitation in the local storm was 9.12 in., with the first 15-minute increment being the maximum at $3.80 \mathrm{in.}$

The local storm PMP was selected as the primary scenario for the PMF analysis because of its much higher intensity and likely greater peak flows compared to the general storm. However, the watershed runoff from the general storm, with and without a hypothetical snowmelt event occurring concurrently, was also simulated for comparison purposes.

Climate data from the Central Facilities Area (CFA; labeled in Figure 1.1) and MFC meteorological stations were obtained from the National Ocean Atmospheric Administration (NOAA) and evaluated for this report. The CFA period of record was from March 1, 1950 to April 30, 2010-60 years—and contained daily records of precipitation (in.), snowfall (in.), and snowpack thickness (in.). The maximum daily precipitation was 1.64 in. The MFC period of record was from April 1, 1993 to May 24, 2010 (17 years) and contained daily precipitation (in.); the maximum was $1.48 \mathrm{in}$. The rainfall maximums at 
these two stations occurred during June and July, respectively. Plots of precipitation at both stations, and snowfall and snow depth at CFA, can be found in Appendix A of this report.

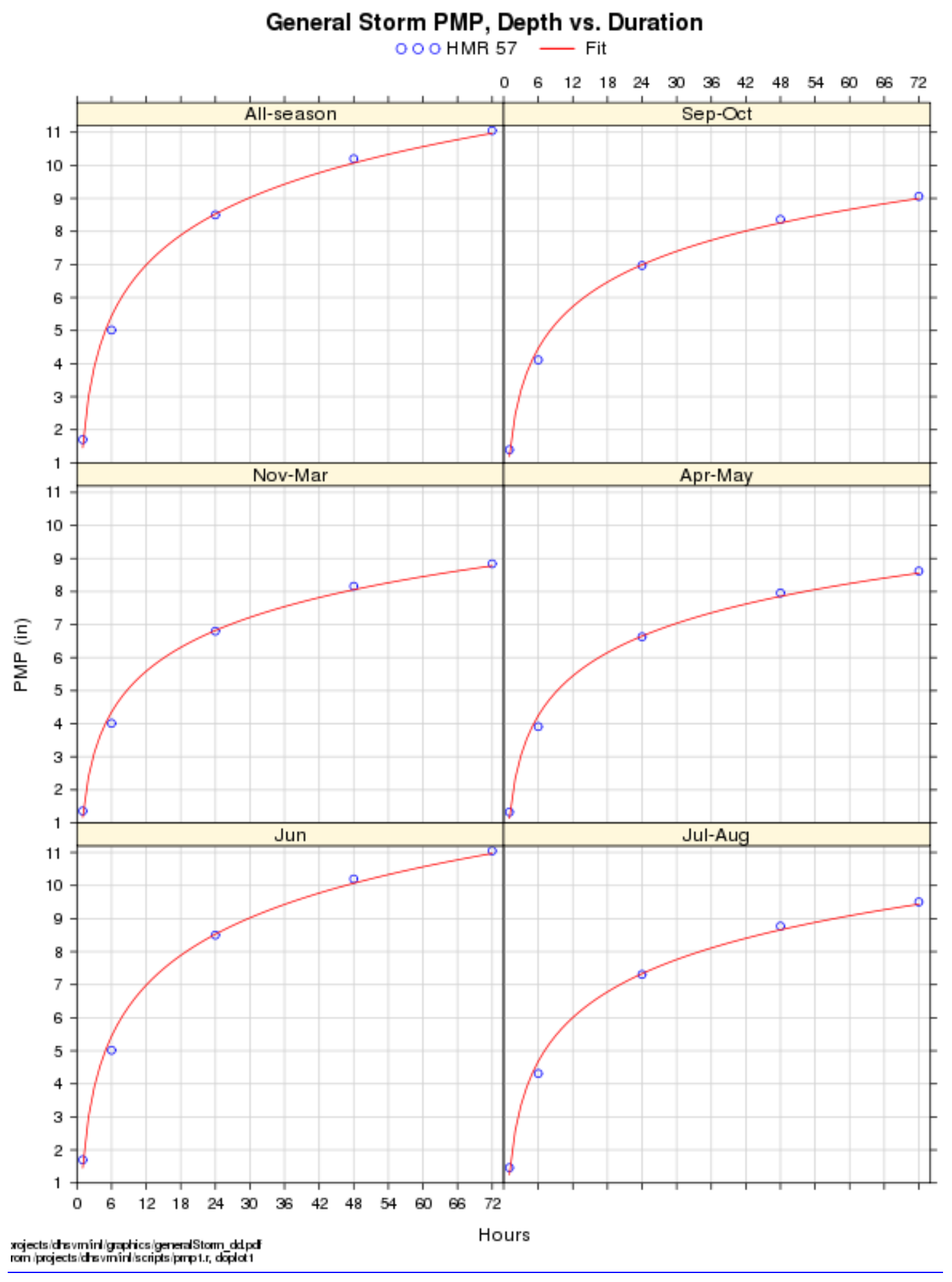

Figure 2.2. General Storm PMP by Season 
General Storm PMP Sequence, 3-hr Intervals

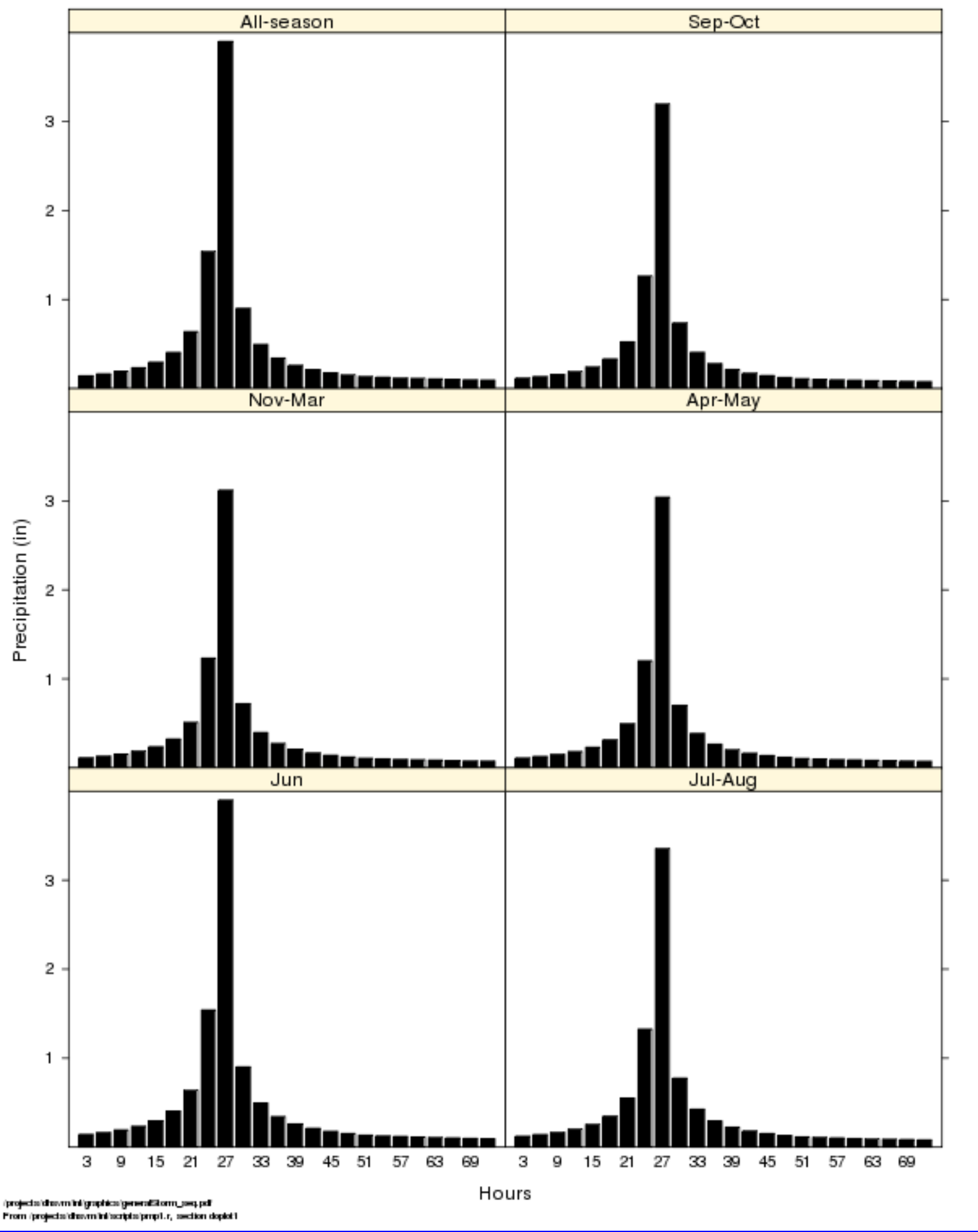

Figure 2.3. Design Storm Hyetographs Based on the General Storm PMP. Six-hour precipitation increments are shown; the hyetograph used as input to HEC-HMS was based on 1-hour increments. 

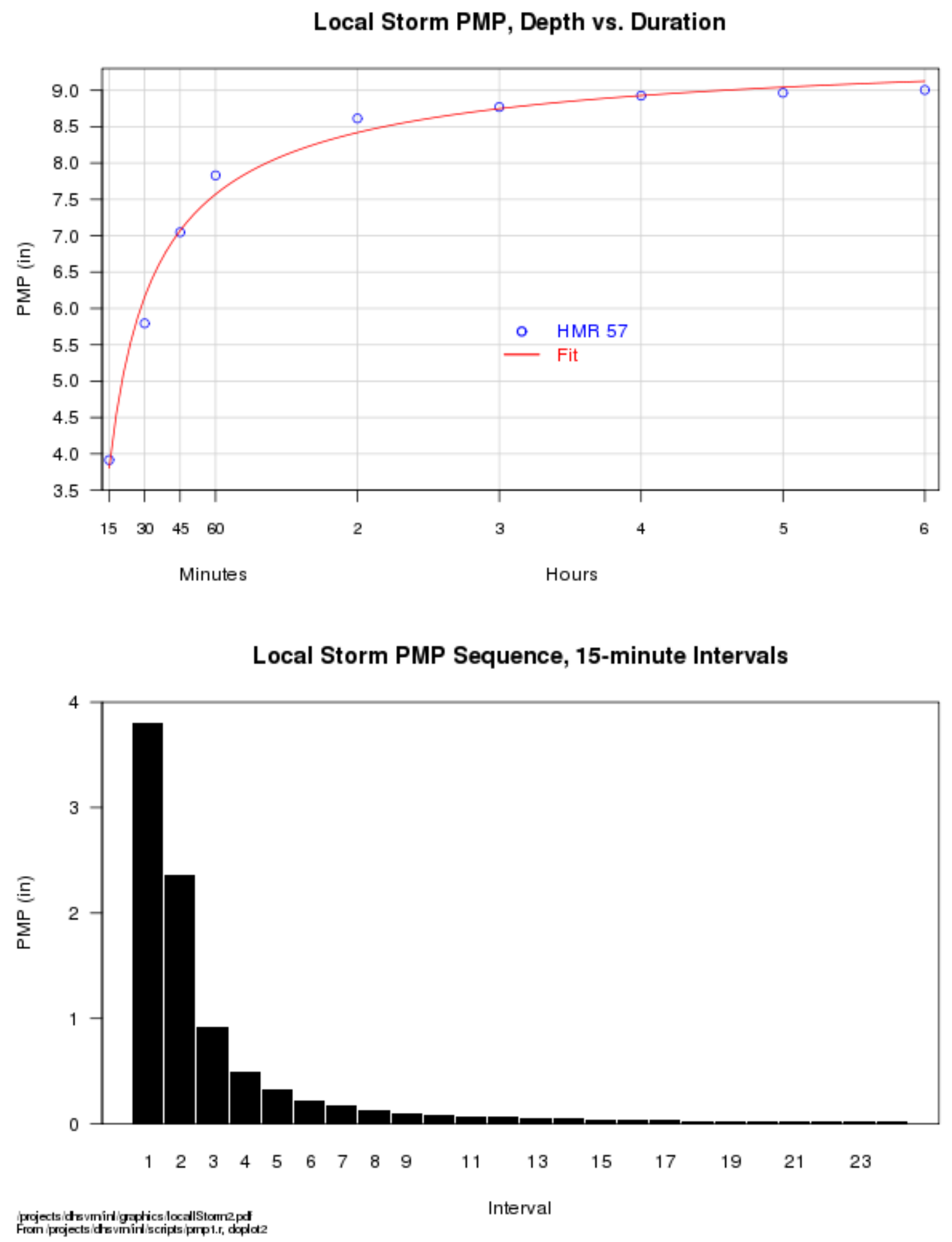

Figure 2.4. Local Storm PMP and Hyetograph with 15-Minute Intervals for the Design Storm 
The CFA meteorological station is located at latitude 43.533 degrees north and longitude 112.948 degrees west at an elevation of $4950 \mathrm{ft}$. Its tower is north of CFA building CF-690. Daily precipitation values are from a manually measured rain gage. The MFC meteorological station (tower code EBR) is located at latitude 43.594 degrees north and longitude 112.652 degrees west at an elevation of $5143 \mathrm{ft}$. Its tower is near the MFC. A tipping bucket rain gage is used to measure precipitation.

Historical observations at INL have indicated that a rain-on-snow event might provide the largest flood at MFC. In such an event, the amount of water content in the antecedent snowpack is a critical factor for total runoff, along with the amount of rainfall in the storm. To estimate a worst-case, highestwater-content snowpack, data from the snowiest year at CFA were used. The maximum observed snow depth of 30 in. occurred during 1993 and lasted for 11 days (Figure 2.5). It was preceded by a long accumulation season with relatively little mid-winter melting. The precipitation that fell during this time period totaled $4.12 \mathrm{in}$., which was assumed to be the maximum possible water content of the snowpack. The actual water content of the snowpack was probably less because of loss by infiltration of liquid water into the ground and sublimation. The corresponding water content of 0.137 is somewhat more than typical new-fallen snow in temperate climates. This observed snow condition was assumed to be suitable for the antecedent condition in the PMF analysis.

CFA Daily Snow Depth, WY 1993

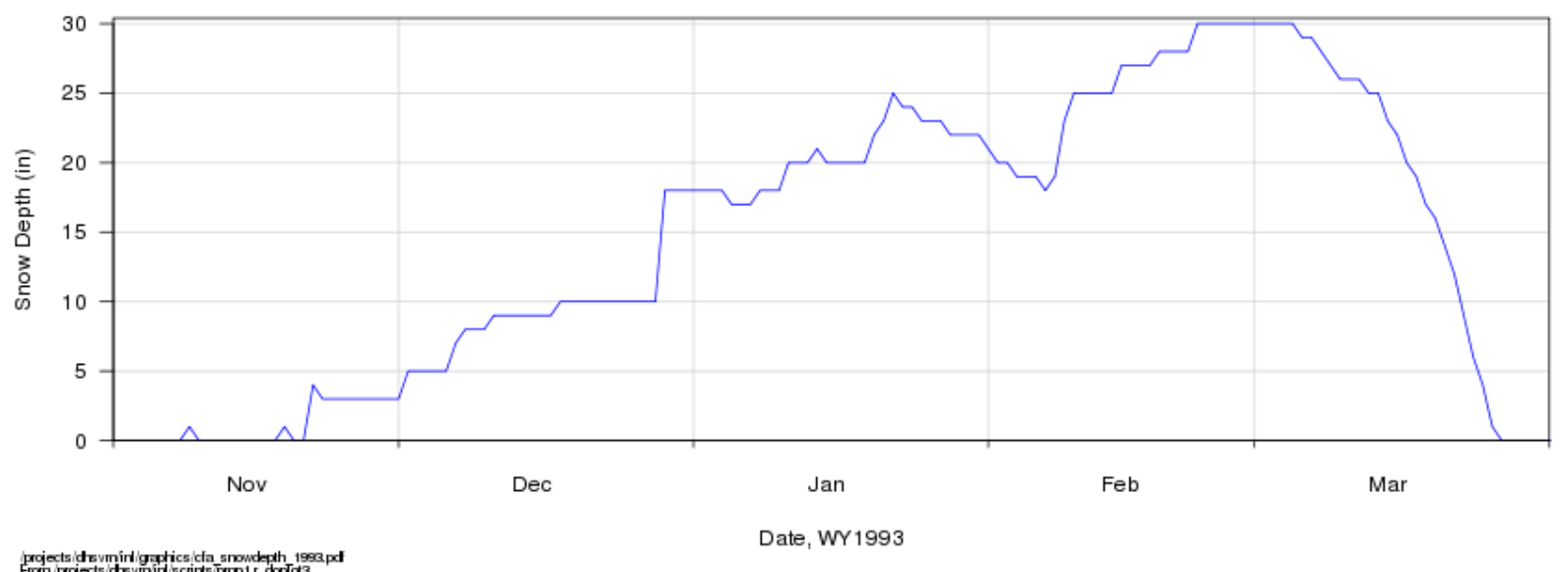

Figure 2.5. Snow Depth at the CFA Meteorological Station During Water Year 1993

The second design storm method was based on the 10,000-year precipitation previously estimated by Dames \& Moore (D\&M 1993). The rainfall amounts at 5, 10, 15, 30 minutes and 1, 2, 3, 6 hours from that report are shown in Figure 2.6. Not shown here for the sake of plot clarity but included in the 24-hour design storm are values for 12 and 24 hours. Five-minute increments of rainfall were derived by taking the difference between sequential cumulative amounts along the line shown in Figure 2.6. Linear interpolation was used so that the original point values were used as is; however, the value at 2 hours was omitted because it does not fit the general pattern of increase shown by the other Dames \& Moore values. The first 6 hours of the 5-minute increments used to drive the watershed model are shown in Figure 2.7. 
10,000-year Precipitation, Depth vs. Duration

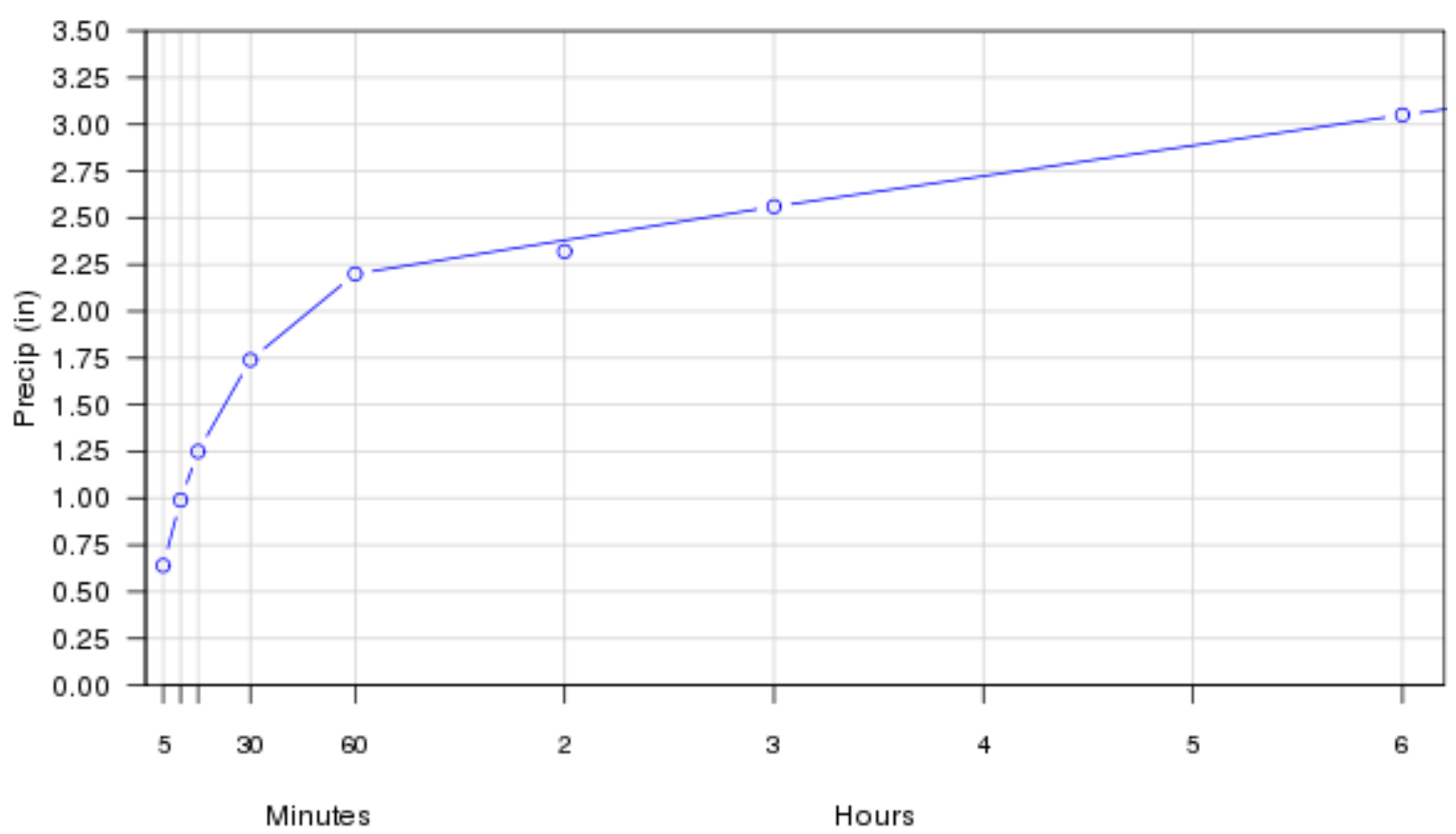

10,000-year Precipitation Sequence, 5-minute Intervals

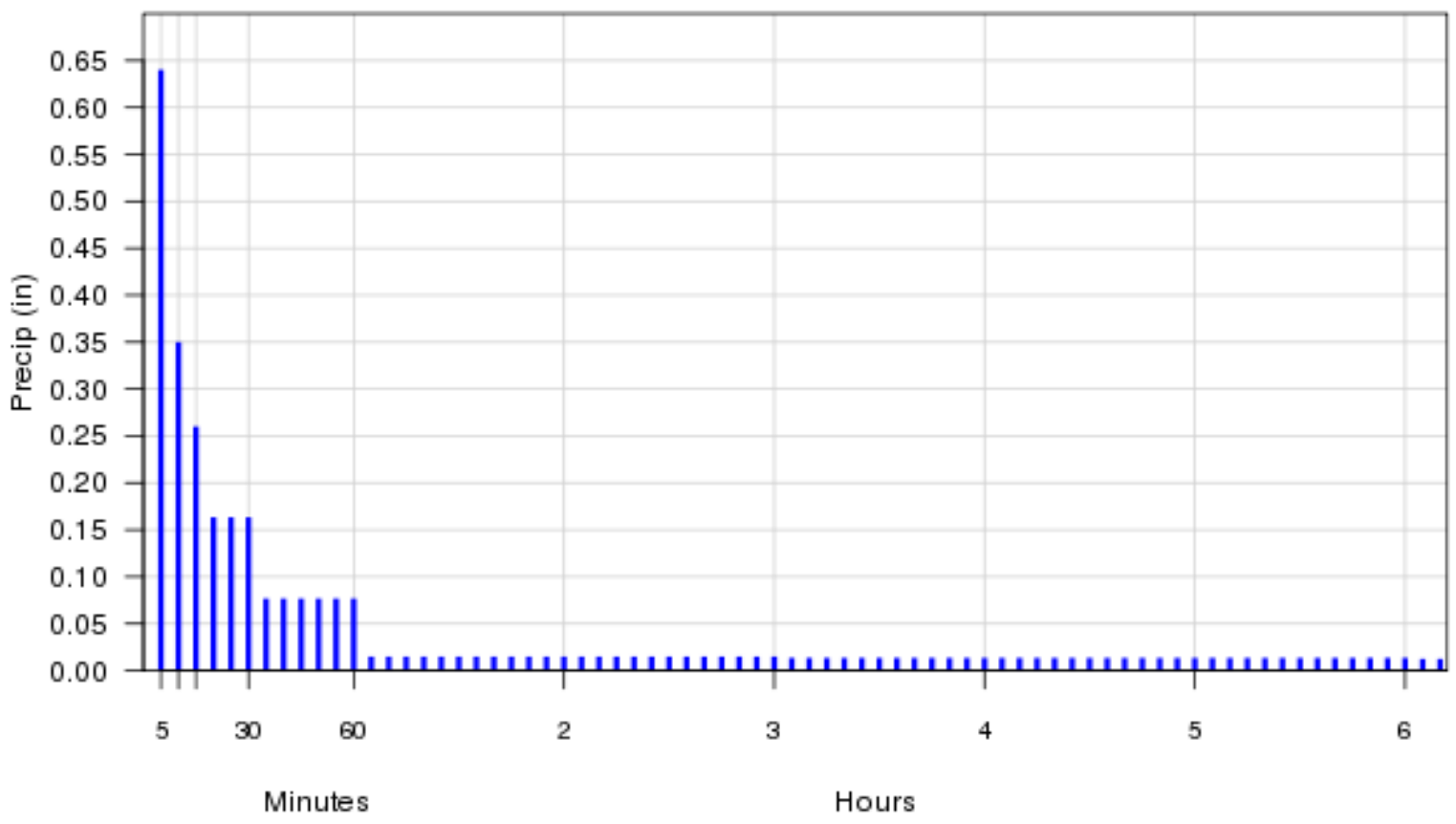

Figure 2.6. 10,000-Year Precipitation Event Depth vs. Duration and 5-Minute Interval Storm Sequence 
Watershed Outflows: 10,000-year Precipitation

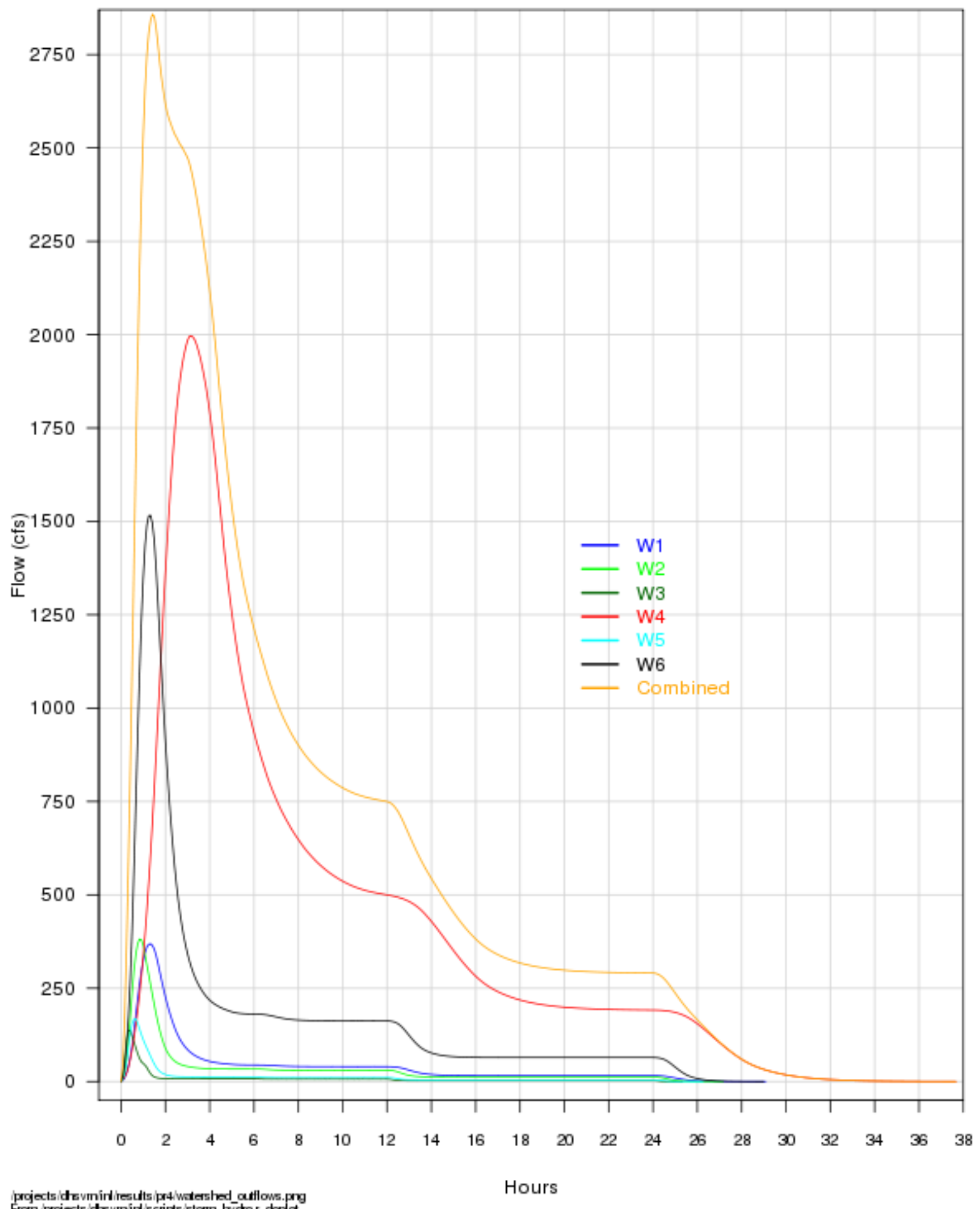

Figure 2.7. Hydrographs for the 10,000-Year Event 


\subsection{Determination of the Probable Maximum Flood and 10,000-Year Flood}

The watershed model HEC-HMS was used to transform the design storms into watershed outflows, which were used as inflows for HEC-RAS hydraulic model analysis. As stated previously, losses due to surface ponding, infiltration, and evaporation were assumed to be zero, which provides a conservative (highest) estimate of runoff for the PMF analysis. Therefore, the runoff volumes equaled the precipitation over the watersheds. Given that historical streamflow records were not available for the MFC site, synthetic unit hydrographs (UHs) were used as the transform method to convert the design storm hyetographs to streamflow hydrographs.

\subsubsection{Unit Hydrographs}

The UH is conceptually the direct runoff response of one unit of excess precipitation occurring uniformly over the watershed during a specified time period. The key assumptions of UHs are that they are linear and time-invariant, so that runoff from greater or less than one unit of precipitation is simply a multiple of the UH ordinates, and that this relationship holds regardless of antecedent conditions or other circumstances. In the absence of historical rainfall-runoff records, the best available method for estimating steamflows is the synthetic UH. Synthetic UHs are parameterized entirely from watershed properties such as topography and land cover, rather than analysis of rainfall and runoff data, and as such are highly uncertain.

Methods in the following resources were used to develop the synthetic UHs: Handbook of Hydrology (Maidment 1993), Hydrology for Engineers (Linsley et al. 1982), and Hydrology and Floodplain Analysis (Bedient and Huber 1992). The simplest approach is the Soil Conservation Service (SCS) unit hydrograph method, which requires knowing only the duration of excess rainfall and the time lag, or the time from the midpoint of the precipitation period to the time of peak flow. Periods of 15 minutes and 1 hour were both used for the duration of 1 in. of excess rainfall. The SCS time lag was computed as follows (Bedient and Huber 1992):

$$
\mathrm{t}_{\mathrm{p}}=\left(\mathrm{L}^{\wedge} 0.8 *(\mathrm{~S}+1)^{\wedge} 0.7\right) /\left(1900 * \mathrm{~s}^{\wedge} 0.5\right)
$$

where $\quad t_{p}=$ time lag (hr)

$\mathrm{L}=$ length of main channel from outlet to basin divide ( $\mathrm{ft}$ )

$\mathrm{S}=$ storage coefficient

$\mathrm{s}=$ mean watershed slope (\%).

$$
\mathrm{S}=(1000 / \mathrm{CN})-10
$$

where CN is the SCS curve number for the particular soil type and land cover.

Peak flow is then computed as

$$
\mathrm{Qp}=483.4 * \mathrm{~A} / \mathrm{T}_{\mathrm{r}}
$$


where $\mathrm{Q}_{\mathrm{p}}=$ peak flow rate $(\mathrm{cfs})$

$\mathrm{A}=$ basin area $\left(\mathrm{mi}^{2}\right)$,

$\mathrm{T}_{\mathrm{r}}=$ time of rise $=$ time from start of rainfall (and runoff) to time of peak (hr). Time of rise is

$$
\mathrm{T}_{\mathrm{r}}=0.5 * \mathrm{D}+\mathrm{t}_{\mathrm{p}}
$$

where $\mathrm{D}$ is the duration of rainfall excess (hr).

The resulting triangular UHs based on 1 in. over 15 minutes and 1 in. over 1 hour for W4 are shown in Figure 2.8. For comparison, UHs based on other methods were also developed. UH theory does not consider the nonlinear watershed response to high-intensity rainfall associated with PMPs (i.e., higher peak flows and shorter times of rise). To account for this phenomenon, the peak was increased by $20 \%$ and the time of rise decreased by 33\%. The modified SCS UHs in Figure 2.8 do that, with an added property of maintaining the time base of runoff instead of having it decrease to preserve runoff volume in a triangle. This was done by adding an ordinate between the peak flow and the end of the hydrograph, such that the falling limb has an indentation. The time for this ordinate was set at $25 \%$ of the falling limb time base, and the flow at that time calculated such that runoff volume was preserved. As shown in Figure 2.8, the SCS method produces the largest peak flow and provides the most conservative estimate.

HEC-HMS alters the SCS UH so that it is a curve rather than a triangle. The HMS time of rise is the same as that derived by the manual triangle method, but the peak flow is somewhat higher (Figure 2.9).

HEC-HMS also offers a Snyder UH option, with a time lag peaking coefficient, $\mathrm{C}_{\mathrm{p}}$, required as input. Two different equations for time lag were used:

$$
\mathrm{t}_{\mathrm{p}}=\mathrm{Ct} *\left(\mathrm{~L} * \mathrm{~L}_{\mathrm{c}}\right) \wedge 0.3 \text { (Bedient and Huber 1992) }
$$

where Ct is a coefficient, $\mathrm{L}$ has units of miles, and Lc is the length of main channel from the outlet to a point opposite the basin centroid (mi).

The other time lag equation is

$$
\mathrm{t}_{\mathrm{p}}=\mathrm{C}_{\mathrm{t}} *\left(\mathrm{~L} * \mathrm{~L}_{\mathrm{c}} /{ }_{\mathrm{sr}} \wedge 0.5\right) \wedge 0.38 \text { (Linsley et al. 1982) }
$$

where $\mathrm{s}_{\mathrm{r}}$ is a weighted channel slope $(\mathrm{ft} / \mathrm{ft})$.

For the coefficients $C_{t}$ and $C_{p}$, various combinations of values were used, in the ranges suggested in the literature. Table 2.1 lists the resultant values for $t_{p}$. All Snyder UHs resulted in peak flows that were lower than those derived using the SCS methods.

For this analysis, loss due to infiltration was assumed to be zero, but in the SCS UH method the curve number $(\mathrm{CN})$ and dependent storage coefficient, S, also affect the shape of the hydrograph via the time lag, with lower peaks and longer runoff durations as CN decreases. The CN was set to 89, representing poorly permeable soil group $\mathrm{D}$ and rangeland in poor condition (Bedient and Huber 1992). The curvilinear version of the 15-minute SCS UH with CN = 89 was the one used for the PMF analysis; this is shown for all watersheds in Figure 2.9. 


\section{W4 Unit Hydrographs}

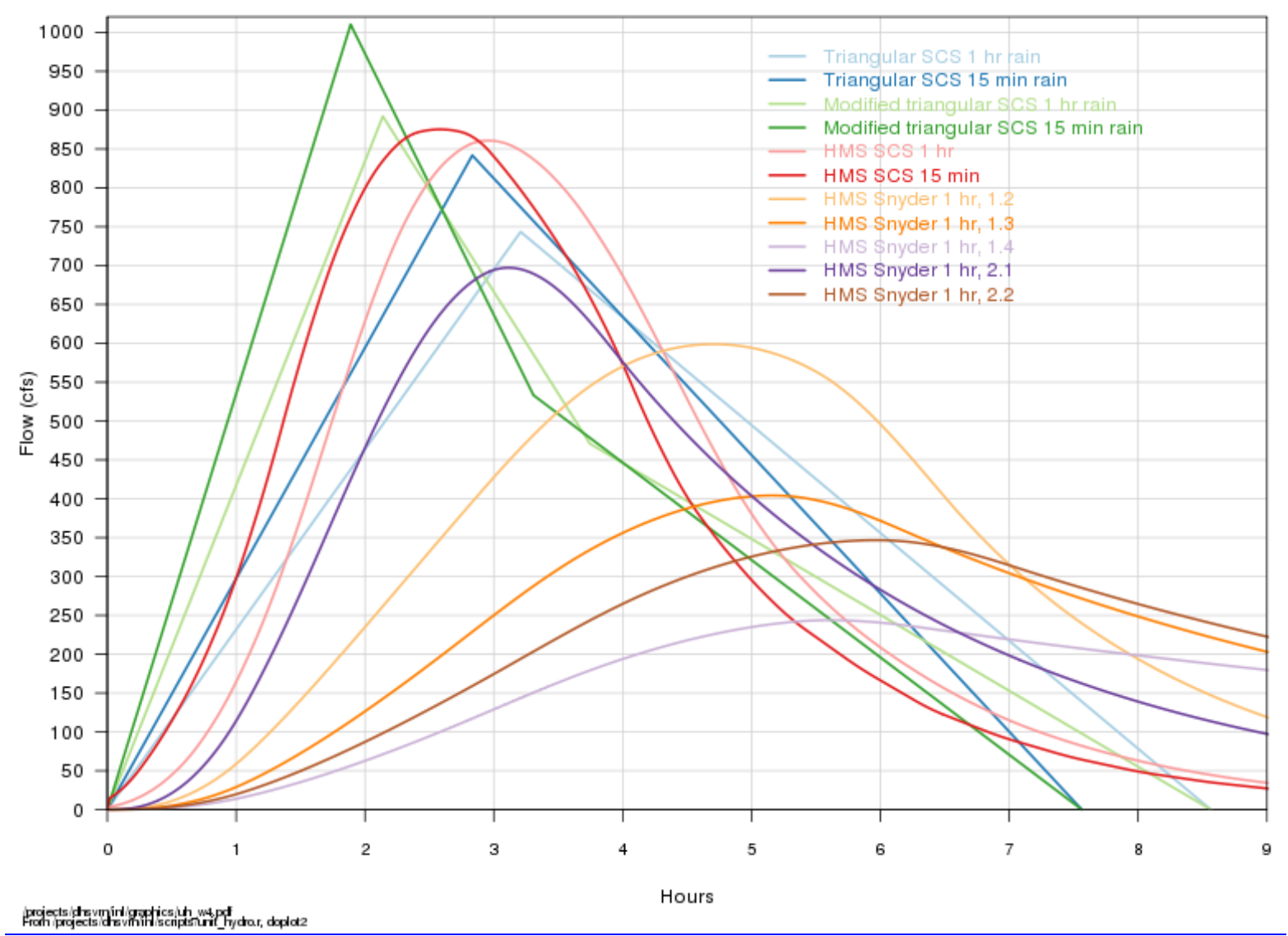

Figure 2.8. Unit Hydrographs for Watershed 4 (W4)

\subsubsection{HEC-HMS Model Results}

The local storm PMP and the UH were used in HEC-HMS to generate separate storm flows for all six watersheds. The resulting streamflows are shown in Figure 2.10. Watershed 4 (W4) is by far the largest contributor of flow, but the peak of the combined flows happens earlier than the W4 peak, at about 1.5 hours.

For comparison, the design hyetograph based on the general storm PMP was also used to drive the HEC-HMS model. As expected, the storm flows from this lower-intensity, longer-duration storm were less than half of those produced by the higher-intensity local storm (Figure 2.11). To include the contribution of snowmelt from an antecedent snowpack, a design storm with assumed complete melting over 4 hours was also run through HEC-HMS. The 4.12 in. of assumed snow water content was divided equally (1.03 in.) and added to each of the 4 hours of maximum rainfall intensity. The final water increments after addition of snowmelt during those 4 hours were 1.67, 2.49, 2.57, and 1.93 in., respectively. The resulting hydrographs are shown in Figure 2.12. This scenario resulted from a collection of maximizing assumptions for the general storm PMF: use of the all-season PMP instead of the lower winter season PMP, no loss of precipitation or snowmelt, a very high snowpack water content, 
and very rapid melting of the snowpack coincident with the time of highest rainfall. Even with all of these assumptions, the peak flows are still less than those from the warm season local storm. This outcome justified the use of the local storm for the subsequent HEC-RAS analysis of channel flood routing.
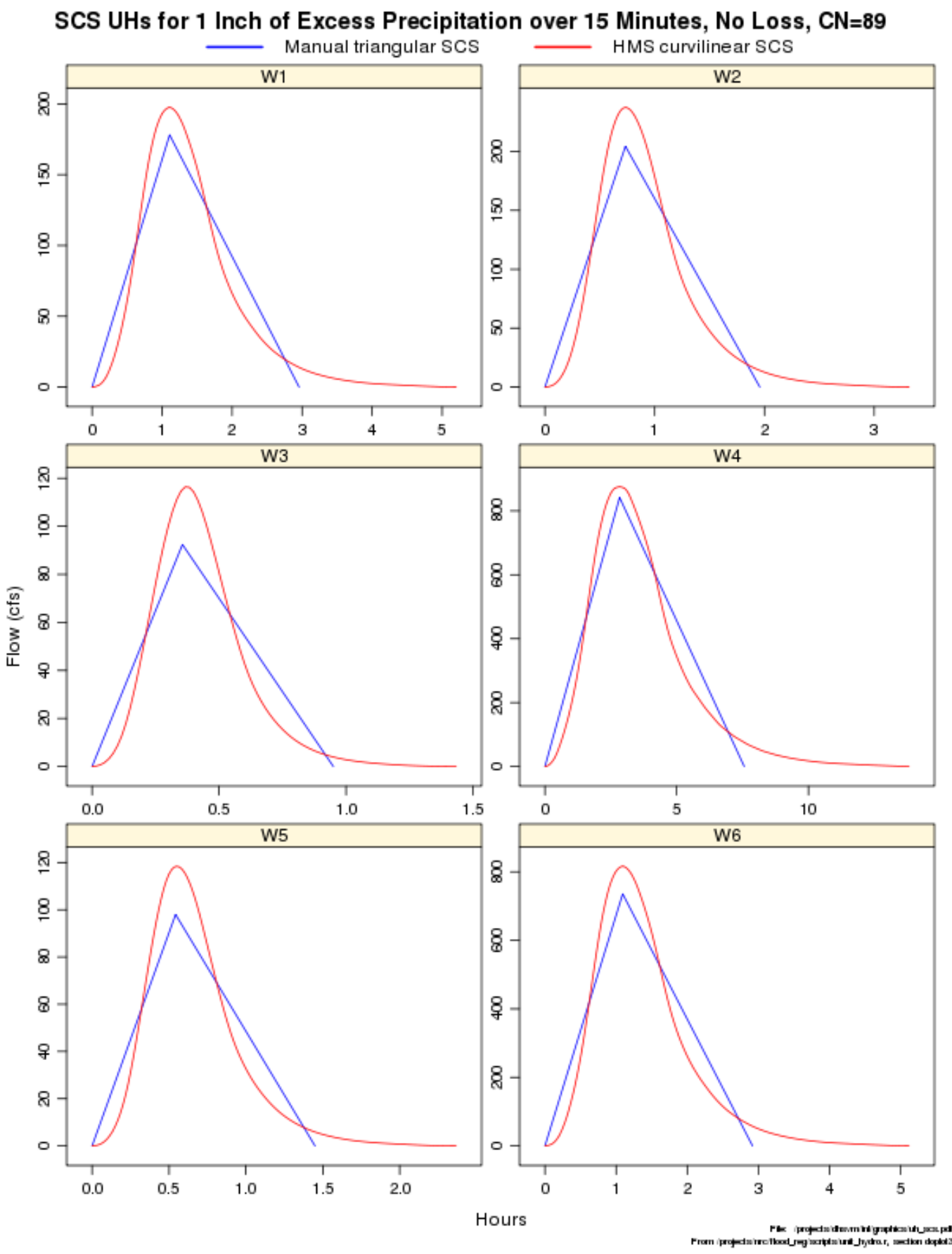

Figure 2.9. SCS Triangular and HMS Curvilinear Unit Hydrographs for All Watersheds 


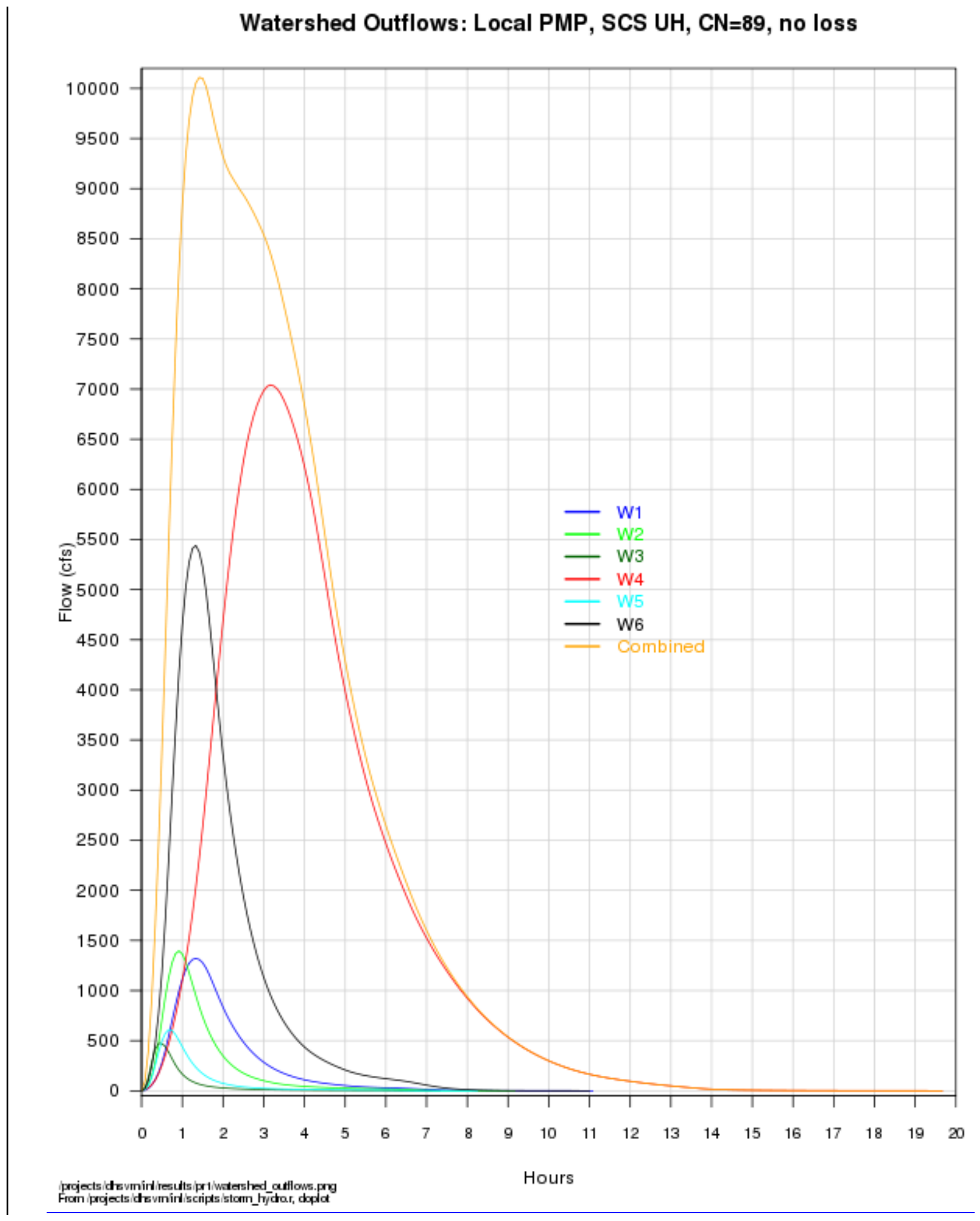

Figure 2.10. PMF Hydrographs for the Local Storm 
Watershed Outflows: General PMP, SCS UH, $\mathrm{CN}=89$, no loss

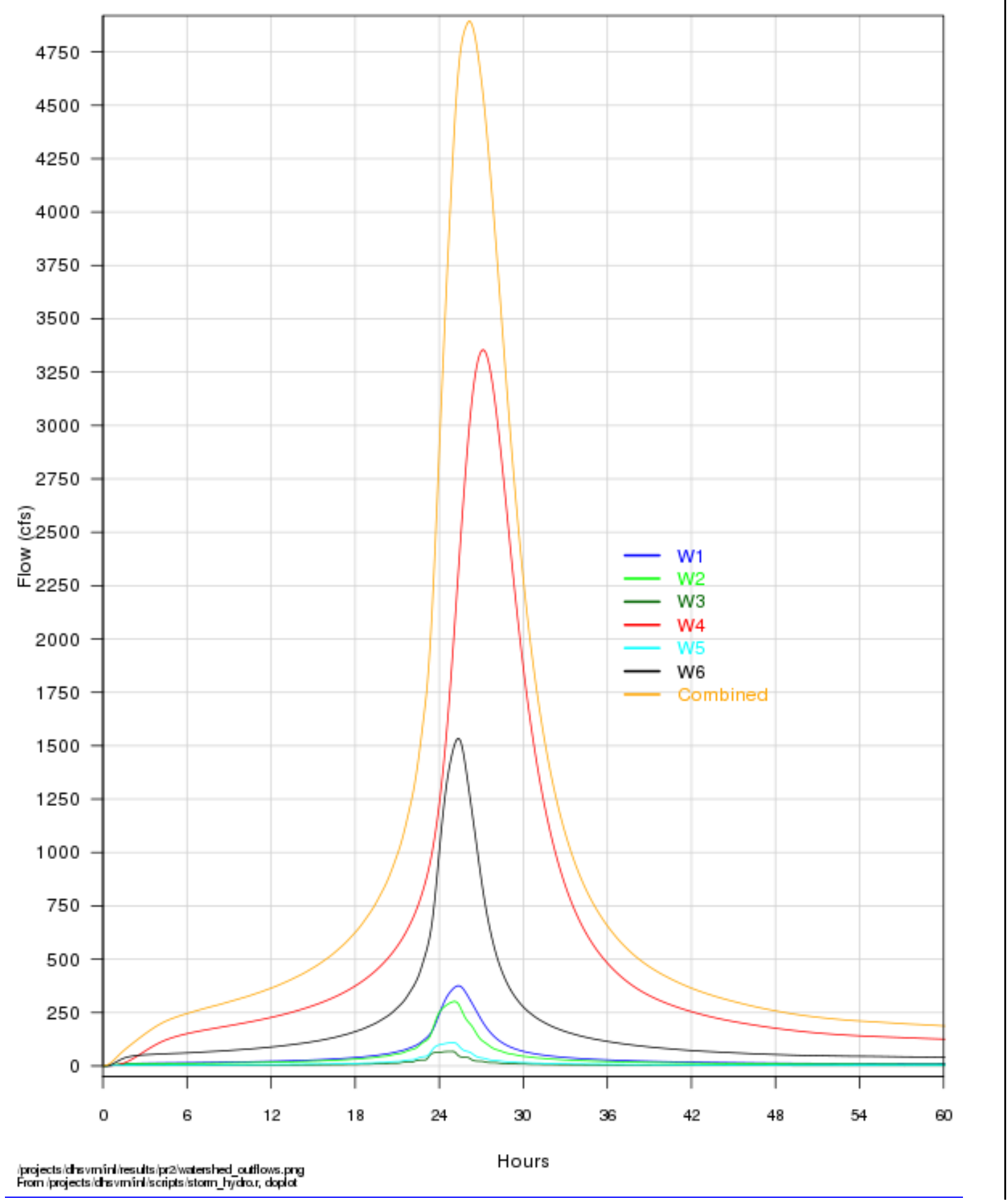

Figure 2.11. PMF Hydrographs for the General Storm 


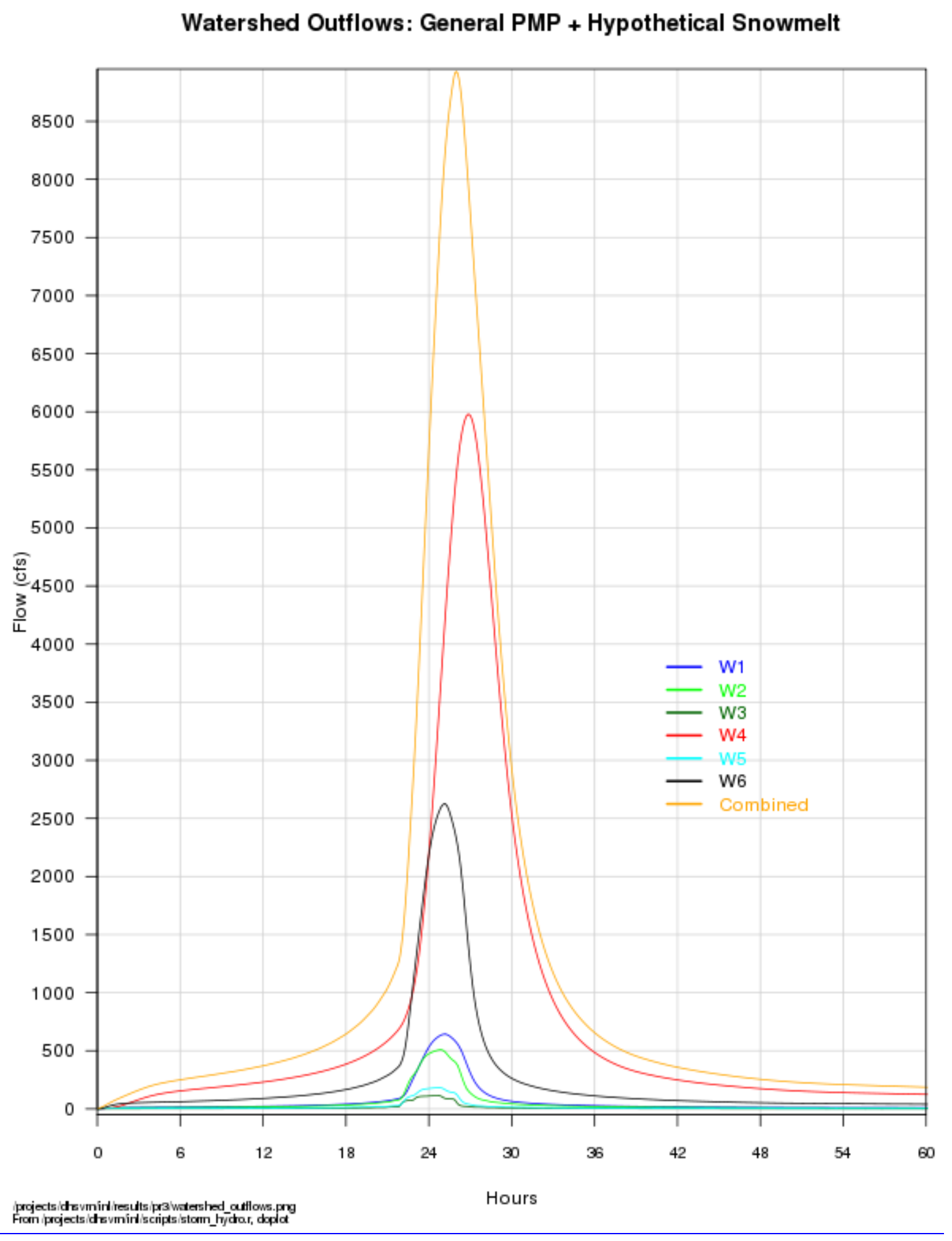

Figure 2.12. PMF Hydrographs for the General Storm with Hypothetical Snowmelt Added. The storm flows from the 10,000-year precipitation, shown in Figure 2.6, are much less than any of the PMP-based flows. The combined runoff from all six watersheds has peak value about $28 \%$ of that of the local storm PMP peak. 


\subsection{Hydraulic Analysis and Determination of Peak Elevation}

The hydraulic analysis and peak elevation determinations for the MFC and the TREAT Facility are described in this section. The analysis uses the HEC-RAS hydraulic model to compute flow velocity and depth. Water-surface elevations are computed by the addition of depth and cross-section elevations.

\subsubsection{MFC Site}

The hydraulic analysis was conducted to estimate the maximum water-surface elevations during the PMF and a 10,000-year return period event at the MFC site. The analysis uses the HEC-RAS hydraulic model to route flow through the site with consideration of backwater effects that could occur due to diversion dams, roads, and blocked culverts. HEC-RAS is a one-dimensional model and its setup requires thoughtful assembly of cross-sectional and control-structure characteristics of the system.

\subsubsection{Hydraulic Model Setup}

Cross-section data input into HEC-RAS were extracted from available Light Detection and Ranging (LiDAR) data (see Appendix B). The geometric representation of the MFC site and surrounding areas included cross sections that characterize the presence of drainage channels, roads, and buildings. The site was divided into four subbasins: Subbasins 1 through 4 (labeled as B1, B2, B3, and B4 in Figure 2.13). Geographic information system (GIS) software (Global Mapper) was used to extract cross sections from high-resolution LiDAR data (Figure 2.13). A higher density of cross sections was added within the MFC site to characterize building structures, culverts, ditches, and roads, while a smaller number of cross sections were used in surrounding areas but nonetheless included features that provided hydraulic control (dams, channels, and roads). Cross sections were input to the HEC-RAS model using a GIS format, and each cross section was identified and checked against the original LiDAR data.

The one-dimensional channel connections were setup as follows (Figures 2.13 and 2.14):

- Subbasin B1 was selected as the mainstream basin.

- Subbasin B4 was connected to subbasin B1 from the left-hand side and subbasin B3 was connected to subbasin B1 from the right-hand side.

- Subbasin B3 receives flows from subbasin B2.

Figure 2.15 shows the plan view from the HEC-RAS model setup. Due to the one-dimensional method used in HEC-RAS, it was necessary to account for the connections between subbasins via lateral flow exchange. These flow exchanges were handled using lateral weir structures in HEC-RAS with the weir elevation and width based on LiDAR data. These weirs were included between subbasins B1 and B2 and between subbasins B1 and B3 (Figure 2.13).

The following assumptions were used for the analysis:

- Flow was one-dimensional using the HEC-RAS hydraulic model.

- The subbasins were lightly vegetated sagebrush (Manning's $n=0.035$ ) with sandy channels (Manning's $n=0.030$ ). 
- Roads and dams were handled as weirs with the weir elevation based on road elevation derived from the LiDAR data. The default weir coefficient of 2.6 provided by HEC-RAS during model setup was used in all analyses.

- Two levels of conservatism were examined:

- Most conservative with all culverts in the MFC area (subbasin B3) blocked. Also, the diversion channel that reroutes flow from the upper reach of subbasin B2 into the upper reach of Basin 1 was blocked. This is referred to as the Blocked case.

- Least conservative with all of the ditches in the MFC area (subbasin B3) open. Also, the diversion channel that reroutes flow from the upper reach of subbasin B2 into the upper reach of subbasin B1 was open. This is referred to as the Open case.

- For both levels of conservatism, the bridge under the access road crossing subbasin B1 was in place.

- The downstream boundary was set as a normal depth boundary with a friction slope of 0.0002 . This value was estimated from the local topography near the downstream boundary.

- The stormwater detention pond northwest of MFC was filled.

- Local inflow from precipitation onto HEC-RAS subbasins was based on the Rational Method with no precipitation loss and was linearly distributed along the subbasins, with the distribution based on surface area.

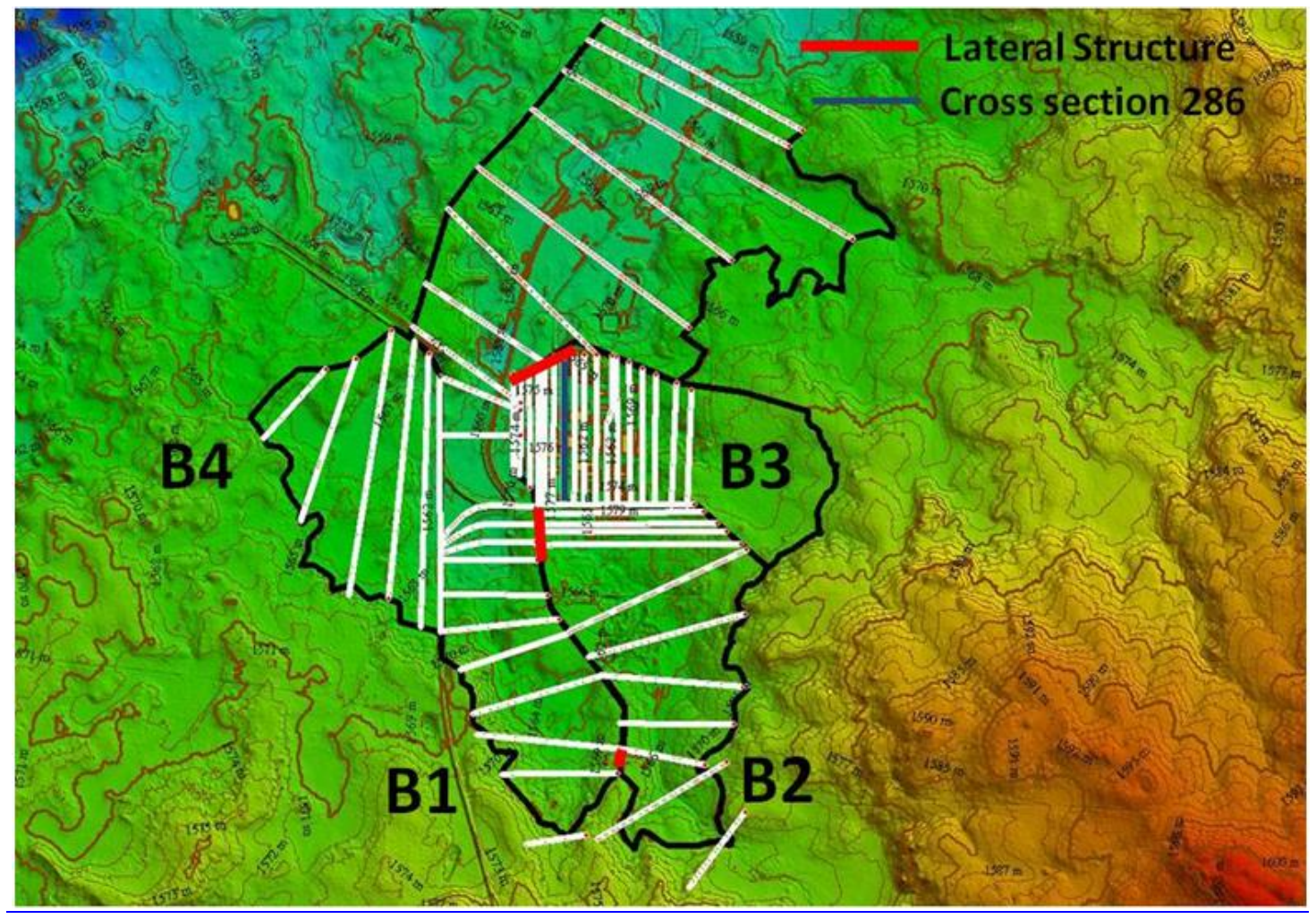

Figure 2.13. Four Subbasins Used for the HEC-RAS Model Analysis and HEC-RAS Cross-Section Layout for the MFC Site and Surrounding Areas 


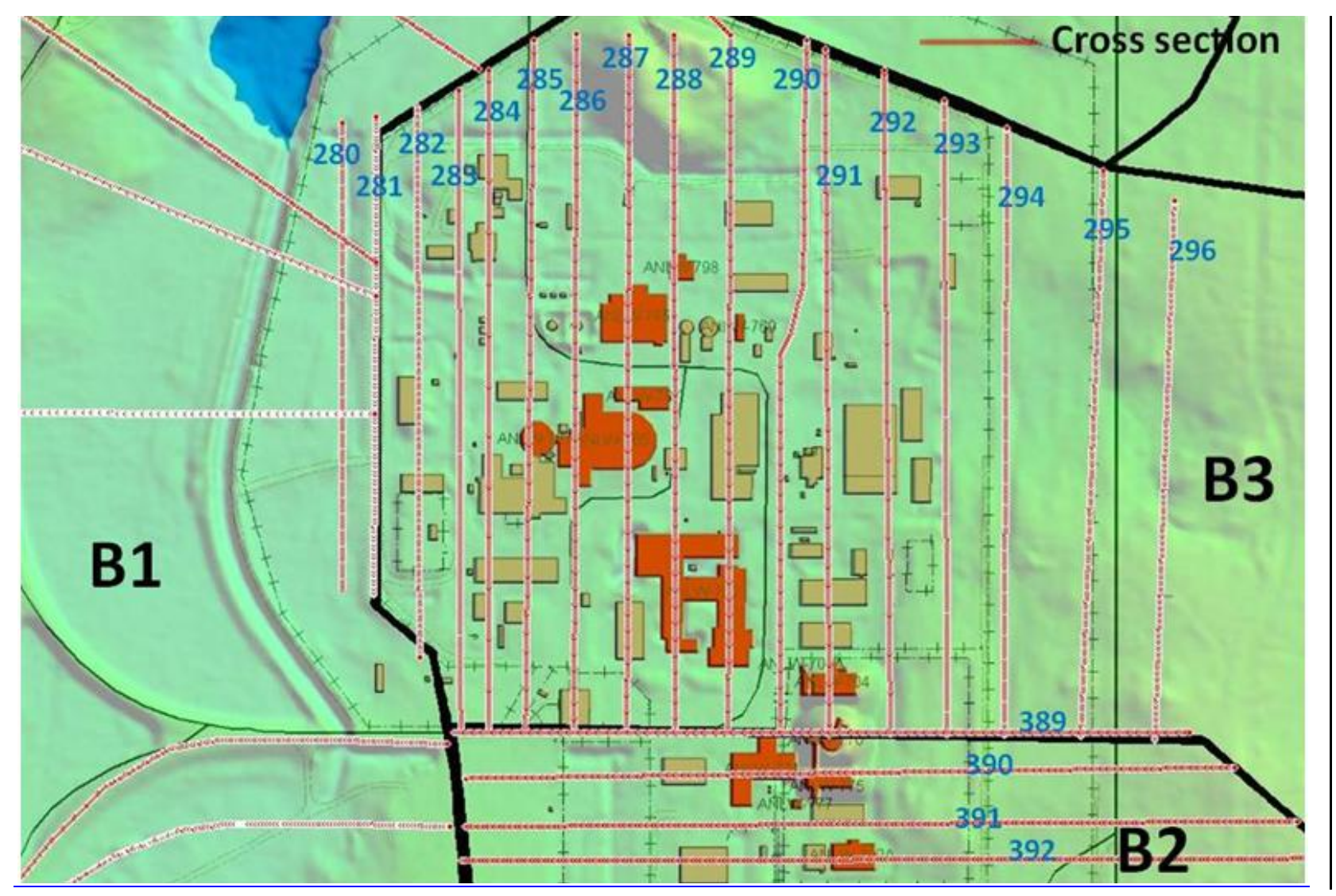

Figure 2.14. Detail of HEC-RAS Cross Sections Overlaid onto the Buildings of the MFC Site

Inflow hydrographs from HEC-HMS analyses provided the watershed drainage flows (discussed in Section 2.2), and the local inflow estimates mentioned above were input at 5-minute intervals. For the local runoff from the HEC-RAS basins (i.e., the drainage areas not included in the HEC-HMS analysis in the immediate vicinity of the channels), the spatial scale is small enough that lag time need not be considered. In addition, using the rational method and assuming no loss to infiltration provides a conservative estimated runoff. Any attenuation of the local runoff (and watershed runoff) occurs in the HEC-RAS model as a consequence of the geometric configuration of the system and the assumed surface roughness parameters. The flooding analysis included an examination of flows generated from two precipitation events: the PMP (generating the PMF) and the 10,000-year return period event. The watershed drainage and local inflows for the PMF event are shown in Figure 2.16, while the inflows for the 10,000-year return period are shown in Figure 2.24. Note that the estimated local inflows were large with respect to the watershed drainage especially in the 10,000-year return period event. Because the local inflows were computed from local precipitation intensities in the HEC-RAS basins, they peaked prior to the watershed drainage inflows.

Initial flows for the HEC-RAS model were set to be the same as the first 5-minute flows from the watershed drainage inflow hydrographs. For the PMF analysis, the model time step was 1 minute, and the simulation period was 11.5 hours. The analysis showed that the passage of the PMF peak through the site took about 4 hours from the start of the simulation. For the 10,000-year return period analysis, the 
model time step was 1 minute, and the simulation period was 13 hours. The analysis showed that the passage of the 10,000-year return period peak through the site took about 3.5 hours from the start of the simulation.

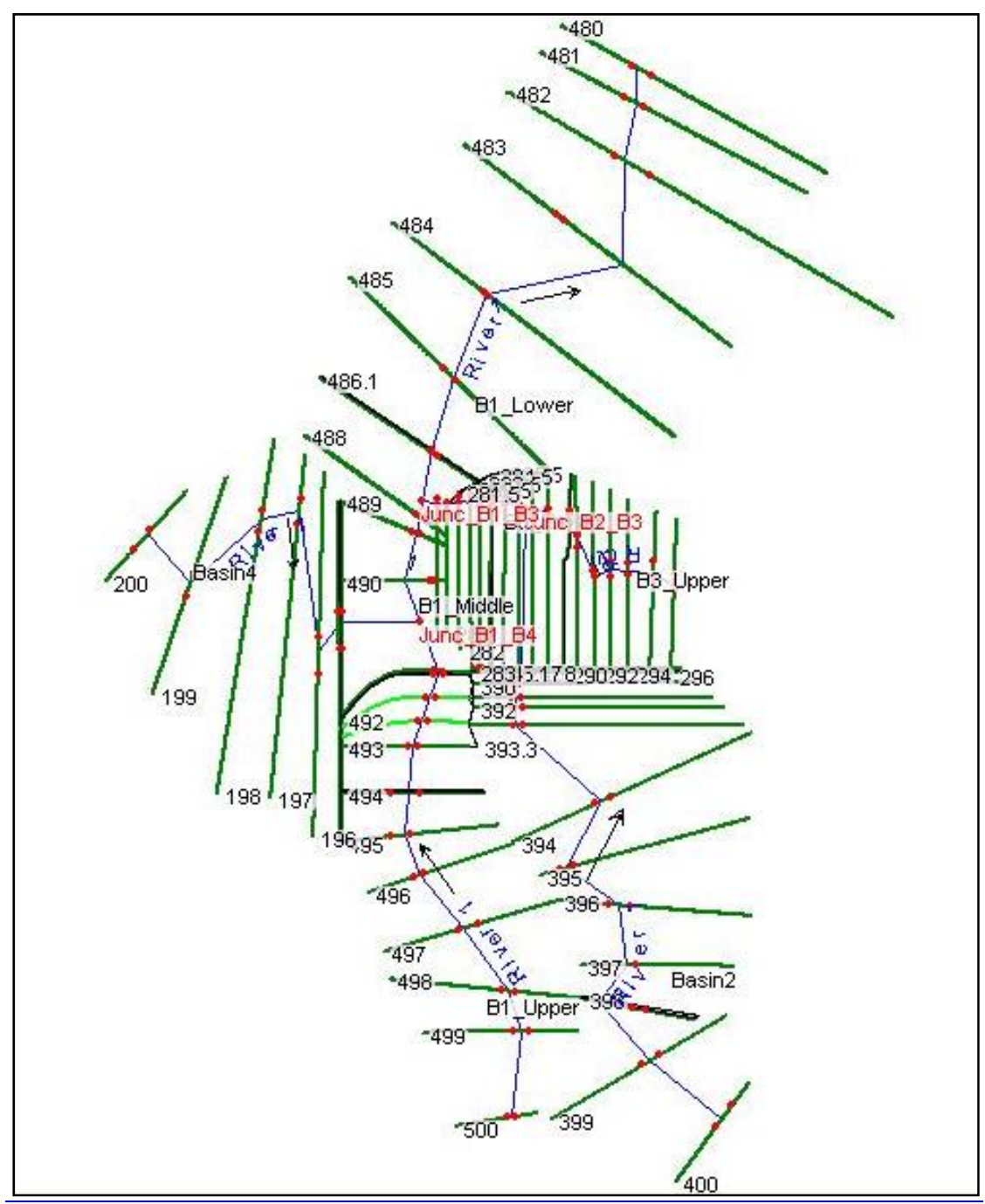

Figure 2.15. Plan View of HEC-RAS Model Setup for the MFC Site and Surrounding Areas

\subsubsection{PMF Results at the MFC Site}

As previously noted, the inflows for the PMF event are shown in Figure 2.16. Subbasin B1 and subbasin B2 watershed drainage inflows had comparable peak flows; however, the timing of the peak from subbasin B2 was about 2 hours later than from subbasin B1. Subbasin B1 had the largest area of the four HEC-RAS basins included in the analysis; consequently the local inflows are the greatest of the four, although these peaked early in the analysis.

The plots of maximum water level profiles from the HEC-RAS model analyses for the Blocked and Open cases show the hydraulic relationships between the subbasins. For the Blocked case, Figure 2.17 
shows the combined profiles for all of the subbasins, while Figure 2.18 shows the profiles for individual subbasins. Figure 2.19 shows the maximum water-surface elevation for the Blocked case in the middle of the MFC site at cross-section station 286 (for reference, Figures 2.13 and 2.14 show the cross-section locations). At cross-section station 286, the maximum elevation was $5125.55 \mathrm{ft}$.
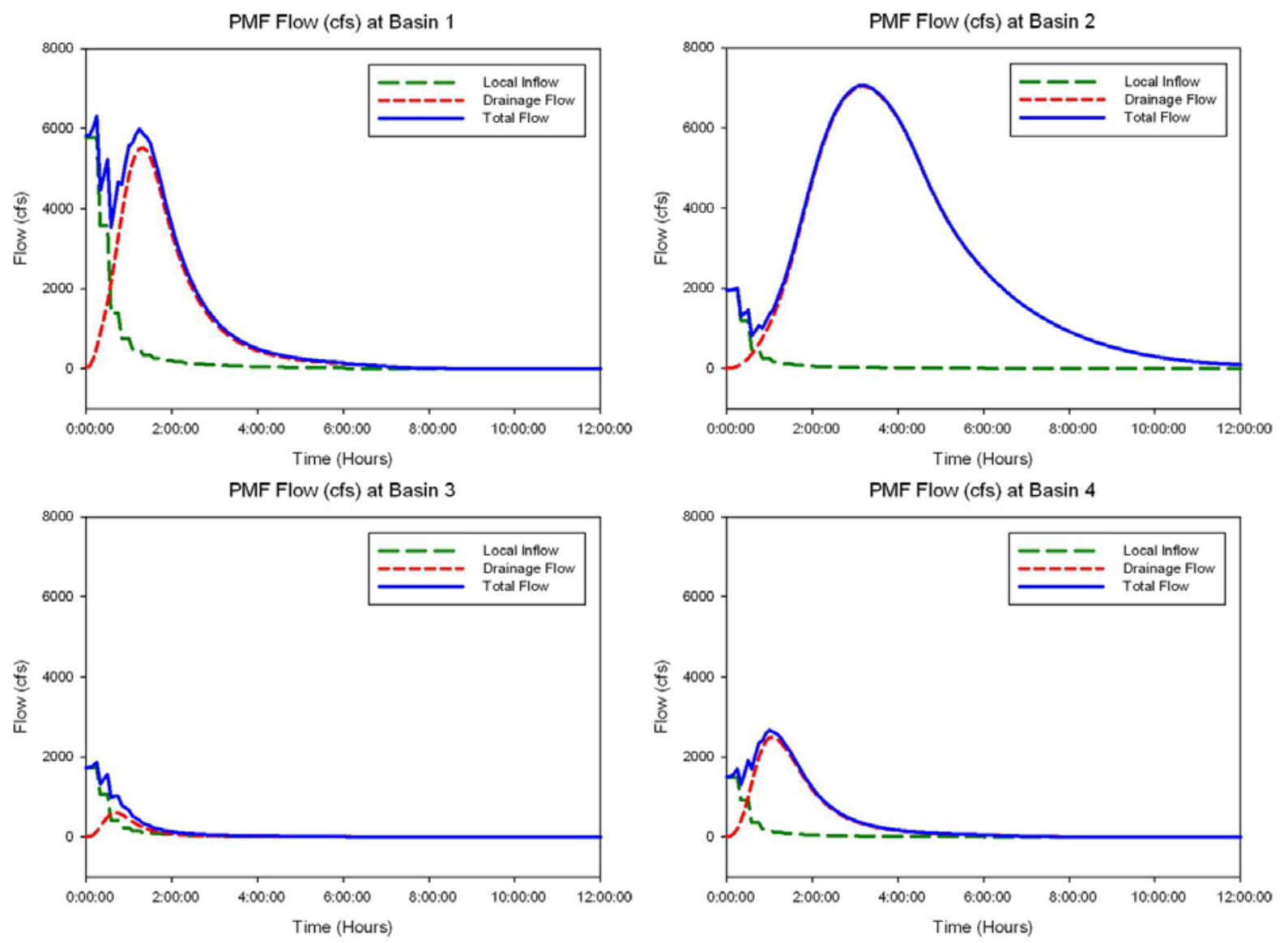

Figure 2.16. Flows Input to the HEC-RAS Hydraulic Model for the PMF Event. The plots include the watershed drainage flow from the HEC-HMS analysis plus the local inflow estimated using the rational method with the PMP intensities. The drainage flow is input at the upstream end of each basin, while the local inflows are linearly distributed along the basin. 


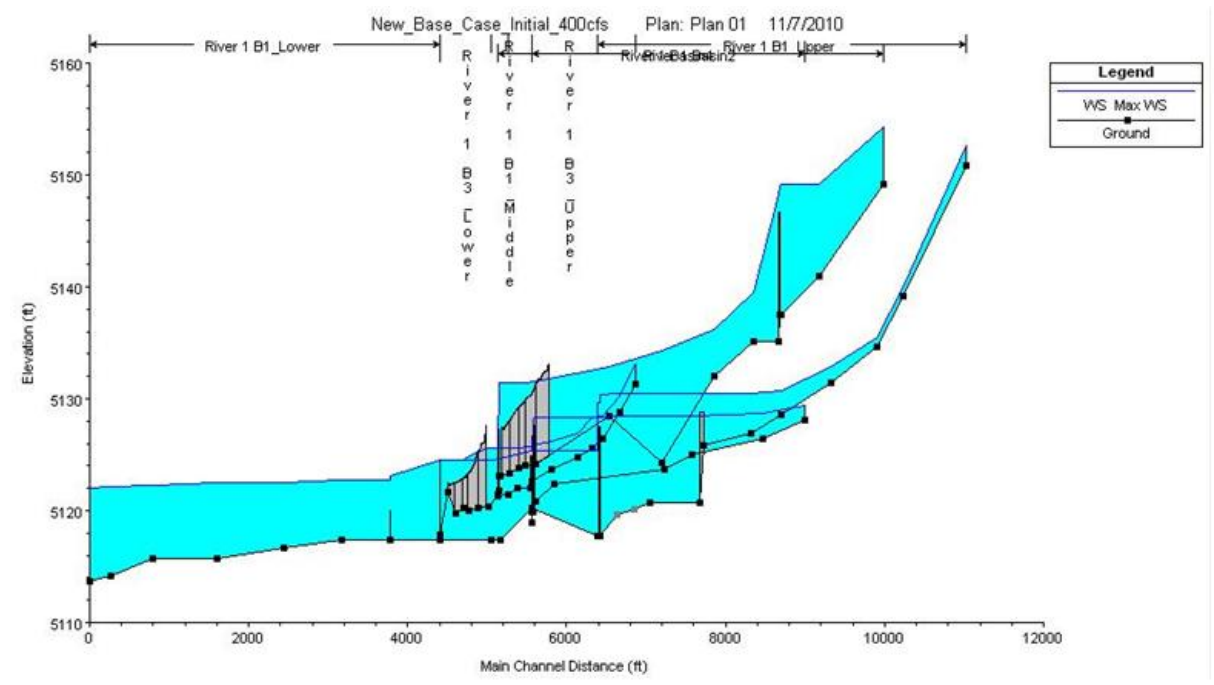

Figure 2.17. Combined Profiles of the Maximum Water Level for all Subbasins from the PMP Event (Note: gray shaded areas designate weirs.)
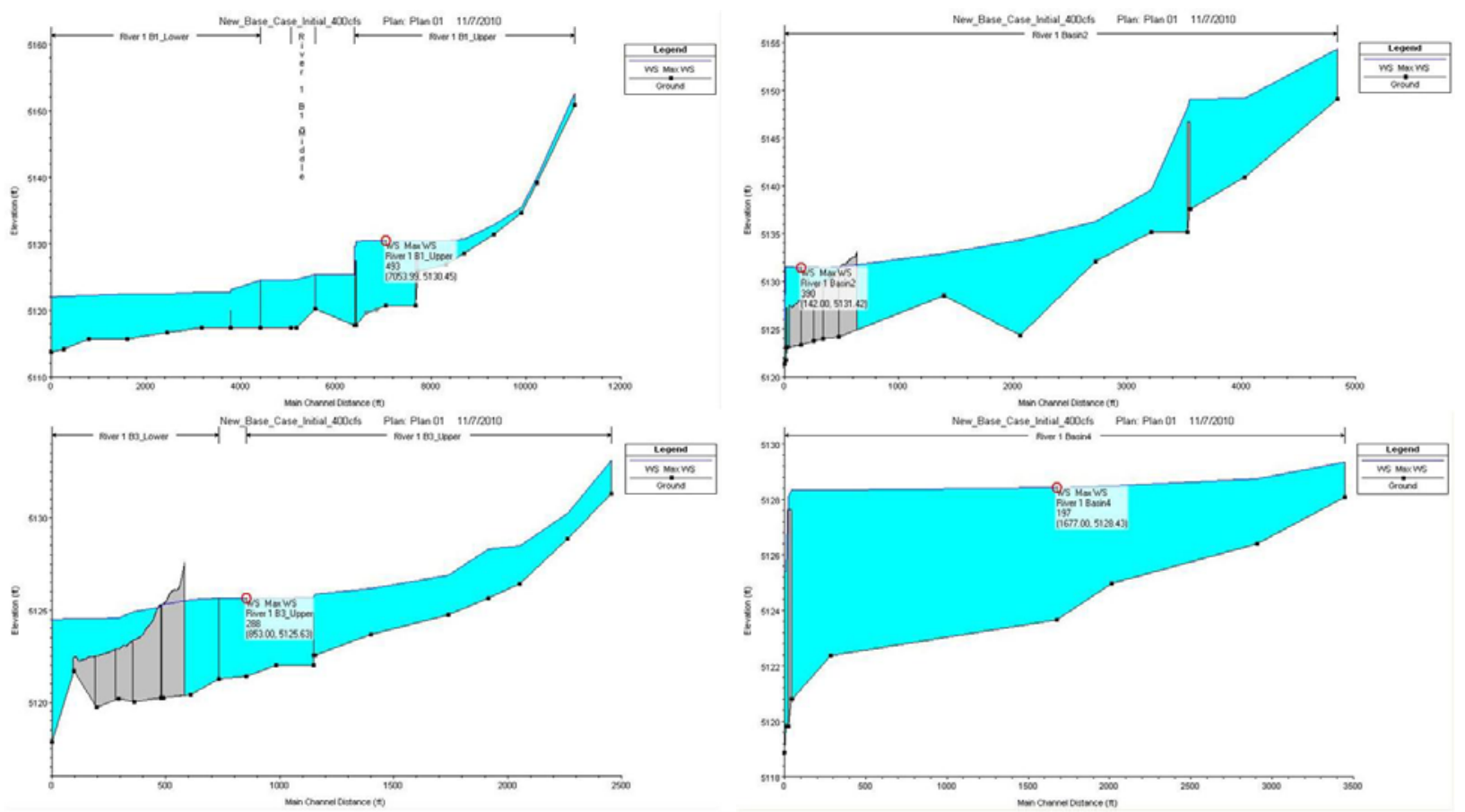

Figure 2.18. Individual Profiles of the Maximum Water Level for Each Subbasin from the PMP Event (Note: gray shaded areas designate weirs.) 


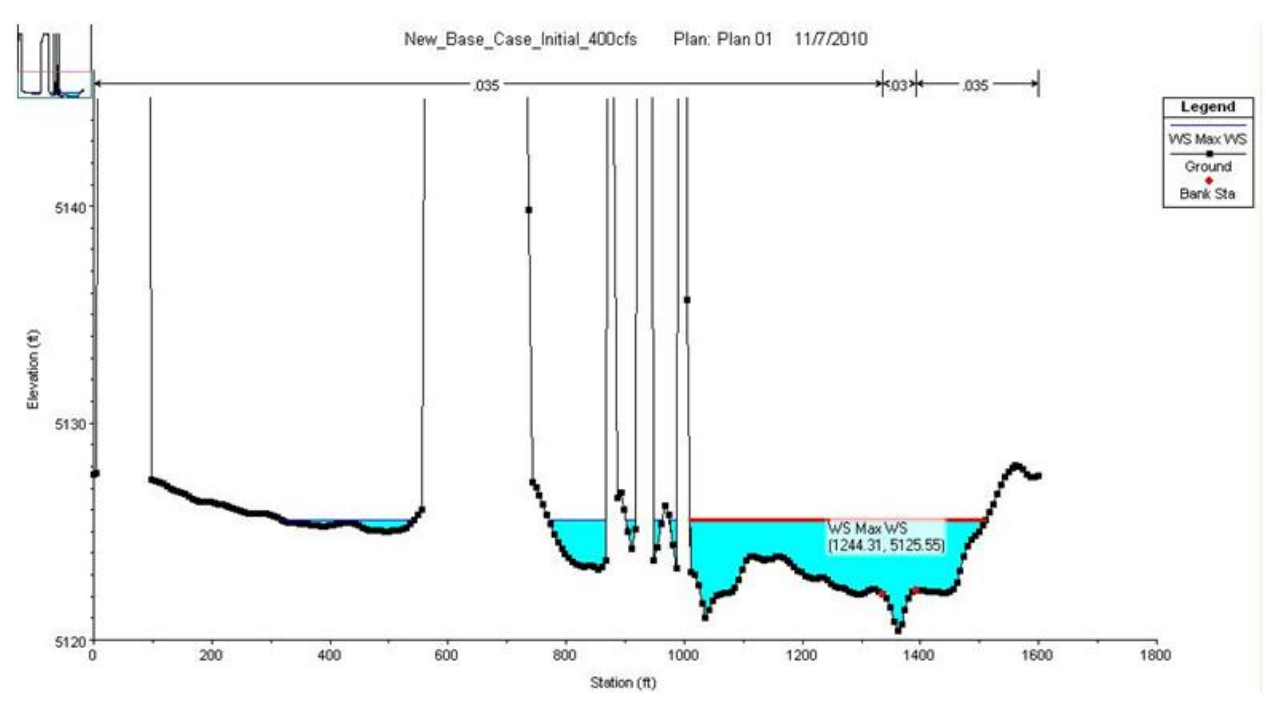

Figure 2.19. Maximum Water Level at Cross-Section 286 from the PMP Event

For the Open case, Figure 2.20 shows the combined profiles for all the subbasins, while Figure 2.21 shows the profiles for individual subbasins. Figure 2.22 shows the maximum water-surface elevation for the Open case in the middle of the MFC site at cross-section station 286 (for reference, Figures 2.13 and 2.14 show the cross-section locations). At station 286, the maximum elevation for the cross section was $5125.30 \mathrm{ft}$. This Open case elevation is $0.25 \mathrm{ft}$ lower than for the Blocked case.

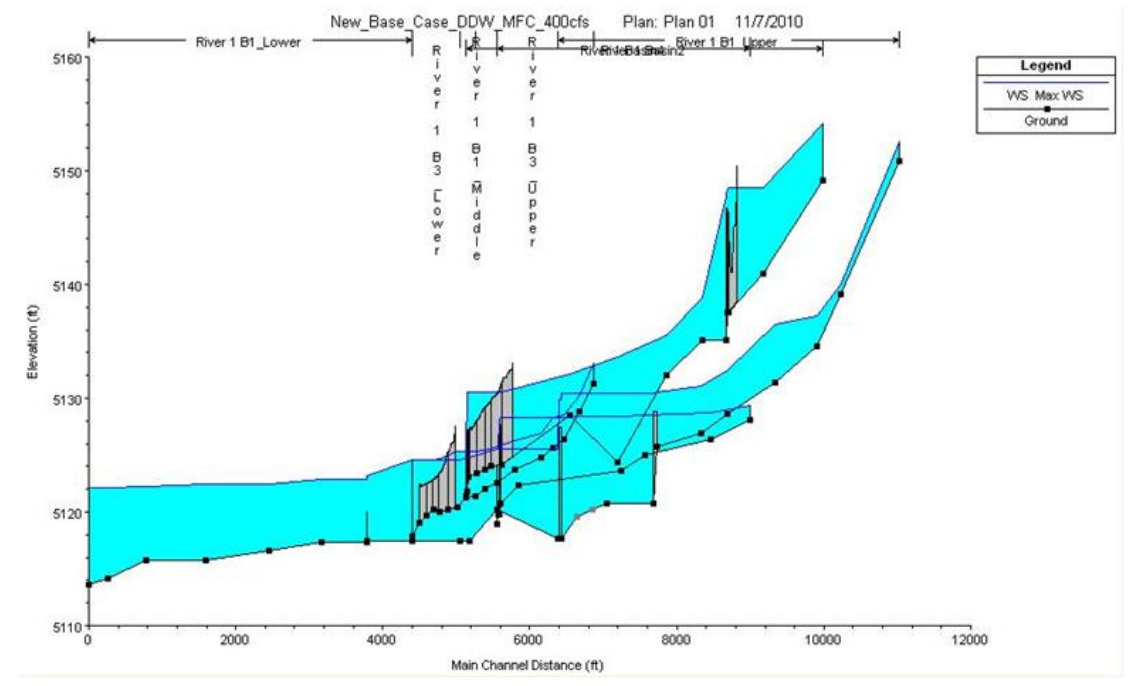

Figure 2.20. Combined Profiles of the Maximum Water Level for all Subbasins from the PMP Event (Note: gray shaded areas designate weirs.) 

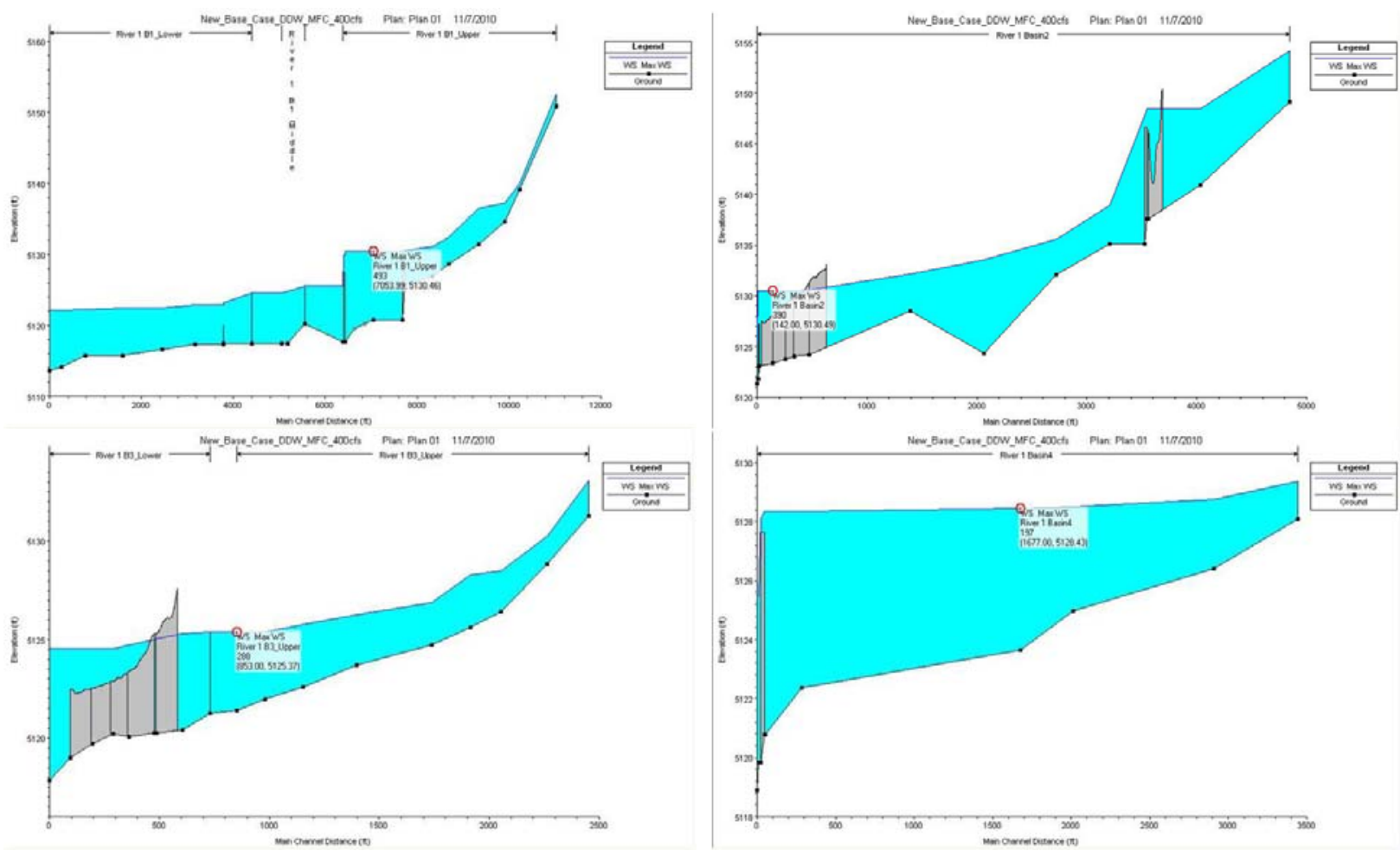

Figure 2.21. Individual Profiles of the Maximum Water Level for Each Subbasin from the PMP Event (Note: gray shaded areas designate weirs.)

Figure 2.23 illustrates the flow paths of the PMF runoff for both the Blocked and Open cases by indicating the location, direction, and magnitude of the maximum flows at the boundaries of the subbasins where flow is exchanged. For the PMF, overtopping of the diversion dam occurs for both the Blocked and Open cases, with both cases discharging large flows into the middle reach of Basin 2. Inclusion of the diversion channel (the Open case) reduces the maximum flow that overtops the diversion dam from 7031 cfs to 4320 cfs, a reduction of 39\%. For the Open case, the 2706 cfs maximum flow diverted into Basin 1 reduces flow from Basin 2 into Basin 3 (the MFC site) by only about 900 cfs; the flow drops from 3812 cfs for the Blocked case to 2924 cfs for the Open case. 


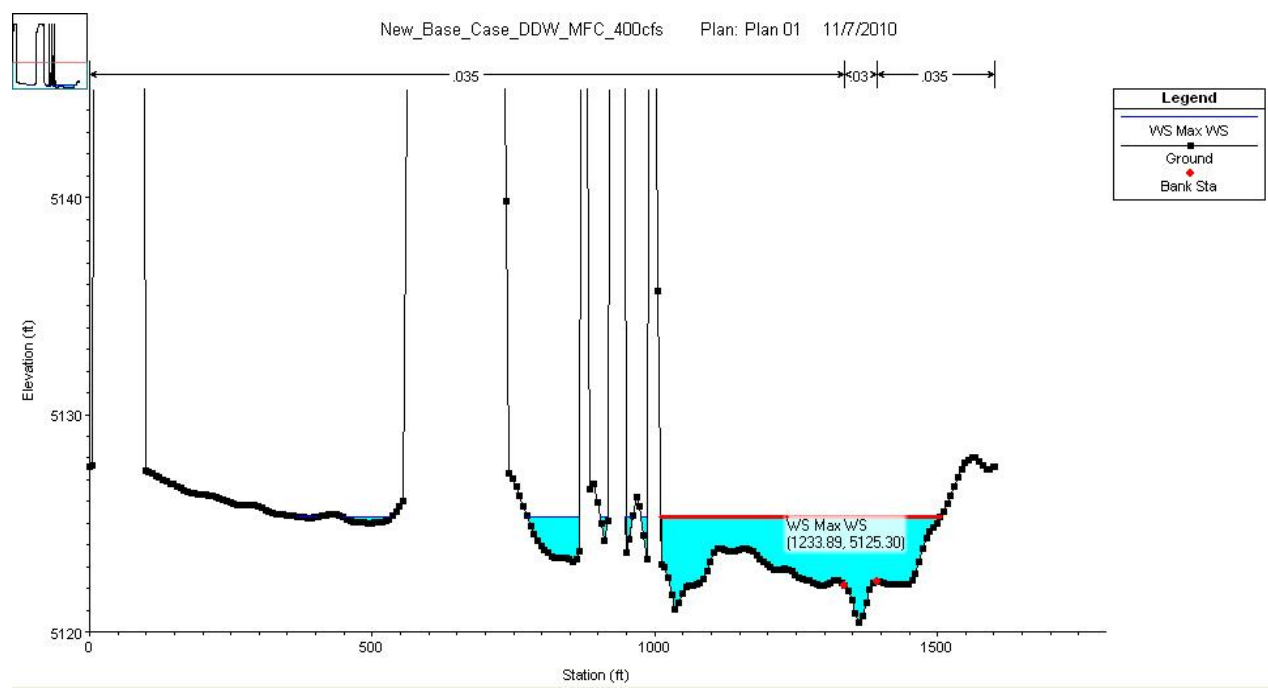

Figure 2.22. Maximum Water Level at Cross-Section 286 from the PMP Event

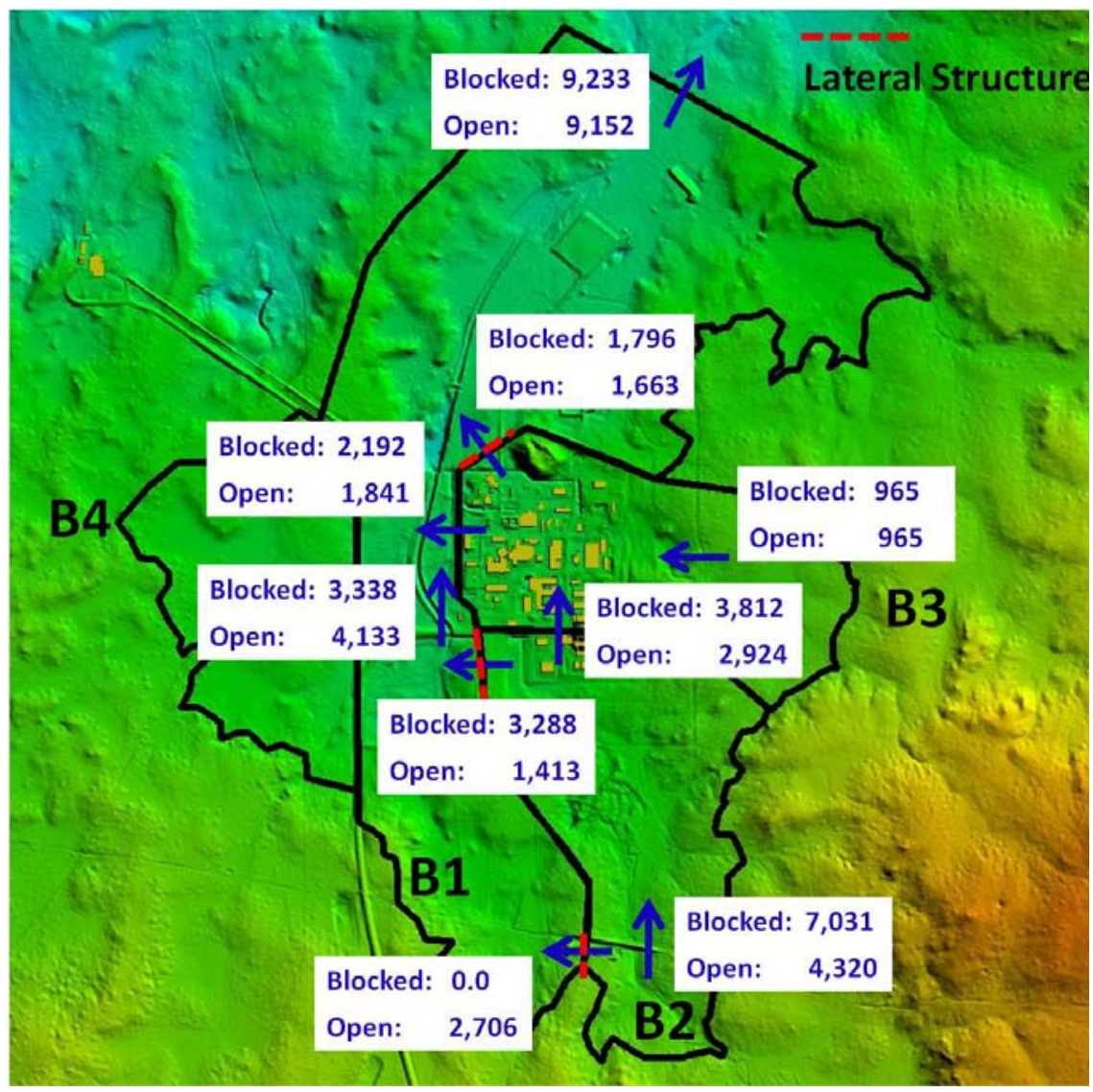

Figure 2.23. Flows Paths and Maximum Flows (cfs) for the PMF for Blocked and Open Cases

As previously noted, Figure 2.14 shows the layout of the HEC-RAS cross sections with respect to critical buildings in the MFC. Table 2.2 shows the maximum water-surface elevations extracted at cross sections associated with the critical buildings. The PMF results with the Blocked case shows nine 
buildings at which the maximum water surface elevation exceeds the floor elevations. For subbasin B3 stations, the exceedances were up to $1.4 \mathrm{ft}$, while for the subbasin B2 stations, an exceedance of over $3 \mathrm{ft}$ occurred. The Open case shows eight buildings at which the elevation is exceeded. The exceedances are smaller for the Open case compared to the Blocked case, with the maximum exceedance being less than $3 \mathrm{ft}$. While the diversion of flows from subbasin B2 into subbasin B1 in the Open case reduces overtopping of the diversion dam from $7031 \mathrm{cfs}$ to $4320 \mathrm{cfs}$, the flows entering the MFC site directly are nonetheless large enough to affect the maximum water-surface elevations of the MFC site in subbasins B2 and B3.

Table 2.2. Comparison of the Floor Elevations of Buildings at the MFC Site and the Maximum WaterSurface Elevations Obtained from the HEC-RAS Model. The HEC-RAS identification (ID) numbers are the cross-section stations that are at or just upstream of the building. The building locations and the cross sections are shown in Figure 2.14. Maximum water-surface elevations highlighted in gray indicate the value exceeds the flood elevation. The Open cases have the subbasin B3 culverts and subbasin B2 diversion channel open, while the Closed cases have all culverts and the diversion channel blocked.

\begin{tabular}{|c|c|c|c|c|c|c|c|}
\hline \multirow{2}{*}{$\begin{array}{c}\text { Building Number and } \\
\text { Name }\end{array}$} & \multirow[b]{2}{*}{ Location } & \multirow{2}{*}{$\begin{array}{l}\text { Finished } \\
\text { Floor } \\
\text { Elevation }\end{array}$} & \multirow{2}{*}{$\begin{array}{l}\text { Station } \\
\text { ID and } \\
\text { Subbasin }\end{array}$} & \multicolumn{2}{|c|}{ PMF } & \multicolumn{2}{|c|}{ 10,000-yr Return Period } \\
\hline & & & & Blocked & Open & Blocked & Open \\
\hline $\begin{array}{l}\text { MFC-704 Fuel } \\
\text { Manufacture Facility } \\
\text { (FMF) }\end{array}$ & N. Door & 5127.59 & $\begin{array}{c}291 \\
\text { B3 }\end{array}$ & 5126.14 & 5126.25 & 5125.53 & 5125.59 \\
\hline $\begin{array}{l}\text { MFC-752 Laboratory } \\
\text { and Office Building }\end{array}$ & W. Dock & 5128.23 & $\begin{array}{c}288 \\
\text { B3 }\end{array}$ & 5125.63 & 5125.37 & 5124.91 & 5124.28 \\
\hline $\begin{array}{l}\text { MFC-752 Laboratory } \\
\text { and Office Building }\end{array}$ & E. Dock & 5128.24 & $\begin{array}{c}289 \\
\text { B3 }\end{array}$ & 5125.63 & 5125.40 & 5124.91 & 5124.37 \\
\hline $\begin{array}{l}\text { MFC-752 Laboratory } \\
\text { and Office Building }\end{array}$ & $\begin{array}{l}\text { N. Door East } \\
\text { Side }\end{array}$ & 5128.23 & $\begin{array}{c}289 \\
\text { B3 }\end{array}$ & 5125.63 & 5125.40 & 5124.91 & 5124.37 \\
\hline $\begin{array}{l}\text { MFC-752 Laboratory } \\
\text { and Office Building }\end{array}$ & $\begin{array}{l}\text { S. Door East } \\
\text { Side }\end{array}$ & 5126.73 & $\begin{array}{c}289 \\
\text { B3 }\end{array}$ & 5125.63 & 5125.40 & 5124.91 & 5124.38 \\
\hline $\begin{array}{l}\text { MFC-765 Fuel } \\
\text { Conditioning Facility } \\
\text { (FCF) }\end{array}$ & SE Door & 5128.23 & $\begin{array}{l}287 \\
\text { B3 }\end{array}$ & 5125.63 & 5125.37 & 5124.91 & 5124.28 \\
\hline $\begin{array}{l}\text { MFC-765 Fuel } \\
\text { Conditioning Facility } \\
\text { (FCF) }\end{array}$ & W. Bay Door & 5126.21 & $\begin{array}{c}286 \\
\text { B3 }\end{array}$ & 5125.55 & 5125.30 & 5124.86 & 5124.26 \\
\hline $\begin{array}{l}\text { MFC-767 EBR-II } \\
\text { Reactor Plant Building }\end{array}$ & $\begin{array}{l}\text { Adj. to } \\
\text { Building } \\
\text { North }\end{array}$ & 5126.94 & $\begin{array}{c}285 \\
\text { B3 }\end{array}$ & 5125.27 & 5125.01 & 5124.61 & 5124.02 \\
\hline $\begin{array}{l}\text { MFC-767 EBR-II } \\
\text { Reactor Plant Building }\end{array}$ & $\begin{array}{l}\text { N. Truck } \\
\text { Dock }\end{array}$ & 5128.01 & $\begin{array}{c}285 \\
\text { B3 }\end{array}$ & 5125.27 & 5125.01 & 5124.61 & 5124.02 \\
\hline $\begin{array}{l}\text { MFC-767 EBR-II } \\
\text { Reactor Plant Building }\end{array}$ & $\begin{array}{l}\text { Adj. to } \\
\text { Building } \\
\text { West }\end{array}$ & 5125.17 & $\begin{array}{c}285 \\
\text { B3 }\end{array}$ & 5125.27 & 5125.01 & 5124.61 & 5124.02 \\
\hline $\begin{array}{l}\text { MFC-774 ZPPR } \\
\text { Support Wing }\end{array}$ & N. Door & 5128.22 & $\begin{array}{c}390 \\
\mathrm{~B} 2\end{array}$ & 5131.42 & 5130.49 & 5128.91 & 5127.91 \\
\hline $\begin{array}{l}\text { MFC-775 ZPPR Vault- } \\
\text { Workroom Eq Rm }\end{array}$ & $\begin{array}{l}\text { Inside S. } \\
\text { Security } \\
\text { Door }\end{array}$ & 5128.74 & $\begin{array}{l}390 \\
\mathrm{~B} 2\end{array}$ & 5131.42 & 5130.49 & 5128.91 & 5127.91 \\
\hline
\end{tabular}


Table 2.2. (contd)

\begin{tabular}{|c|c|c|c|c|c|c|c|}
\hline \multirow{2}{*}{$\begin{array}{l}\text { Building Number and } \\
\text { Name }\end{array}$} & \multirow[b]{2}{*}{ Location } & \multirow{2}{*}{$\begin{array}{l}\text { Finished } \\
\text { Floor } \\
\text { Elevation }\end{array}$} & \multirow{2}{*}{$\begin{array}{l}\text { Station } \\
\text { ID and } \\
\text { Subbasin }\end{array}$} & \multicolumn{2}{|c|}{ PMF } & \multicolumn{2}{|c|}{ 10,000-yr Return Period } \\
\hline & & & & Blocked & Open & Blocked & Open \\
\hline $\begin{array}{l}\text { MFC-776 ZPPR } \\
\text { Reactor Cell }\end{array}$ & $\begin{array}{c}\text { Based on } \\
775 \text { El. \& } \\
\text { Design } \\
\text { Drawings }\end{array}$ & 5128.74 & $\begin{array}{c}389 \\
\text { B2 }\end{array}$ & 5131.47 & 5130.52 & 5128.90 & 5127.87 \\
\hline $\begin{array}{l}\text { MFC-785 Hot Fuel } \\
\text { Examination Facility } \\
\text { (HFEF) }\end{array}$ & S. Main door & 5124.18 & $\begin{array}{c}287 \\
\text { B3 }\end{array}$ & 5125.63 & 5125.40 & 5124.91 & 5124.28 \\
\hline $\begin{array}{l}\text { MFC-786 HFEF } \\
\text { Substation }\end{array}$ & N. Door & 5124.23 & $\begin{array}{l}286 \\
\text { B3 }\end{array}$ & 5125.55 & 5125.30 & 5124.86 & 5124.26 \\
\hline $\begin{array}{l}\text { MFC-787 Fuels and } \\
\text { Applied Science } \\
\text { Building (FASB) }\end{array}$ & N. Door & 5125.23 & $\begin{array}{l}287 \\
\text { B3 }\end{array}$ & 5125.63 & 5125.37 & 5124.91 & 5124.28 \\
\hline $\begin{array}{l}\text { MFC-792A Space \& } \\
\text { Security Power Sys Fac } \\
\text { Annex }\end{array}$ & N. Side & 5130.26 & $\begin{array}{c}392 \\
\text { B2 }\end{array}$ & 5131.43 & 5130.52 & 5128.98 & 5127.93 \\
\hline $\begin{array}{l}\text { MFC-798 Radioactive } \\
\text { Liquid Waste } \\
\text { Treatment Facility }\end{array}$ & N. Bay Door & 5124.71 & $\begin{array}{c}288 \\
\text { B3 }\end{array}$ & 5125.63 & 5125.37 & 5124.91 & 5124.28 \\
\hline $\begin{array}{l}\text { MFC-1702 } \\
\text { Radiochemistry } \\
\text { Laboratory (RCL) }\end{array}$ & NW Door & 5128.20 & $\begin{array}{c}288 \\
\text { B3 }\end{array}$ & 5125.63 & 5125.37 & 5124.91 & 5124.28 \\
\hline
\end{tabular}

\subsubsection{10,000-Year Return Period Results at the MFC Site}

As previously note, the inflows for the 10,000-year return period event are shown in Figure 2.24. Subbasin B1 and B2 watershed drainage inflow had comparable peak flows; however, the timing of the peak from B2 was about 2 hours later than that from B1. Subbasin B1 had the largest area of the four HEC-RAS basins included in the analysis; consequently the local inflows are the greatest of the four basins, although these peaked early in the analysis.

The plots of maximum water-level profiles from the HEC-RAS model analyses for the Blocked and Open cases show the hydraulic relationships between the subbasins. For the Blocked case, Figure 2.25 shows the combined profiles for all of the subbasins, while Figure 2.26 shows the profiles for individual subbasins. Figure 2.27 shows the maximum water-surface elevation for the Blocked case in the middle of the MFC site at cross-section station 286 (for reference, Figures 2.13 and 2.14 show the cross-section locations). At cross-section station 286, the maximum elevation was $5124.86 \mathrm{ft}$.

For the Open case, Figure 2.28 shows the combined profiles for all of the subbasins, while Figure 2.29 shows the profiles for individual subbasins. Figure 2.30 shows the maximum water-surface elevation for the Open case in the middle of the MFC site at cross-section station 286 (for reference, Figures 2.13 and 2.14 show the cross-section locations). At station 286, the maximum elevation for the cross section was $5124.26 \mathrm{ft}$. This elevation is $0.40 \mathrm{ft}$ lower than for the Blocked case. 

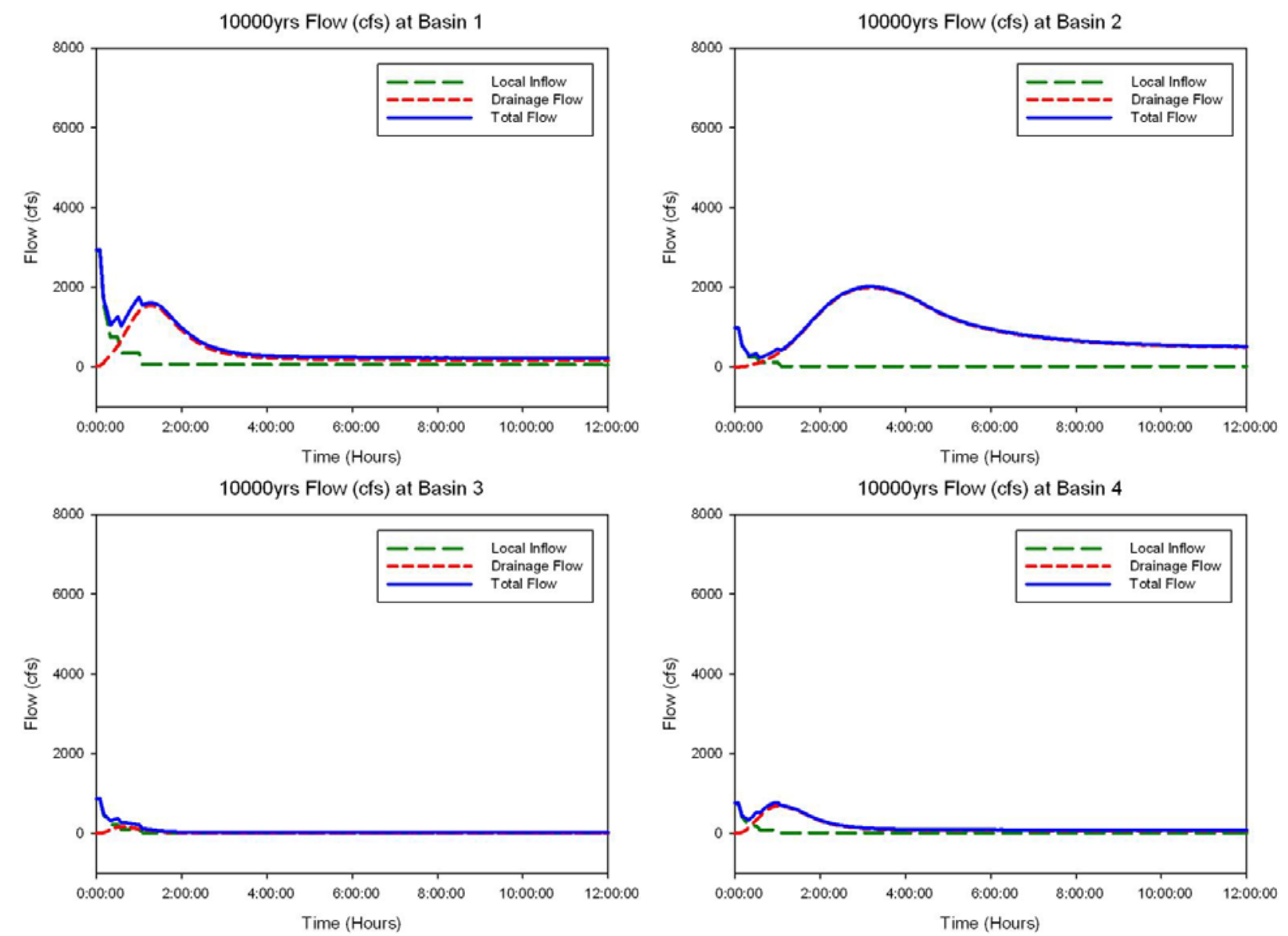

Figure 2.24. Flows Input to the HEC-RAS Model for the 10,000-Year Return Period Event. The plots include the watershed drainage flow from the HEC-HMS analysis plus the local inflow estimated using the rational method with the 10,000-year precipitation intensities. The drainage flow is input at the upstream end of each subbasin, while the local inflows are linearly distributed along the subbasin. The vertical scale for flow is kept the same as that used for Figure 2.16 for comparison with the PMF.

Figure 2.31 illustrates the flow paths of the 10,000-year return period event runoff by indicating the location, direction, and magnitude of the maximum flows at the boundaries of the subbasins where flow is exchanged. For the 10,000-year return period event, overtopping of the diversion dam occurs for both the Blocked and Open cases, although they are much reduced in comparison with the PMF. Inclusion of the diversion channel significantly reduces the maximum flow that overtops the diversion dam from $1994 \mathrm{cfs}$ to 334 cfs. For the Open case, 1657 cfs was the maximum flow into the diversion channel. The diversion for the Open case produced a significant rerouting of watershed drainage flow around the MFC site at the upstream ends of Basins 1 and 2. However, under the Blocked case most of the flow was routed through the MFC site. 


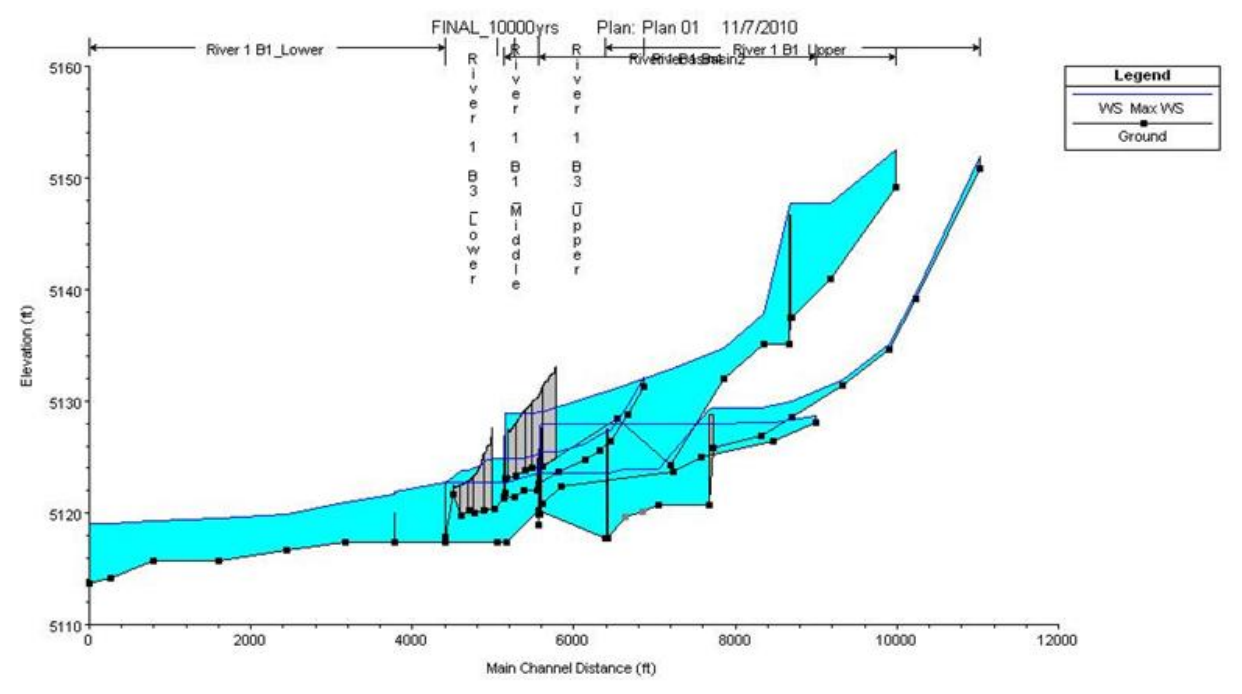

Figure 2.25. Combined Profiles of the Maximum Water Level for all Subbasins from the 10,000-Year Return Period Event (Note: gray shaded areas designate weirs.)
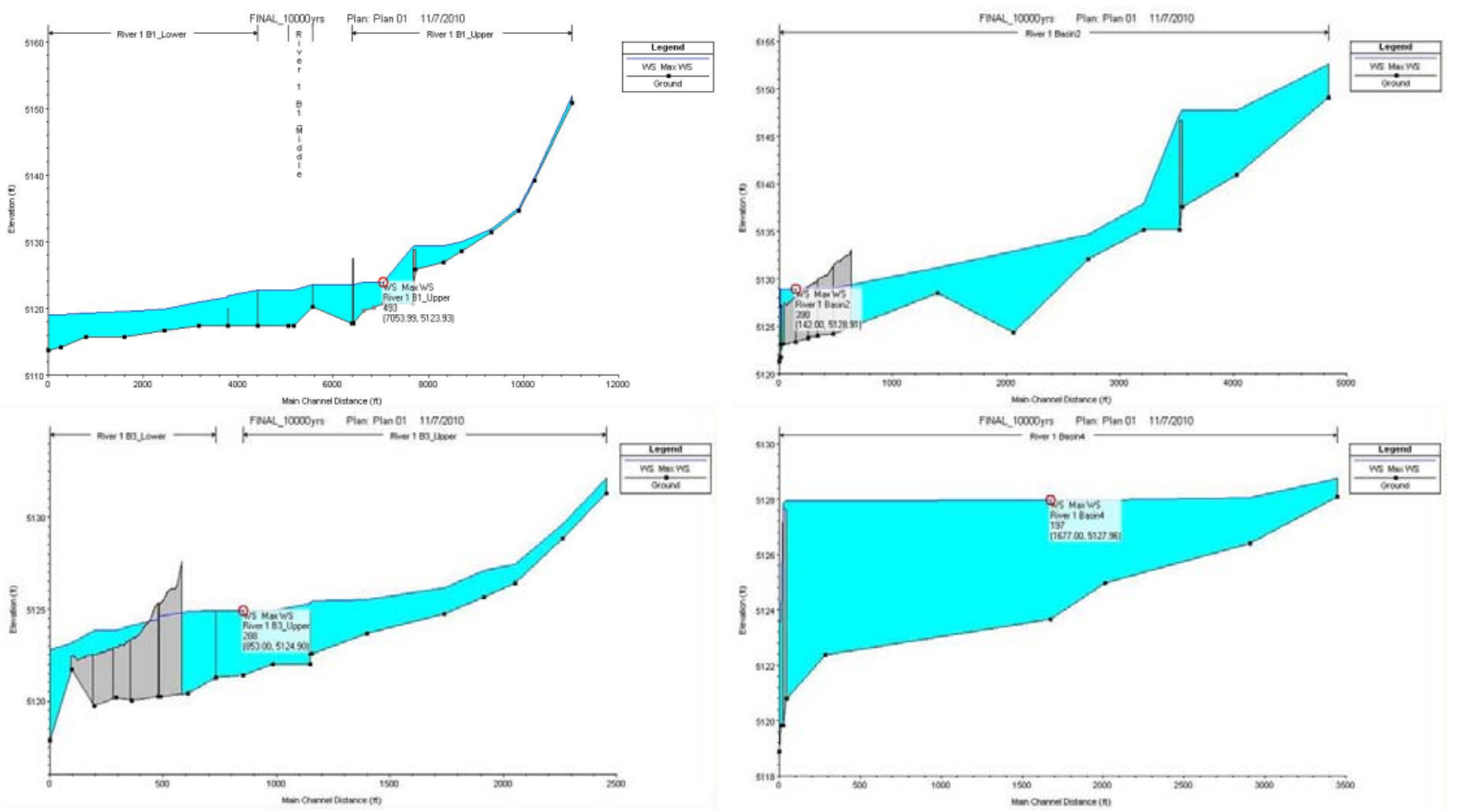

Figure 2.26. Individual Profiles of the Maximum Water Level for Each Subbasin from the 10,000-Year Return Period Event for the Blocked Case (Note: gray shaded areas designate weirs.) 


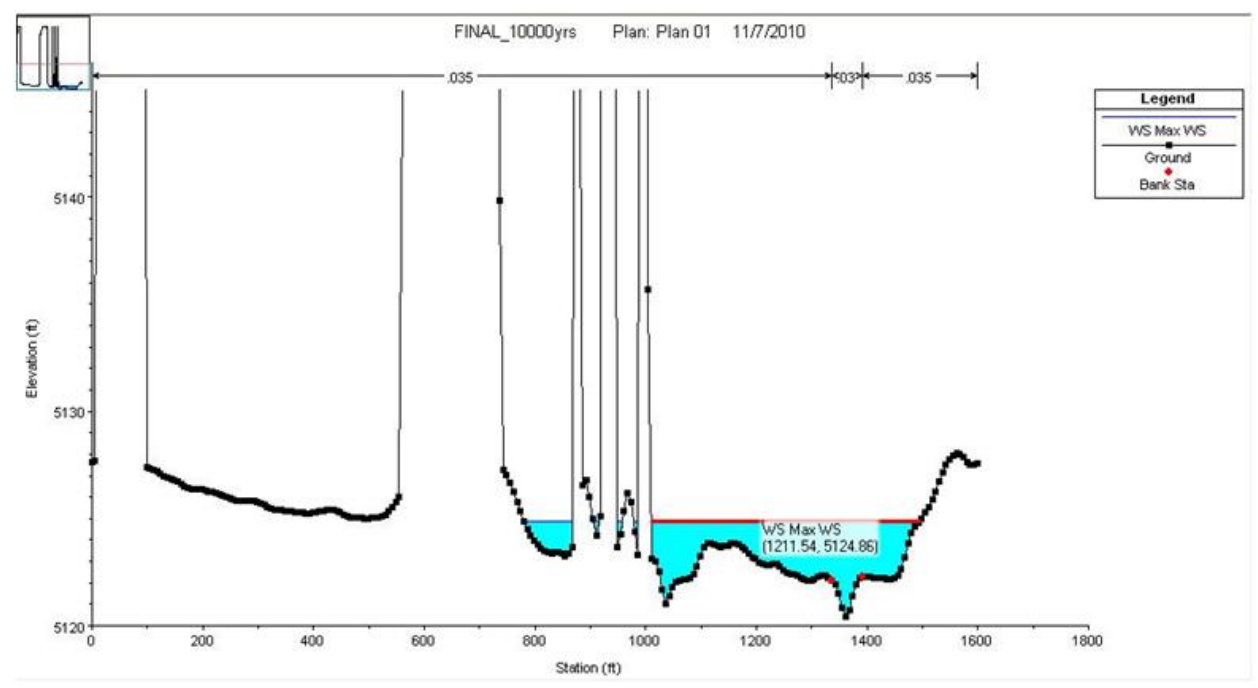

Figure 2.27. Maximum Water Level at Cross-Section 286 from the 10,000-Year Return Period Event

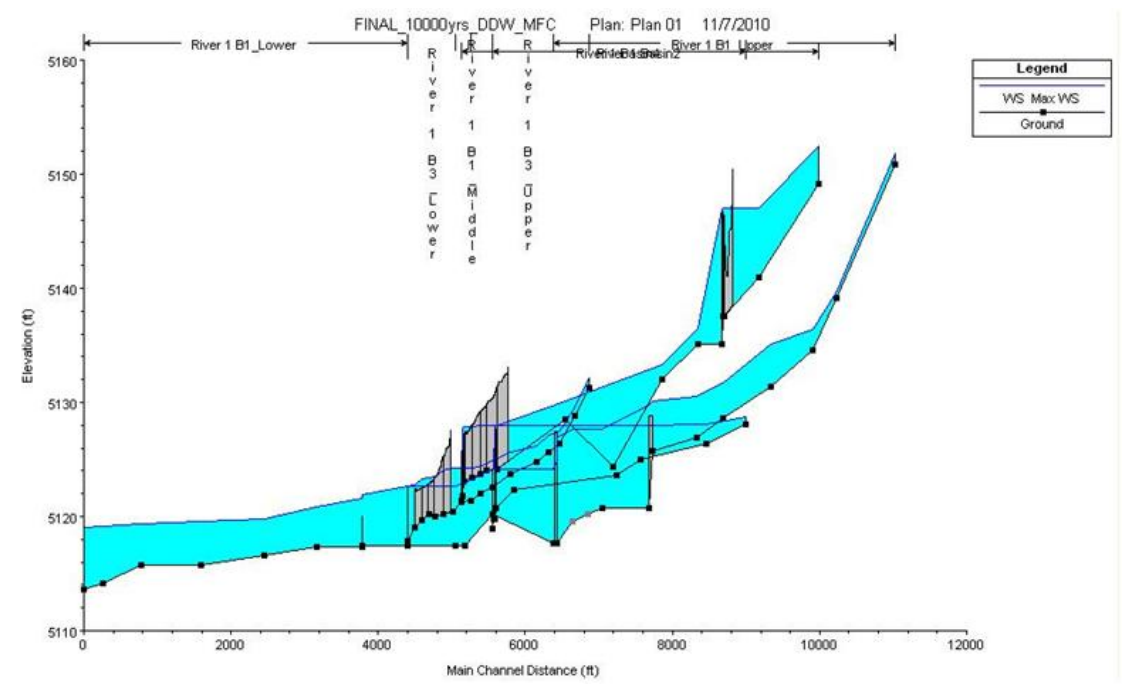

Figure 2.28. Combined Profiles of the Maximum Water Level for all Subbasins from the 10,000-Year Return Period Event (Note: gray shaded areas designate weirs.) 

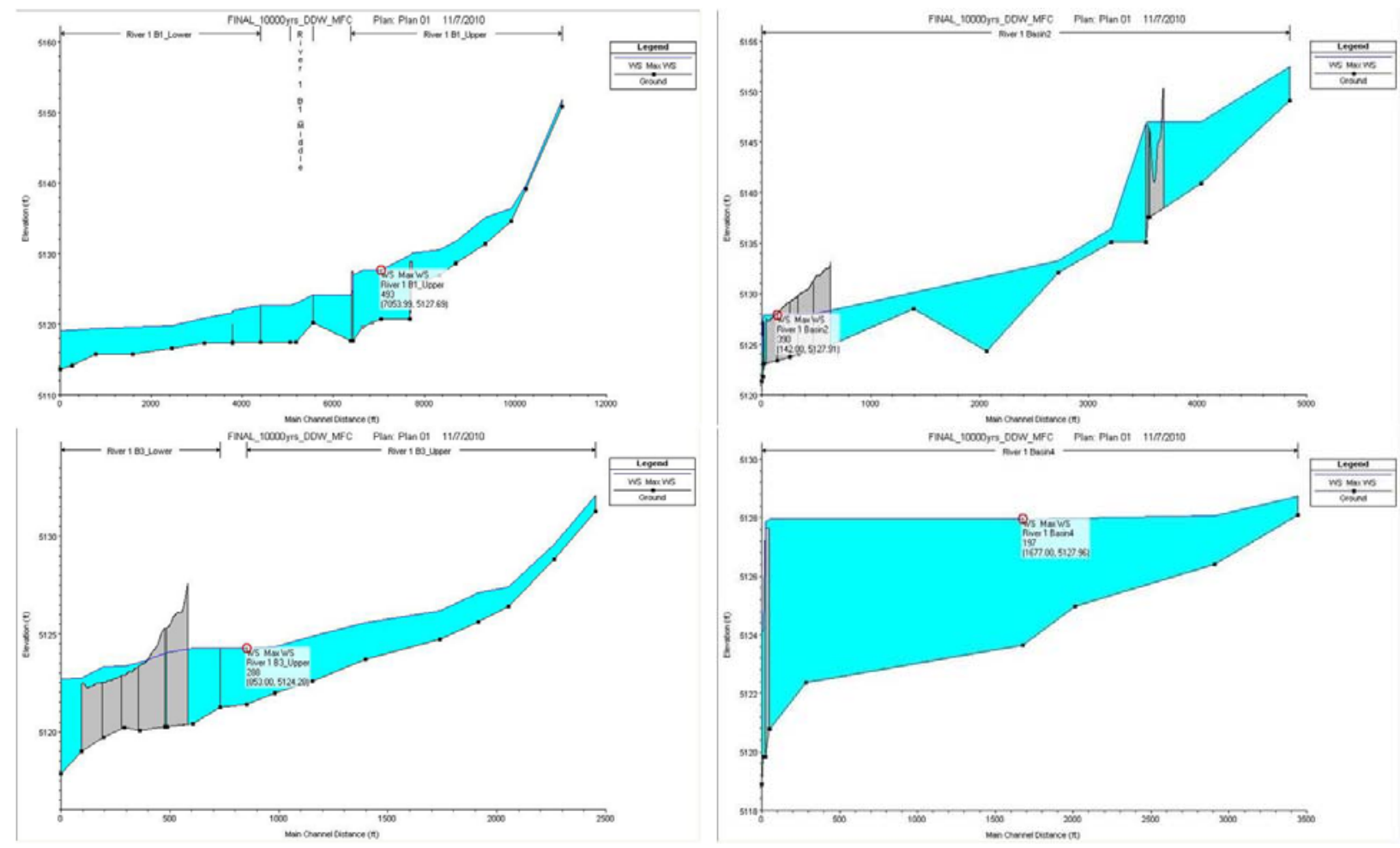

Figure 2.29. Individual Profiles of the Maximum Water Level for Each Subbasin from the 10,000-Year Return Period Event (Note: gray shaded areas designate weirs.)

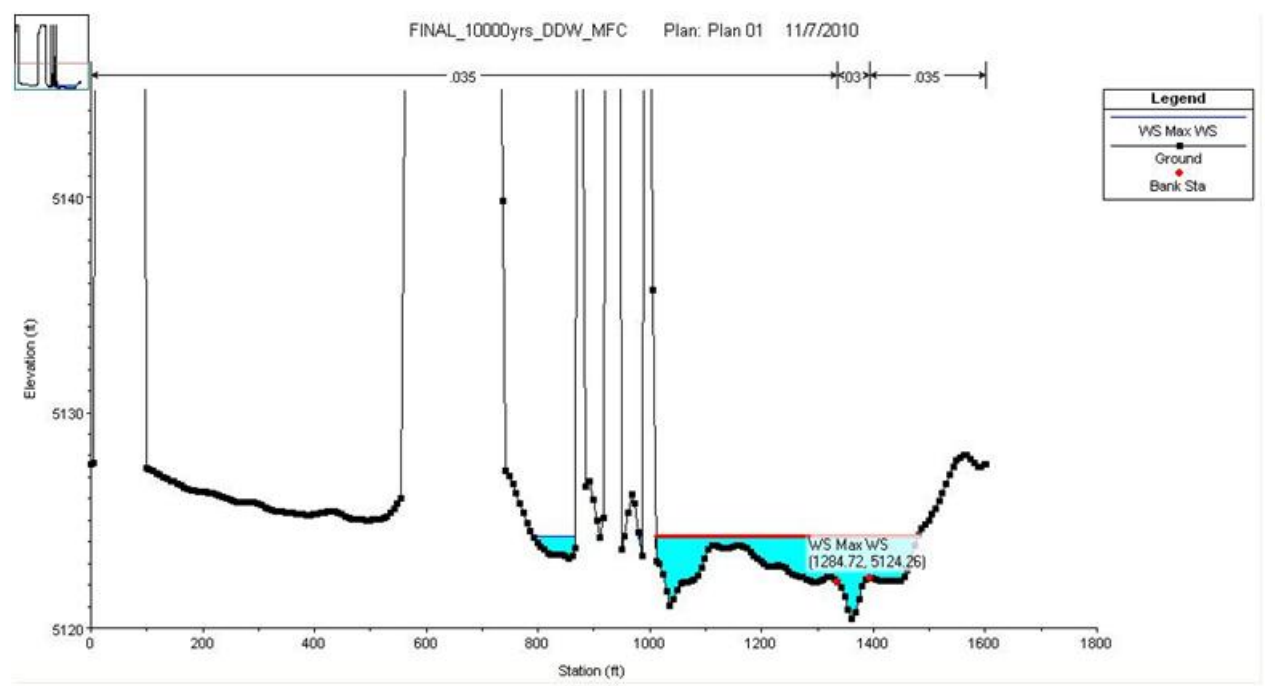

Figure 2.30. Maximum Water Level at Cross-Section 286 from the 10,000-Year Return Period Event 


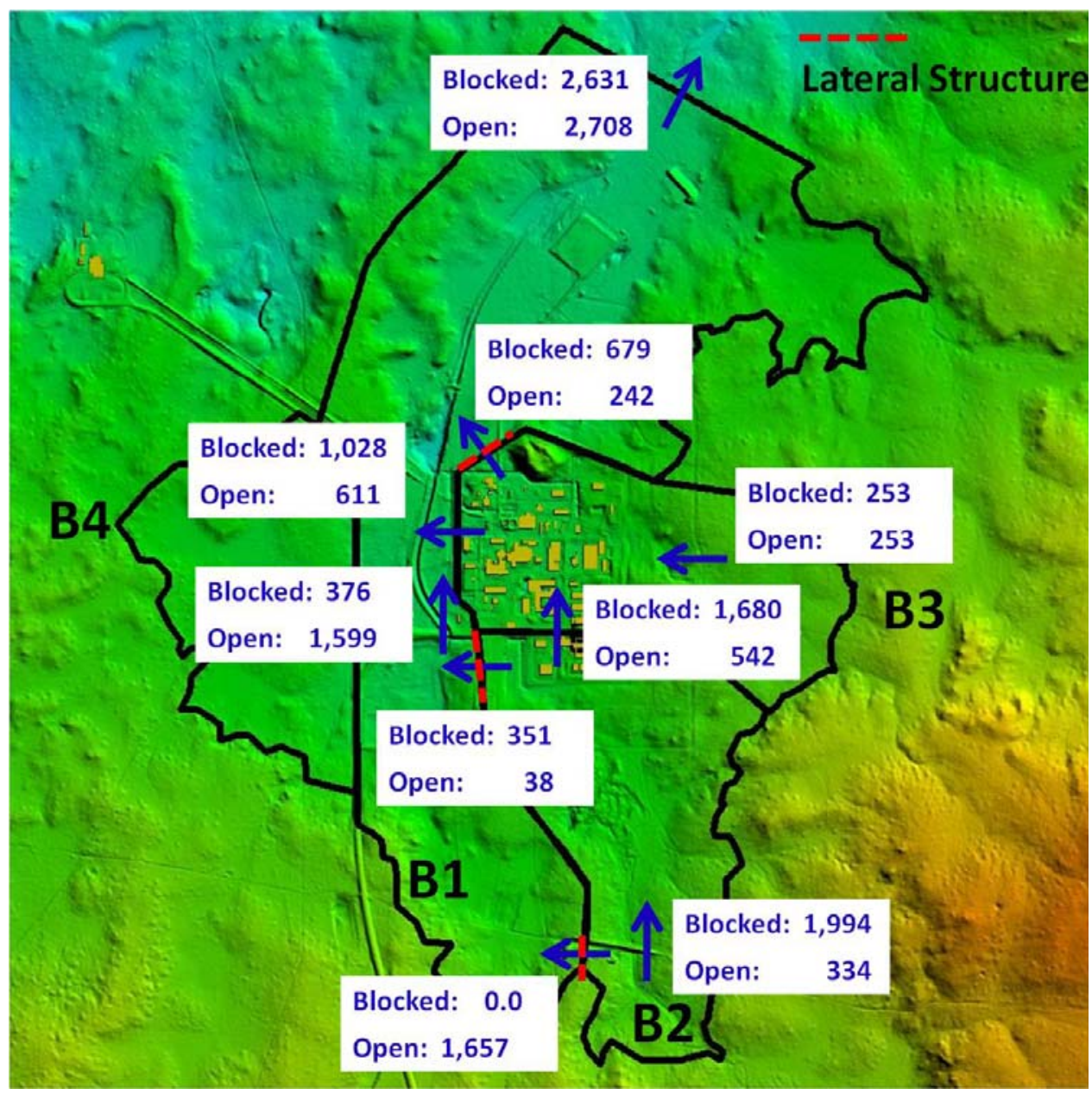

Figure 2.31. Flows Paths and Maximum Flows (cfs) for the 10,000-Year Return Period Event for Blocked and Open Cases

As previously noted, Figure 2.14 shows the layout of the HEC-RAS cross sections with respect to critical buildings in the MFC site. Table 2.2 shows the maximum water-surface elevations extracted at cross sections associated with the critical buildings. The 10,000-year results with the Blocked case shows six buildings at which the maximum water-surface elevation exceeds the floor elevations, although they are fewer than for the PMF cases. The maximum exceedance was about $0.7 \mathrm{ft}$, which was much smaller than in the PMF cases. The Open case shows two buildings at which the elevation is exceeded, with the maximum exceedance being about $0.1 \mathrm{ft}$. The diversion of flows from Basin 2 into Basin 1 in the Open case greatly reduces overtopping of the diversion dam from $1994 \mathrm{cfs}$ to $334 \mathrm{cfs}$. The MFC site was still subject to flooding from locally generated runoff within the MFC subbasins themselves, particularly Basins 2 and 3. For example, the maximum flow at station 286 for the Open case was $611 \mathrm{cfs}$.

\subsubsection{Sensitivity Analyses}

To provide additional perspective of the relative significance of the results described previously, a limited sensitivity analysis was conducted on the hydraulic analysis evaluating the maximum 
water-surface elevations as a function of the assumed roughness coefficients used in the hydraulic analysis. The response of the water-surface elevations at the MFC was examined by adjusting two input parameters to the HEC-RAS model, as follows:

- downstream boundary condition slope (0.0002, 0.002, and 0.02). This was conducted to ascertain if there was a backwater effect produced by the assumed boundary friction value.

- Manning's roughness of the overbank portions of the cross section within the MFC site $(0.035$, 0.013). The 0.013 value is based on smooth asphalt (Chow 1959).

Table 2.3 presents the maximum water-surface elevations at cross-section station 286 for the four cases and the two sensitivity tests.

Table 2.3. Results from Sensitivity Analyses Comparing the Maximum Water-Surface Elevations at Cross-Section Station 286 at the MFC Site

\begin{tabular}{|c|c|c|c|c|}
\hline \multirow[b]{2}{*}{ Sensitivity Test } & \multicolumn{2}{|c|}{ PMF } & \multicolumn{2}{|c|}{ 10,000-yr Return Period } \\
\hline & Blocked & Open & Blocked & Open \\
\hline \multicolumn{5}{|c|}{ Downstream Boundary Friction Slope } \\
\hline $\begin{array}{l}0.0002 \text { (base } \\
\text { condition) }\end{array}$ & 5125.55 & 5125.30 & 5124.86 & 5124.26 \\
\hline 0.002 & 5125.55 & 5125.30 & 5124.86 & 5124.26 \\
\hline 0.02 & 5125.55 & 5125.30 & 5124.86 & 5124.26 \\
\hline \multicolumn{5}{|c|}{ Manning's Roughness in the Overbanks of the MFC Site } \\
\hline $\begin{array}{l}0.035 \text { (base } \\
\text { condition) }\end{array}$ & 5125.55 & 5125.30 & 5124.86 & 5124.26 \\
\hline 0.013 & 5125.19 & 5125.04 & 5124.67 & 5124.14 \\
\hline
\end{tabular}

For the sensitivity test with the downstream boundary condition, the results at the MFC stations were insensitive to a change in boundary condition value (Table 2.3). This indicates that the channel properties in the lower end of Basin 1 govern the conveyance of floodwaters through the system. We also examined the influence of the assumption of the stormwater pond being filled by including it in the conveyance area. The results for this, too, were also found to be insensitive, but they are not included in Table 2.3.

For the sensitivity test of the Manning's roughness at the MFC site, the maximum water-surface elevation results at MFC station 286 were found to have decreased by less than $0.4 \mathrm{ft}$ for the PMF and less than about $0.2 \mathrm{ft}$ for the 10,000-year return period event (Table 2.3). Comparison at cross-section stations 286 and 287 of the maximum elevations from the Manning's roughness sensitivity test to the floor elevations in Table 2.2 shows that only the 10,000-year event for the Open case showed maximum elevations lower than the building floor elevations as follows:

- MFC-786 floor elevation $=5124.23 \mathrm{ft}$ compared to the maximum water-surface elevation of $5124.14 \mathrm{ft}$ at cross-section station 286.

- MFC-785 floor elevation $=5124.18 \mathrm{ft}$ compared to the maximum water-surface elevation of $5124.15 \mathrm{ft}$ at cross-section station 287. 


\subsubsection{TREAT Site}

The TREAT site is located approximately $4700 \mathrm{ft}$ northwest of the MFC site and lies in catchment area of 140 ac (Figure 2.32). A preliminary assessment of the TREAT site suggested that, given the relatively small contributing area and the height of the facility floor above the channel, the flood hazard was low. Results of the preliminary assessment were confirmed by a highly conservative, but somewhat simple analysis. The approach used for PMF analysis was to estimate flows for the drainage area and the local inflows, by transforming the maximum precipitation to runoff using the Rational Method with no precipitation loss. The estimated maximum runoff was input to HEC-RAS model at the upstream end of the catchment as a constant flow for the steady-state hydraulic modeling analysis. Coupled with the use of the maximum runoff, a series of model runs were also made over a range of flows that bracketed the estimated maximum runoff to provide information about how much flow would it take to reach the target elevation of $5121.85 \mathrm{ft}$.

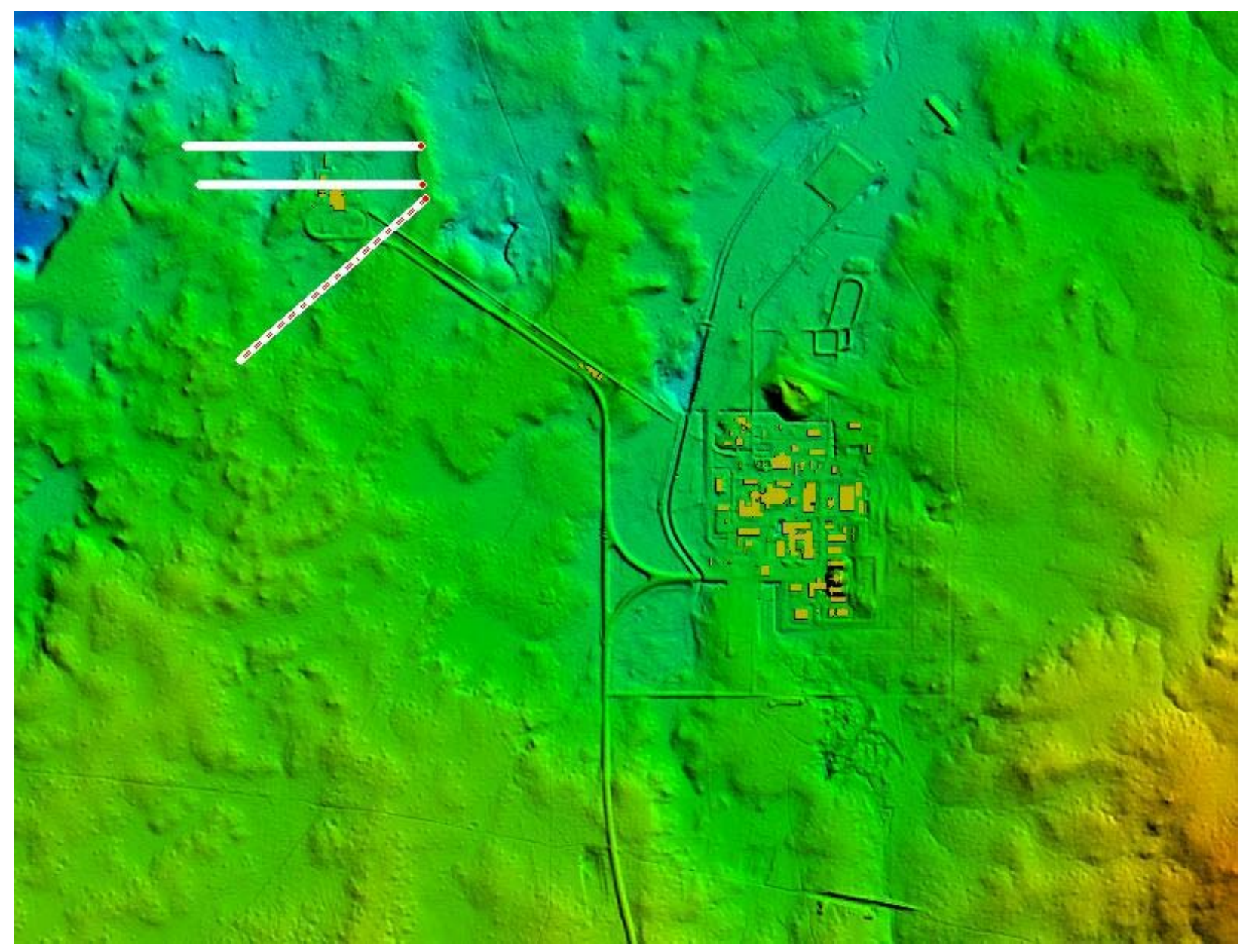

Figure 2.32. Cross Sections Used for the TREAT Site 
The maximum precipitation intensity was $15.22 \mathrm{in./hr}$, which gave an estimated runoff of $2161 \mathrm{cfs}$. The bracketing flows examined ranged from 200 to 5000 cfs.

As was previously done for the MFC site, cross-section data input into HEC-RAS were extracted from LiDAR data of the TREAT subbasin, which included cross sections that characterize the presence of drainage channels, roads, and buildings (Figure 2.32).

The following assumptions were used for the analysis:

- Flow was one-dimensional using the HEC-RAS hydraulic model.

- The subbasins were lightly vegetated sagebrush (Manning's $n=0.035$ ) with sandy channels (Manning's $n=0.030$ ).

The water-surface elevation profile for the maximum flow is shown in Figure 2.33. The cross section that includes the TREAT site is shown in Figure 2.34, with a water-surface elevation of $5114.82 \mathrm{ft}$ for the maximum flow.

The results from the series of bracketing flows are shown in Figure 2.35. Also shown is the result of the runoff from the peak precipitation intensity. The target elevation $5121.85 \mathrm{ft}$ is not reached even with a flow of $5000 \mathrm{cfs}$, which is more than double the flow from runoff with the maximum PMP intensity.

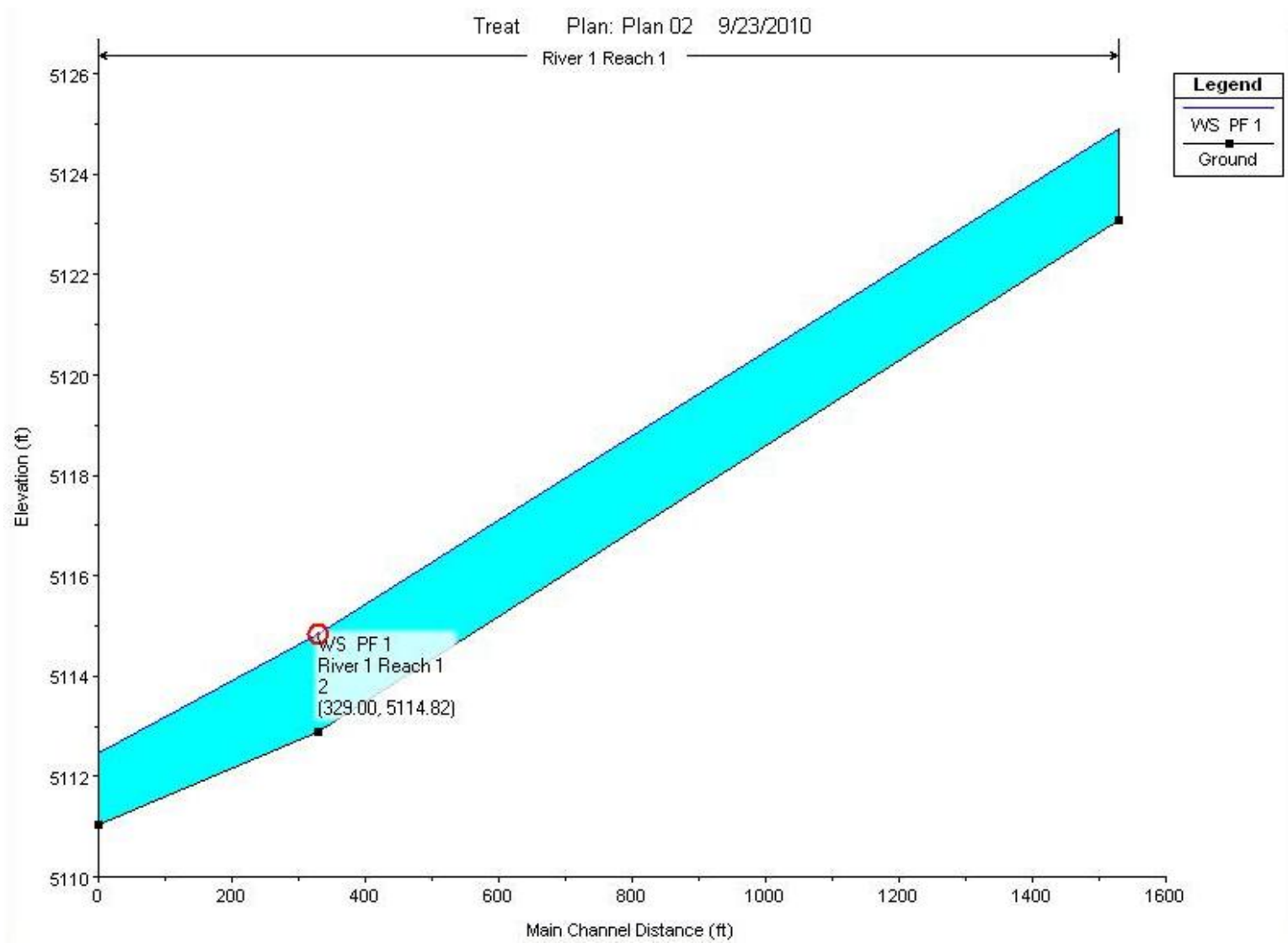

Figure 2.33. Profile and Location Where the Maximum Water Level Was Extracted for TREAT 


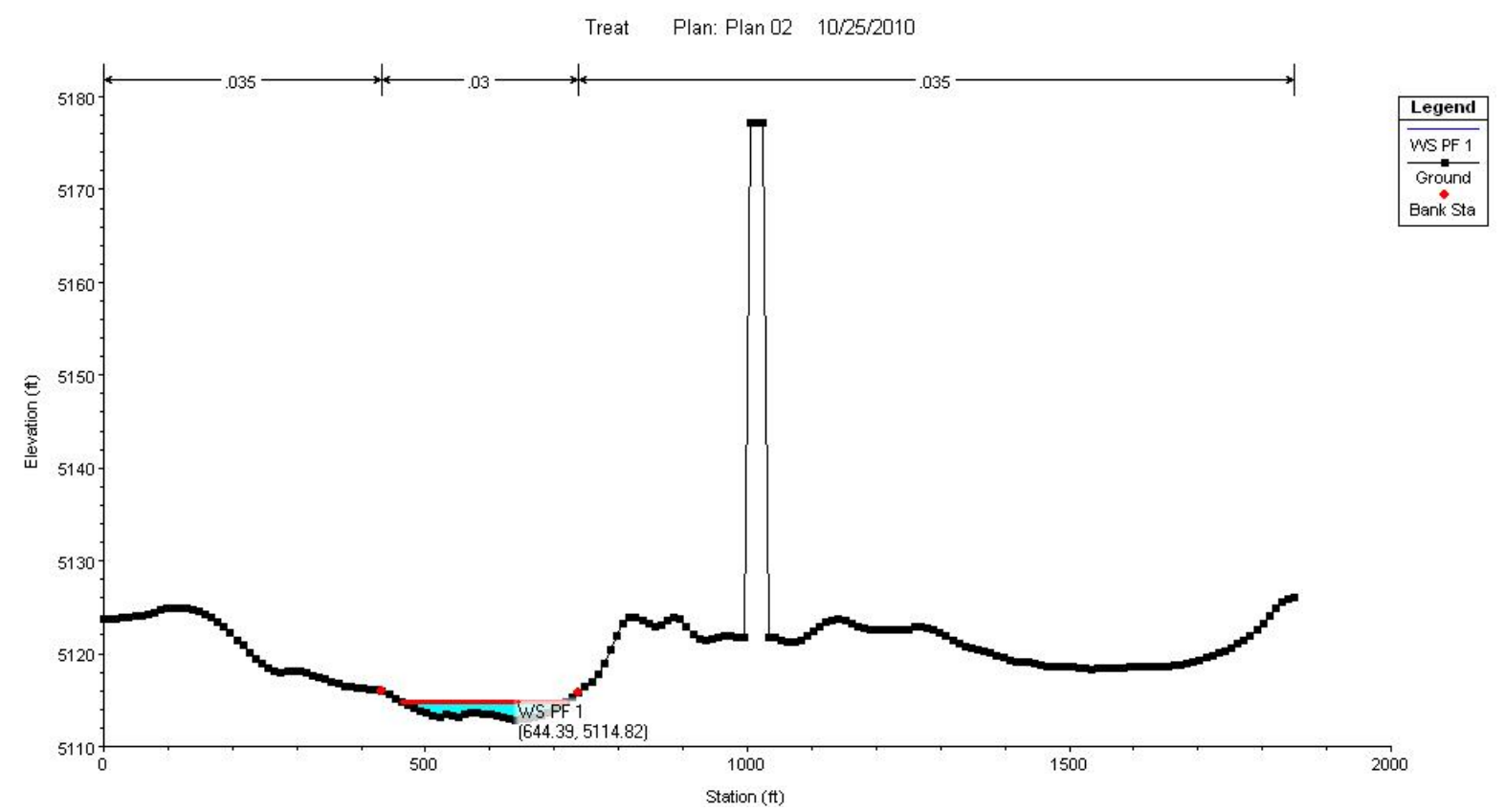

Figure 2.34. Inundation Areas and Maximum Water Level at the Middle Cross Section for TREAT Site

Flow vs. Water Elevation at TREAT

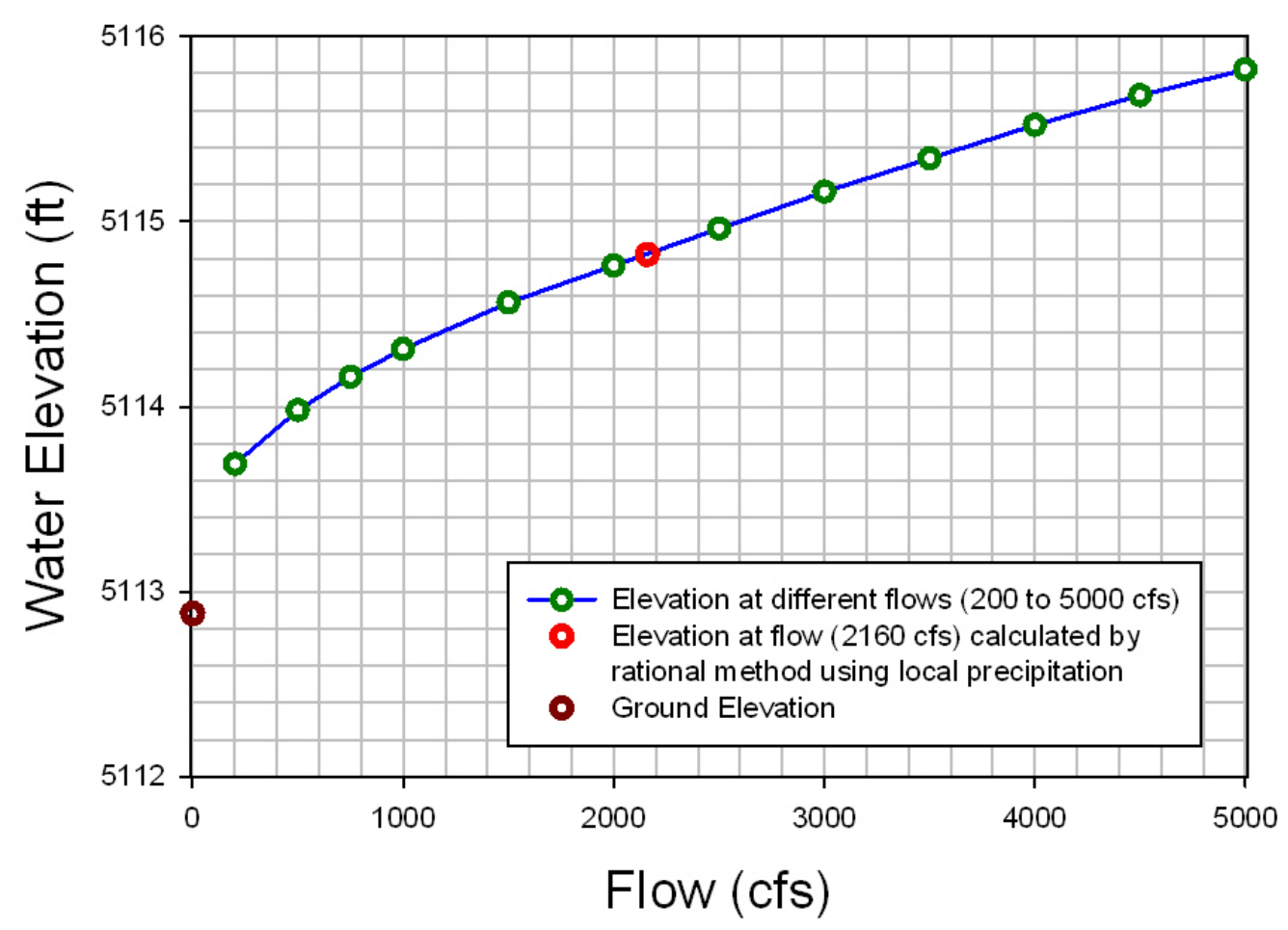

Figure 2.35. Comparison of Maximum Water-Surface Elevations for a Range of Flows and with a Flow Estimated from the Rational Method of the Peak PMP Intensity 


\subsection{Conclusions}

The PMF and 10,000-year return period events were analyzed at the MFC site. The peak discharges for the PMF and 10,000-year events at the MFC site were 10,200 cfs and 2,880 cfs, respectively. Comparison of the maximum water-surface elevation results from the HEC-RAS model to floor elevations at critical building locations showed the following:

- Under the most conservative assumption used (i.e., PMF with the diversion channel and culverts blocked), nine locations were inundated to depths ranging from $0.10 \mathrm{ft}$ to $3.20 \mathrm{ft}$.

- Under the least conservative assumptions used (i.e., 10,000-year event with the diversion channel and the culverts open), two locations (MFC-786 and MFC-785) were inundated to depths $0.03 \mathrm{ft}$ and $0.10 \mathrm{ft}$, respectively.

It is noteworthy that the changes in maximum water-surface elevations at these two locations for the two events and different assumptions were relatively small. For example, for the PMF with the diversion channel and culverts blocked the maximum water-surface elevation at MFC-785 was 5125.63. For the 10,000-year event with the diversion channel and culverts open, the maximum water-surface elevation was only reduced $1.35 \mathrm{ft}$. Similarly, at MFC-786 the reduction was only $1.29 \mathrm{ft}$. This strongly suggests that maximum water-surface elevations are primarily determined by backwater effects from downstream hydraulic controls. An example is the road along the perimeter of the MFC site to the northwest that is overtopped and produces backwater effects at the MFC buildings during both the PMF and 10,000-year events.

As was noted in the report, analyses and results presented are based on a number of conservative assumptions in the absence of site-specific data and/or information. Examples include:

- use of the SCS UH because it had the highest peak discharge of the synthetic UHs evaluated

- use of the Rational Method to calculate local inflows to the hydraulic model, thus ignoring the attenuating affects of lag

- assuming zero infiltration losses.

In evaluating the flood hazard at the MFC site, under these conservative assumptions, during the 10,000 -year event, the site is inundated at only two locations to depths of $0.10 \mathrm{ft}$. or less.

In addition, a limited sensitivity study of the assumed Manning's roughness coefficient showed that by reducing the coefficient from 0.035 to 0.013 , the computed water-surface elevations for the 10,000-year event were reduced sufficiently that no critical building locations were inundated. 



\subsection{References}

Bedient PB and WC Huber. 1992. Hydrology and Floodplain Analysis. Addison-Wesley, New York.

Chow VT. 1959. Open-Channel Hydraulics. McGraw-Hill Book Company, New York.

D\&M - Dames \& Moore. 1993. Flood Evaluation Study, Radioactive Waste Management Complex, Idaho National Engineering Laboratory, Idaho Falls, Idaho. Denver, Colorado.

Linsley RK, MA Kohler, and JL Paulhus. 1982. Hydrology for Engineers. Third edition, McGraw-Hill, New York.

Maidment DR. 1993. Handbook of Hydrology. McGraw-Hill, New York.

National Weather Service( NWS). 1994. Hydrometeorological Report No. 57, Probable Maximum Precipitation--Pacific Northwest States. National Weather Service, National Oceanic and Atmospheric Administration, U.S. Department of Commerce, Silver Spring, Maryland.

U.S. Department of Energy (DOE). 2005. Facility Safety. DOE Order 420.1B, Washington, D.C. Available at: https://www.directives.doe.gov/directives/current-directives/420.1-BOrder-1b/view.

U.S. Department of Energy (DOE). 2002. Natural Phenomena Hazards Site Characterization Criteria for Department of Energy Facilities. DOE-STD-1020-2002, Washington, D.C. 

Appendix A

Additional Climate Data Plots 



\section{Appendix A}

\section{Additional Climate Data Plots}
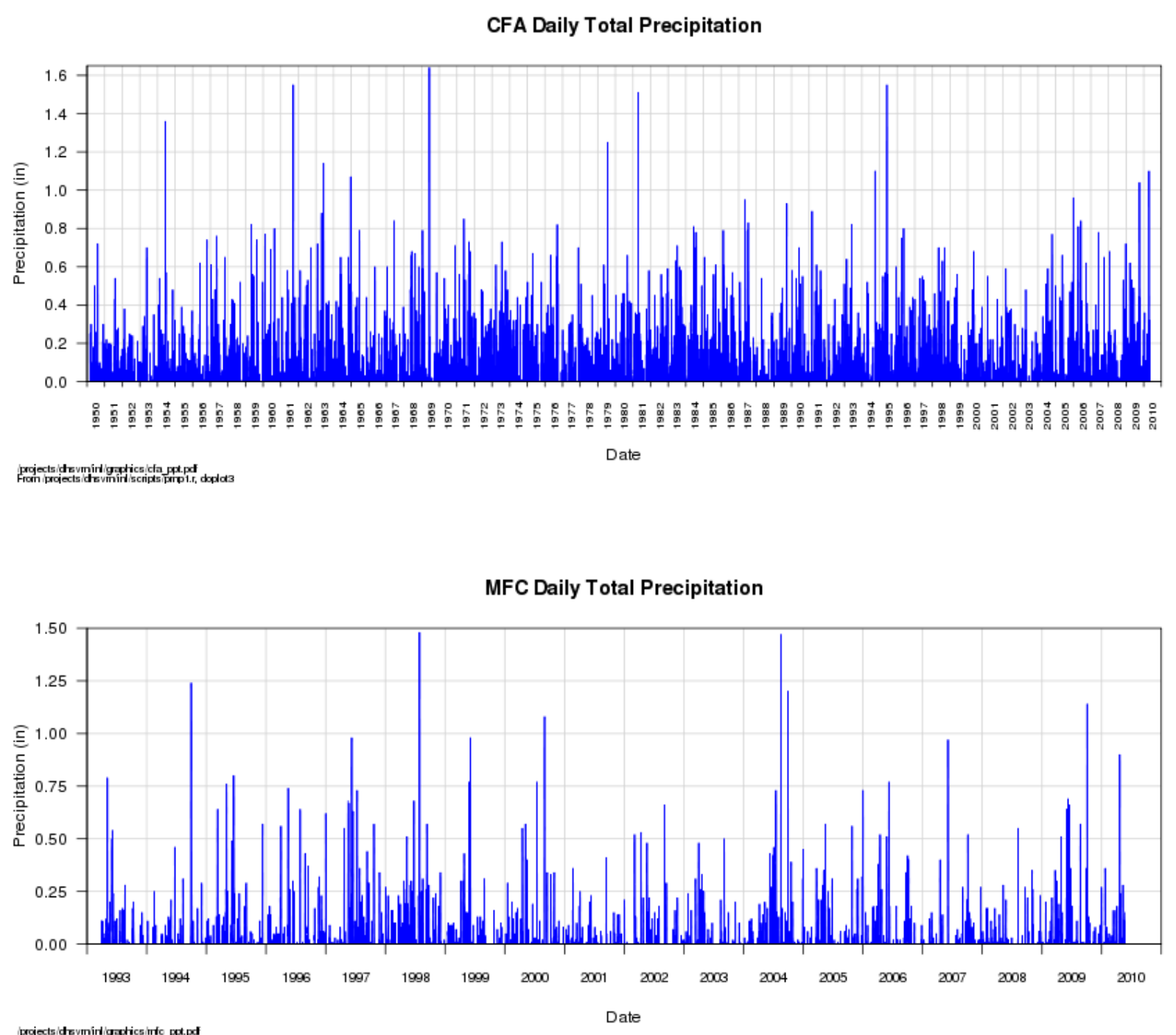

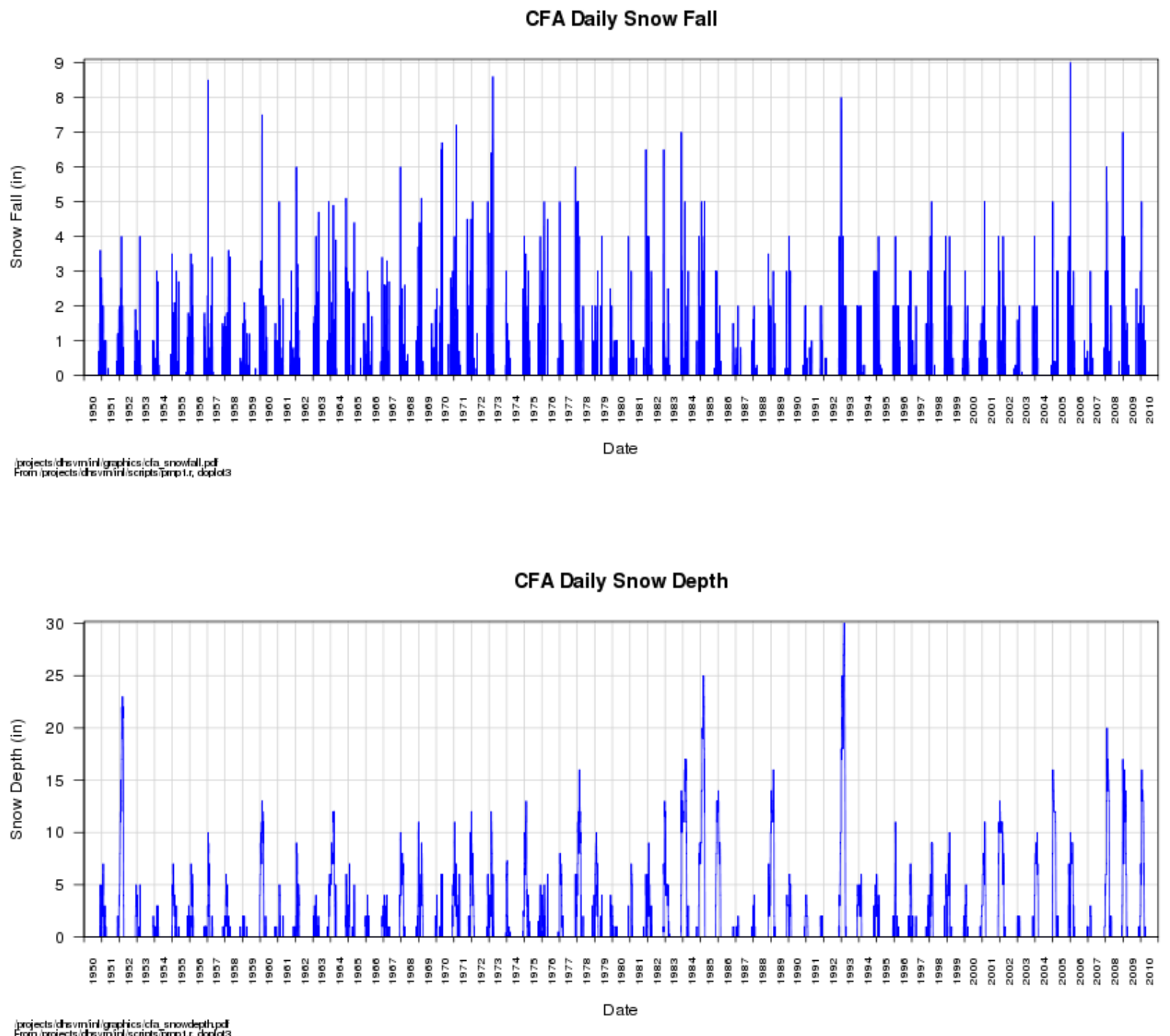
Appendix B

\section{Terrain Data Processing}





\section{Appendix B}

\section{Terrain Data Processing}

Two primary tasks were involved in pre-processing the available terrain data prior to performing the terrain and hydrologic analysis. First was the preparation of the source terrain data and second was the development and pre-processing implementation of an algorithm to overcome false terrain barriers. The objectives of the terrain data preparation were to 1) capture all the required areas (as defined by drainage basins), and 2) ensure all data share a common vertical datum of NAVD88 (North American Vertical Datum of 1988). The vertical datum issue became important because the extent of the catchment area was not fully covered by the available Light Detection and Ranging (LiDAR) data provided by the Idaho National Laboratory (INL). Standard 10-meter Digital Elevation Model (DEM) data from the U.S. Geological Survey (USGS) National Elevation Dataset were used to cover the additional extent. Because each of the two referenced terrain data sets were captured for different purposes and thus varying scales and degrees of accuracy are inherent to the data, it was determined that these data sets would be best used by keeping independent spatial domains and not mixing/overlapping the data.

Once the proper spatial extent of DEM coverage was achieved, the only data set requiring conversion into the NAVD88 vertical datum was the USGS 10-meter DEM data set. The DEM data were converted to ASCII X,Y,Z format, transformed from NGVD29 (National Geodetic Vertical Datum of 1929) to NAVD88 datum using CorpsCon v.6 software, and reimported as a raster data set that was used in some of the remaining tasks. The LiDAR data were converted from 'las' files to simple ASCII X,Y,Z format using Global Mapper 10. The 'las' file format is a common binary format used in dealing with LiDAR data sets. These files were further refined for input into Anudem via pre-written $\mathrm{C}++$ code. Compiled code was used versus scripting languages due to the size of the overall LiDAR data set of about 60 million points. Interpreted languages simply will not process files of this magnitude quickly and efficiently enough.

A problem with artificial terrain barriers was identified early on with the surface interpolation of the LiDAR data. These barriers impeded flow in certain areas, thus creating a surface that was not hydrologically correct. Because the goal was to be able to produce accurate drainage basin boundaries, it was imperative that these barriers be dealt with in a realistic manner. Both high resolution aerial photography and the LiDAR surface were used to identify problem areas in the data. The problem with a LiDAR terrain model is that it does not recognize the presence and/or absence of these obstructions.

LiDAR data can be so sensitive to change that nothing more than a scrub or small boulder could block the flow of a small stream. Simple line features were created at the problem areas to allow flow to pass and a more accurate terrain model to be developed.

Once the hydrologically correct terrain model was completed the hydrologic processing was done using the ArcHydro tools. An artificial stream network was modeled for both the LiDAR and USGS terrain models. A single pour point was identified for the six drainage areas that surrounded the upstream portion of the MFC site. The location of the pour point was determined by looking at the drainage pattern of the modeled stream network. Points were chosen along what was considered to be major contributing drainage networks. Pour-point selection gave way to drainage basin delineation, which could then be used in deriving other hydrologic parameters for the Hydrologic Engineering Centers Hydrologic 
Modeling System (HEC-HMS) model. Each of the prefixed 'W' basins was joined with the prefixed 'B' Hydrologic Engineering Centers River Analysis System (HEC-RAS) basins with the overlapping areas subtracted out (see Figure B.1). Total catchment area was calculated for each basin along with the path of the longest drainage channel. Both the length of the channel and its length from the geometric centroid of the basin were determined. Slopes were then calculated from the underlying terrain models and the determined main channel path. Two different kinds of slope values were needed. The first was the average slope for each of the six watershed (W) basins. This was done by creating a slope grid from the terrain model within each basin boundary. The second was the slope at each segment of the main channel path. These slope calculations were done by splitting the channel path into equal stream segments based on the terrain model resolution. A point feature was created at each segment split so that the underlying slope grid could be sampled and a slope value determined.

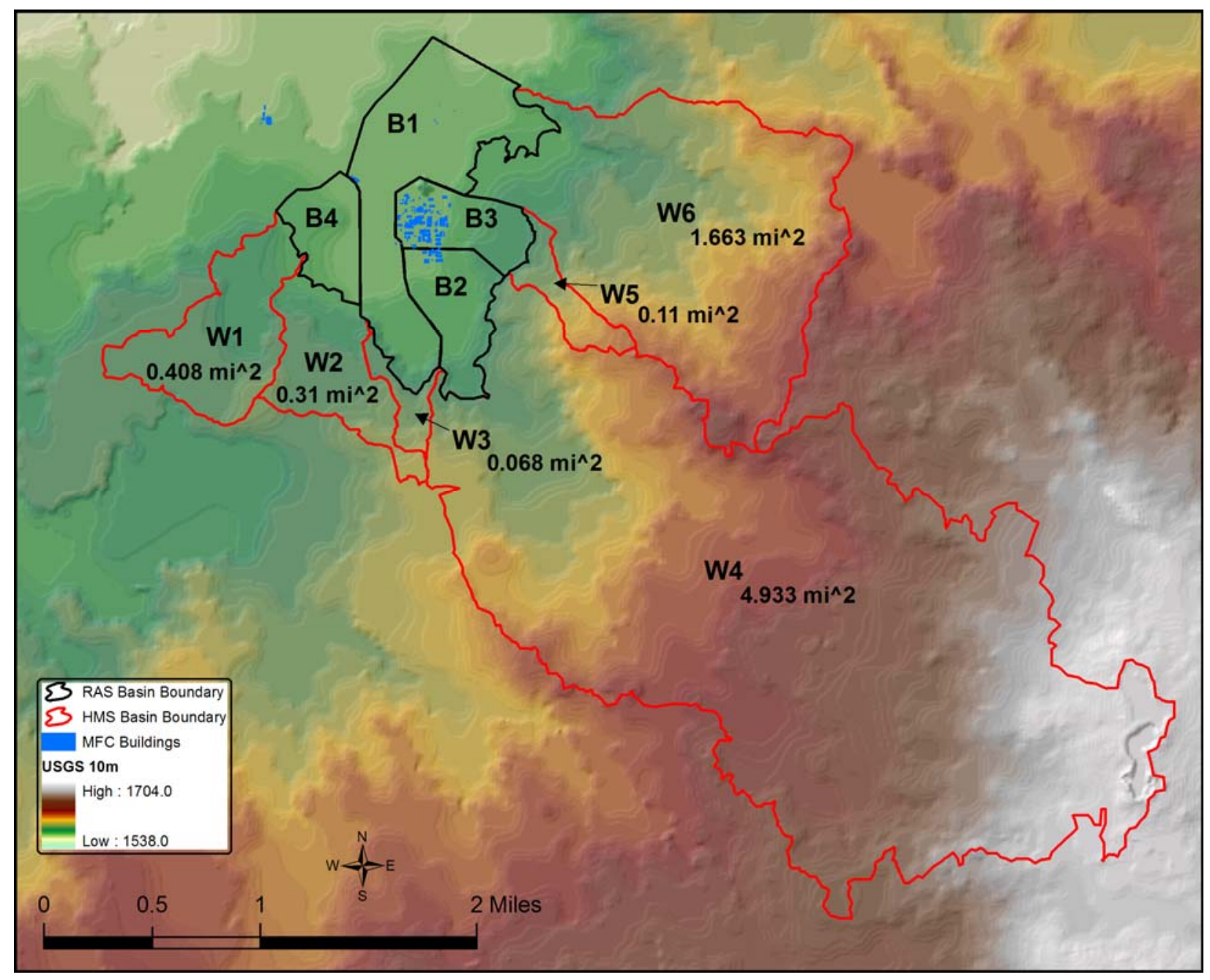

Figure B.1. The Basin Extents for the HEC-RAS and HEC-HMS Models 


\section{Distribution}

No. of

Copies

OFFSITE

P Wichlacz

Idaho National Laboratory

P.O. Box 1625

Idaho Falls, ID 83415-2213 




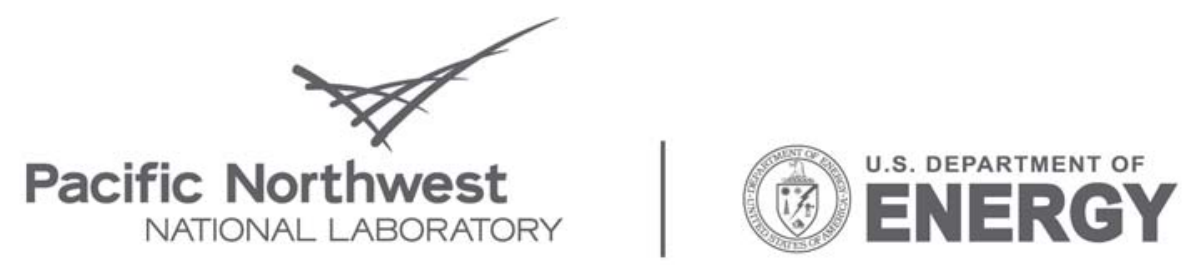

Proudly Operated by Battelle Since 1965

902 Battelle Boulevard

P.O. Box 999

Richland, WA 99352

1-888-375-PNNL (7665)

www.pnl.gov 